\title{
FISHES FROM FORMOSA AND THE PHILIPPINE ISLANDS.
}

\author{
By Henry W. Fowler, \\ of the Academy of Natural Sciences of Philadelphia, \\ and \\ Barton A. Bean, \\ Of the United States National NIuseum.
}

The collections here noticed embrace 588 specimens of fishes, the majority of which were obtained by Dr. Fred Baker at Takao, Formosa, and at Cebu and Zamboanga, Philippine Islands. The remaining few were collected by Dr. Hans Sauter at Koroton, Kagi, and Lake Candidius, in Formosa. A series of the duplicates is to be deposited in the Academy of Natural Sciences of Philadelphia.

The species here recorded represent largely the fauna of the East Indies, Japan, and China. A number are here introduced for the first time as new records both for Formosa and the Philippines, while several rare or little-known forms are described and a number of more or less interest are noted briefly, as some of their salient characters present new information to the study of variation.

We describe as new generic names Rhamphodermogenys and Rhabdosebastes. As new species Cirrhinus melanostigma, Dermogenys bakeri, and Pomacentrus formosanus are described and figured, besides which we give a figure of the rare seahorse, Hippocampus longirostris Cuvier, a species based on the ancient figure by Willughby.

\section{Family DASYATIDAE.}

\section{DASTYATIS KUHLII (Müller and Henle).}

Body entirely smooth. In alcohol above buffy-brown, dusky specks scattered rather closely about eyes, interorbital and frontal region. Scattered about more fleshy part of disk many variable puritan-gray round spots with dark borders. These spots mostly larger on each side behind. Lower surface of body whitish, edges slightly dusky, especially laterally. Tail darker brown than disk, with three broad olive-buff rings. Length, $613 \mathrm{~mm}$.; snout to vent, $123 \mathrm{~mm}$. Cebu. 


\section{Family CHIROCENTRIDAE.}

CHIROCENTRUS DORAB (Forshål).

One from Cebu, $160 \mathrm{~mm}$. long.

\section{Family CLUPEIDAE.}

\section{DUSSUMIERIA ACUTA (Valenciennes).}

One in very poor preservation, $158 \mathrm{~mm}$. long. Head, 3考. Gillrakers $14+35$, about $1 \frac{1}{2}$ in eye. Cebu.

\section{HARENGULA MOLUCCENSIS Bleeker.}

Head, $3 \frac{1}{2}$ to $3 \frac{7}{8}$; depth, 4 to $4 \frac{1}{3}$; D. III, 14; A. III, 16, sometimes 15 ; scales (counted by pockets), 40 in lateral series from upper hind edge of gill-opening to caudal base; snout, $3 \frac{1}{4}$ to $3 \frac{1}{2}$ in head measured from upper jaw tip; eye, $3 \frac{1}{4}$ to $3 \frac{2}{5}$; maxillary, 2 to $2 \frac{1}{8}$; interorbital, 4 to $5 \frac{2}{3}$. Gill-rakers $14+33$, fine, longest seven-eighths of filaments, which are seven-eighths of eye. Scales very deciduous, with 4 transverse vertical striae and sometimes as many more marginals. Abdominal serrae, 16 or $17+13$ or 14 . One small example with caudal tips broadly blackish, in others uniform. Most adults with inner angle or hind edge of caudal dusky. Sixteen examples, largest 120 nım. Takao.

Gunther gives about 38 gill-rakers on lower part of the arch.

\section{Family ENGRAULIDIDAE.}

\section{ANCHOVIA BALIENSIS (Bleeker).}

Head, $4 \frac{1}{3}$ to $4 \frac{1}{2}$; depth, 5 to $5 \frac{1}{2}$; D. III, 13 ; A. II or III, 16 or 17 ; snout, $3 \frac{7}{8}$ to $4 \frac{1}{2}$ in head; eye, $3 \frac{1}{4}$ to $3 \frac{3}{4}$; interorbital, $3 \frac{1}{2}$ to 4 ; maxillary, $1 \frac{1}{3}$ to $1 \frac{2}{5}$, reaches hind preopercle edge or only very slightly beyond. Closed mandible tip about opposite first third in snout length. Teeth in both jaws and maxillary toothed to hind edge. Opercles smooth. Abdominal spines, 4, occasionally 5. Gill-rakers, $20+22$, slender, fine, slightly longer than filaments or $1 \frac{3}{4}$ in eye. Scales caducous, in lateral series about 35 pockets to caudal base, and 20 or 21 predorsal. Ventral scaly flap nearly long as fin. Color in alcohol faded twany-olive. Head with brassy tinge. Median silverywhite lateral band, its greatest expansion over front of anal, where little less than eye, though little more than pupil. On occiput, or at front of predorsal, blotch of bister about size of eye. Iris colonialbuff. Fins all paler than body, dorsal and caudal with grayish tints. Four examples, 137 to $145 \mathrm{~mm}$. Takao.

\section{ANCHOVIA ZOLLINGERI (Bleeker).}

Head, $3 \frac{2}{3}$ to $3 \frac{3}{4}$; depth, $5 \frac{1}{3}$ to $6 \frac{3}{4}$; D. III, 10 ; A. III, 13 ; snout, 4 to $4 \frac{1}{4}$ in head; eye, $3 \frac{1}{3}$ to $3 \frac{3}{4}$; maxillary, $1 \frac{1}{3}$, not reaching preopercle edge; 
interorbital slightly less than eye. Opercle smooth. Gill-rakers about $17+17$, very fine, slender, elongate, much longer than filaments or nearly equal eye. Color in alcohol dull saccardo-umber. Several blackish dots on opercle, shoulder-girdle and row along lower side of abdomen and caudal base. Iris silvery-white. Fins pale uniform brown. Top of head whitish behind eyes. Twenty-five examples, largest $40 \mathrm{~mm}$. Takao.

\section{Family SYNODONTIDAE.}

SAURIDA GRANDISQUAMIS Gunther.

Head, $3 \frac{4}{5}$ to $4 \frac{1}{6}$; depth, $8 \frac{1}{2}$ to $9 \frac{1}{4}$; D. III, 10, I; A. III, 9, I; tubular scales (according to pockets), 42 to 45 in lateral line to caudal base, and 3 to 4 more on latter; 3 (pockets) scales above lateral line to dorsal origin; 18 predorsal (pockets) scales; snout, 4 to 5 in head from upper jaw tip; eye, $3 \frac{3}{4}$ to 5 ; maxillary, $1 \frac{2}{5}$ to $2 \frac{2}{5}$; interorbital, 5 to 6 , slightly concave. Apparently no adipose eyelid. Gill-rakers about $24+48$, lanceolate, slender and somewhat irregular, about 3 in filaments and latter 3 in eye. Scales each with 3 short marginal striae and circuli moderately fine. Dorsal base three-fifths of fin, which is about long as head. Depressed pectoral not reaching within at least 2 scales of dorsal origin. Color in alcohol faded dull brownish above to pale or whitish beneath. Dorsal tinged dusky terminally. Iris whitish. Eight examples, 55 to $90 \mathrm{~mm}$. Takao.

Our examples all in poor preservation. Chiefly on account of their large scales we identify them with the present species, originally described from the Louisades and doubtfully Australia. Apparently not previously reported from Formosa.

TRACHINOCEPHALUS MYOPS (Schneider).

Eleven examples, 50 to $180 \mathrm{~mm}$. Takao.

\section{Family PLOTOSIDAE.}

PLOTOSUS ANGUILLARIS (Bloch).

Head $4 \frac{1}{8}$; depth, $7 \frac{1}{2}$; nasal barbels reach slightly beyond front eye edge; maxillary barbel to hind eye edge; body without pale longitudinal lines; color variably warm sepia; paler to tawny-olive below; vertical fins with dusky edges; mental barbels little paler than upper, though dotted with brown. Length, $130 \mathrm{~mm}$. Cebu.

Also 33 examples, all young, from Zamboanga. Color in alcohol bister, often tinged dark grayish-brown on head. White lines from side of snout tip along each side of caudal base back to caudal. Another from each maxillary end along middle of side of head, extends below eye and fades out behind along middle of side of trunk. Largest, $45 \mathrm{~mm}$. 


\section{Family SILURIDAE.}

\section{PARASILURUS ASOTUS (Linnaeus).}

'Two from Koroton, Formosa, September 1 to 15, 1907. Hans Sauter. Length, 145 to $175 \mathrm{~mm}$.

Oshima ${ }^{1}$ gives the maxillary barbels nearly as long as the head. In our smaller example only the left is slightly less than the head. In the larger example they both extend back close to tips of depressed pectorals. Lower jaw well protruded.

\section{Family CYPRINIDAE.}

\section{CYPRINUS CARPIO Linnaeus.}

One from Koroton, same data as preceding. Length, $183 \mathrm{~mm}$.

CARASSIUS AURATUS (Linnaeus).

Five, same as preceding. Length, 97 to $128 \mathrm{~mm}$.

CIRRHINUS MELANOSTIGMA, new species.

Head, $4 \frac{1}{3}$; depth, 3 ; D. III, 12, I; A. III ; 5, I ; P. I ; 16, V. I, 8 ; scales, 37 in lateral line to caudal base and 4 more in latter; 9 scales above lateral line to dorsal origin, 7 below to anal origin, 5 below to ventral origin; 18 predorsal scales; head width, $1 \frac{2}{5}$ in its length; snout, 3 ; eye, $3 \frac{2}{3}$; mouth width, 3 ; maxillary, $4 \frac{1}{8}$; interorbital, $2 \frac{1}{5}$; first branched dorsal ray, $1+\frac{1}{6}$; first branched anal ray, $1 \frac{1}{5}$; pectoral, $1 \frac{1}{8}$; ventral, $1 \frac{1}{8}$; least depth of caudal peduncle, $1 \frac{4}{5}$; lower caudal lobe. $1+\frac{2}{3}$.

Body elongate, slender, well compressed, deepest at dorsal origin, edges convex, breast and belly broadly so. Caudal peduncle well compressed, little longer than deep.

Head conic in profile, little compressed and rather flattened sides but slightly constricted below eyes. Snout depressed, obtuse, length three-fifths its width and protrudes slightly beyond upper jaw. Eye large, high, hind pupil edge midway in head length. Mouth broad, inferior, gape short. Jaw edges coriaceous, firmly trenchant. Upper lip fringed, fleshy points rather coarse. Lower lip papillose. Pair of rostral barbels extending back far as maxillary end, which reaches opposite front nostril. Nostrils adjoining or simple front one at last two-fifths in snout and with fleshy flap exposing hind one in larger crescent. Interorbital broadly convex. Preorbital long as eye, other elements of suborbital chain narrow. Opercle smooth.

Gill-opening lateral, extends forward about opposite hind preopercle edge leaving broad isthmus. Gill-rakers very short, fringe of numerous slender fleshy points, about $10+65$ and 7 in gill-fila- 
ments. Latter long as eye, and pseudobranchiæ about half as long. Branchiostegals $3-3$, broad. Pharyngeal teeth, 2, 4, 5-5, 4, 2, short, all ends beveled at broad grinding surfaces so that molariform.

Scales adherent, in even longitudinal rows, little smaller along body edges, and especially small along median line of belly and on breast. Caudal base covered with rather large scales. Ventral axil with long pointed scaly flap nearly three-fifths of fin. Apical radiating striae 30 to 32 , and basal circuli fine. Lateral line midway along sides, complete, of short simple tubes, each little exposed.

Dorsal origin much nearer snout tip than caudal base, depressed fin $1_{5}^{2}$ to latter. Anal origin little nearer caudal base than ventral origin, depressed fin reaching caudal base. Pectoral reaches about three-fourths to ventral, latter inserted little behind dorsal origin or

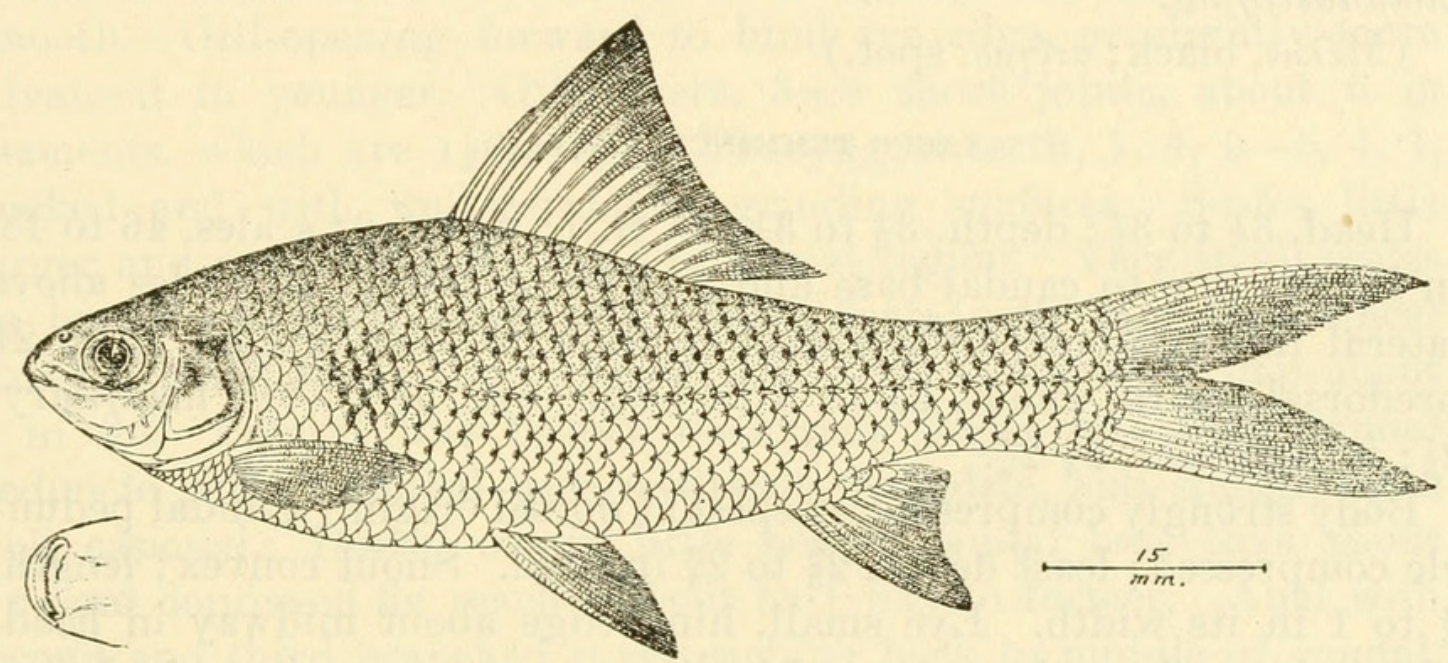

Fig. 1.-Cirrhinus melanostigma, New species.

midway between pectoral and anal origins. Caudal greatly forked, lobes long and pointed. Vent close before anal origin.

Color in alcohol with back dull sepia-brown generally, becoming nearly clay-color on sides and especially below. Pocket at base of each scale with cluster of dusky dots, which shining through appear as if at apical part of scale, on back and sides. These spots begin about over middle of depressed pectoral, where for about first three scales in width all black and formed as a conspicuous marking, slightly inclined backward. Sides of head below with traces of whitish or silvery reflections. Iris with dull yellow tint. Fins very pale brownish, dorsal slightly more grayish and former transverse dusky-gray shade over membranes just below middle of fin.

Length $190 \mathrm{~mm}$.

Type.-Cat. No 84168, U.S.N.M. Koroton, Formosa. September 1 to 15,1907 . Hans Sauter.

Also two others, paratypes, same data, showing: Head 4 to $4 \frac{1}{5}$; depth, 3 to $3 \frac{1}{4}$; D. III, 12 , I or 13 , I: A. III, 5, I; scales, 36 or 37 , in 
lateral line to caudal base and 4 more on latter; 8 or 9 scales above lateral line to dorsal origin, 7 below to anal origin; 14 or 15 predorsal scales; snout, 3 to $3 \frac{1}{5}$ in head; eye, 4 ; mouth width, $3 \frac{1}{3}$ to $3 \frac{2}{3}$; interorbital, $2 \frac{1}{6}$ to $2 \frac{1}{3}$; length, 180 to $185 \mathrm{~mm}$.

This species greatly resembles Cirrhinus mrigala (B. Hamilton), of which we have slightly smaller examples from India for comparison. It differs, however, in its fringed lips, much shorter maxillary and especially in the prominent apical striae. These characters are not evident in our specimen of $C$. mrigala. From $C \cdot$ reba (B. Hamilton), of which we also have Indian examples for comparison, while its upper lip agrees in being fringed its lower lip is entire and not papillose. Also it has shorter barbels, a longer maxillary and nearly smooth scales, without the apical striae of $C$. melanostigma.

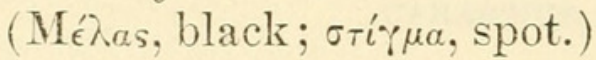

\section{ZACCO TEMMINCKI (Schlegel).}

Head, $3 \frac{1}{5}$ to $3 \frac{1}{3}$; depth, $3 \frac{1}{3}$ to $3 \frac{1}{2}$; D. II, 7 ; A, III, 9 ; scales, 46 to 48 , in lateral line to caudal base and 4 more on latter; 10 scales above lateral line to dorsal origin, 4 or 5 below to anal origin; 19 to 24 predorsal scales; snout, $2 \frac{7}{8}$ to 3 in head; eye, $5 \frac{1}{8}$ to $5 \frac{1}{2}$; maxillary, $2 \frac{1}{5}$; interorbital, $2 \frac{1}{4} 2 \frac{7}{8}$.

Body strongly compressed, deepest at dorsal origin. Caudal peduncle compressed; least depth, $2 \frac{2}{3}$ to $2 \frac{3}{4}$ in head. Snout convex; length, $\frac{4}{5}$ to 1 in its width. Eye small, hind edge about midway in head. Mouth large, jaws about even. Maxillary reaches opposite eye. Interorbital slightly convex. Gill-rakers, $2+6$ short points; about 3 in filaments, which nearly equal eye. Pharyngeal teeth, 1, 4, 4-3, 4, 2, conic, some slightly hooked, with grinding surfaces, especially on larger ones. Scales rather narrowly imbricated along lower sides, closely crowded on chest. Each scale with about 7 to 11 rather weak apical radiating striae, fine circuli 52 to 63 basally. Spawning male with four rows of pearl organs along side of mandible, several rows along preopercle flange and lower part of opercle and irregular double row on suborbital chain. Enlarged anal rays of male with rows of pearl organs, well spaced basally and closer terminally. Lateral line greatly decurved, complete, of simple tubes.

Color in alcohol brownish generally, little paler below. Leadendusky streak along vertebral axis after dorsal fin. Ten obscure leaden cross bars between occiput and caudal. Iris gray-brown. Fins uniform brownish, except dorsal, which has transverse blackish band over membranes, but not on rays. Length 104 to $116 \mathrm{~mm}$. Three examples from Kagi, Formosa. September 1 to 20, 1907. Hans Sauter. 
ZACCO PLATYCEPHALUS (Gunther).

Head, $3 \frac{1}{4}$ to $3 \frac{2}{3}$; depth, $3 \frac{1}{3}$ to $3 \frac{1}{2}$; D. III, 7, I; A. III, 9, I; scales, 47 to 50 in lateral line to caudal base and 3 more on latter; 8 scales above lateral line to dorsal origin, 5 below to anal origin; 22 to 24 predorsal scales; snout, $3 \frac{1}{6}$ to $3 \frac{1}{3}$ in head; eye, $3 \frac{1}{2}$ to $4 \frac{1}{2}$; maxillary, 2 to $2 \frac{2}{5}$; interorbital, 3 .

Body compressed, deepest at dorsal origin, edges all convex. Least depth of caudal peduncle, $2 \frac{1}{8}$ to $2 \frac{2}{3}$ in head. Head well compressed, attenuate. Snout conic; length four-fifths its width. Eye elevated, hind edge midway in its length, little posterior in young. Mouth large, lower jaw included in upper, which slightly projects. Maxillary reaches eye center, to front pupil edge in younger. Lips firmly coriaceous. Interorbital very slightly convex. Suborbital chain broad, covers half of cheek to preopercle ridge. Opercle smooth. Gill-opening forward to hind eye edge, or slightly more advanced in younger. Gill-rakers, $3+8$ short joints, about 5 in filaments, which are $1 \frac{1}{4}$ in eye. Pharyngeal teeth, 1, 4, 5-5, 4, 1, hooked and with well-developed grinding surfaces. Scales little larger and narrowly imbricated on costal region. Very small scales on breast and belly anteriorly. Each scale with radiating apical striae 8 to 10, basal circuli fine. Axillary ventral scaly flap about 5 in fin. Lateral line deeply decurved, slopes up along caudal peduncle side to caudal base medianly, complete, and simple tubes well exposed. Dorsal origin little nearer caudal base than snout tip, and depressed fin reaches about half way to former. Anal with second and third branched rays reaching back to middle of caudal, shorter in younger example, and origin of fin opposite depressed dorsal tip. Caudal deeply forked, lobes pointed and lower often slightly longer. Pectoral $1 \frac{1}{3}$ to $1 \frac{2}{5}$ in head, not reaching ventral. Latter inserted trifle before dorsal origin, not reaching anal, $1 \frac{4}{5}$ to 2 in head.

Color in alcohol faded dull brown, little paler below. Dark narrow streak follows each row of scales on back. Leaden median line along vertebral axis from above ventral to caudal base medially. Fins all pale or dull brownish. Dorsal with median blackish blotch in each membrane. Caudal with grayish marginally behind. Nine examples from Koroton. September 1 to 15, 1907. Hans Sauter.

\section{BARBUS SNYDERI (Oshima).}

Head, 3 to $3 \frac{2}{3}$; depth, $2 \frac{2}{3}$ to $2 \frac{4}{5}$; D. II, I, 8, I, sometimes 7, I; A. III, 5 , I, sometimes 6 , I ; scales, 22 or 23 in lateral line to caudal base and 2 to 4 more on latter; 5 scales above lateral line to dorsal origin, 2 or 3 below to anal origin; 8 or 9 predorsal scales; snout, $3 \frac{2}{3}$ to $3 \frac{7}{8}$ in head; eye, $2 \frac{2}{3}$ to 3 ; maxillary, 3 to $3 \frac{1}{8}$; interorbital, $2 \frac{3}{5}$ to $2 \frac{2}{3}$. Barbels, 4 , posterior 
long as eye. Gill-rakers, 3 or $4+9$ or 10 , about 4 in filaments and latter $1 \frac{1}{2}$ in eye. Pharyngeal teeth, $2,3,5-5,3,2$, hooked, with moderate grinding-surfaces and one or two of outer row little enlarged basally and less marked. Scales with 5 to 10 basal radiating striae, basally 4 or 5 lobes, and 3 to 8 apical radiating striae, circuli very fine. Color in alcohol dull natal brown on back with lavender reflections. Lower surface paler to whitish with silvery reflections. Margins of most scales on back and sides each with border of fine dusky dots, giving all appearance of darkened edges. Underlaid lateral leaden vertebral streak. Along this, row of four brackish spots, little larger than pupil and not large as eye. First of these humeral, next opposite dorsal origin, third opposite tip of depressed dorsal and last at caudal base. Another blackish spot opposite and close to dorsal origin. With age most of spots fade or become obsolete, only caudal and one at dorsal origin usually remaining. Head natal brown like back, side and iris silvery-white, and under surface paler. Dorsal and caudal grayish, other fins largely pale or whitish, only minute pale brown dots medianly or terminally. Fourteen from fresh waters of Zamboanga. Length 30 to $67 \mathrm{~mm}$.

We find all of our examples with four barbels well developed. In Oshima's account of Puntius snyderi ${ }^{2}$ the present species is placed in Puntius, as it is believed to be without barbels. In fact he emphatically separates Puntius from Capoeta and Bartodes, primarily by the absence of barbels. We do not feel justified in attempting to limit our material on this character alone, and as it in most all respects answers Oshima's Puntius snyderi are forced to consider it such. Gunther ${ }^{3}$ pertinently says of Barbus "even the number of barbels is not quite constant, and much caution is required in determining whether a specimen belongs to a species normally with four or two, or without barbels, as these organs are sometimes quite rudimental, and abnormally, may be entirely absent; this is principally the case with the upper barbel, which I have found sometimes on one side and not on the other. Yet on such characters have naturalists ventured to found genera!"

\section{Family COBITIDAE.}

\section{MISGURNUS DECEMCIRROSUS (Basilewsky).}

Head, $5 \frac{4}{5}$ to $5 \frac{7}{8}$; depth, $5 \frac{4}{5}$ to $5 \frac{7}{8}$; D. II, 7 ; A. II, 7 ; scales, 94 to 116 in lateral line to caudal base; 14 or 15 scales above lateral line to dorsal origin, 11 or 12 below to anal origin; 60 to 70 predorsal scales; snout, $2 \frac{2}{5}$ in head; eye, $6 \frac{1}{2}$; mouth width, 4 ; interorbital, $3 \frac{1}{2}$.

${ }^{2}$ Ann. Carnegie Mus., vol. 12, 1919, p. 216, pl. 50, fig. 2. Rigyokutsu; Maruyama ; Daito River.

${ }^{2}$ Cat. Fish. Brit. Mus., vol. 7, 1868, p. 84. 
Gill-rakers, $5+14$, short, compressed strongly, truncate, 3 in filaments and latter equals eye. Scales with 21 to 26 basal radiating striae, of which about 12 to 18 incomplete and marginal, and circuli fine. Color in alcohol dull to dark dusky on back and dull brown below. Sides and back with numerous fine or small ill-defined dusky spots, sometimes sparse and in other examples crowded. Fins pale brown, with dull spots or specks of darker, less distinct than on body. Three from Koroton. Hans Sauter. Length 88 to $125 \mathrm{~mm}$.

\section{Family ANGUILLIDAE.}

\section{ANGUILla MAURITIANA Bennett.}

Dorsal slightly nearer gill-opening than vent. In alcohol, brown, finally dotted and speckled with darker. Lower surface of head and abdomen paler. Length, $48 \mathrm{~mm}$. Zamboanga.

\section{Family CONGRIDAE.}

CONGER ANAGO Schlegel.

Four examples, 197 to $257 \mathrm{~mm}$., from Takao. Also one $198 \mathrm{~mm}$., from Cebu. In the better preserved Formosan examples the lower surface of the head is conspicuous for three dark brown transverse bands. Of these, first at mandible tip, second about opposite middle of eyes, and third close behind hind eye edge.

\section{Family MURAENIDAE.}

\section{STROPHIDON BRUMMERI (Bleeker).}

Head, $11 \frac{1}{8}$; depth at vent, $36 \frac{3}{4}$; to vent, 16 ; head width, 4 in its length; head depth, $2 \frac{1}{3}$; snout, $6 \frac{2}{3}$; eye, $12 \frac{1}{2}$; mouth gape, $2 \frac{2}{5}$; interorbital, $9 \frac{3}{4}$; head, $4 \frac{3}{4}$ to vent.

Body very long, slender, well compressed, and long tail slender. Head compressed, slightly swollen at occipital region, sides flattened and but slightly constricted below. Snout compressed, upper surface convex, likewise profile, about long as broad. Eye little ellipsoid, hind edge about midway in mouth length, without eyelid. Mouth large, horizontal, completely closes. Lips moderate, tough, smooth. Teeth conic, entire, sharply pointed. Upper outer teeth with one just before eye little larger than others, all of which slightly inclined backward and becoming gradually smaller. An inner upper series of eight depressible teeth, slightly larger than outer series. Median row of seven depressible enlarged canines on vomer, last one little behind eye. Mandible with single outer row of teeth and anteriorly each side three larger teeth form an inner row, last of which well before eye. No tongue. Mandible elongate, shallow, surface convex, end equal in front with snout tip. Front nostril in 60466-23-Proc.N.M.vol.62 - 9 
short tube near snout tip. Hind nostril in interorbital space, above front half of eye, opens above at slit slightly inclined posteriorly. Interorbital slightly convex.

Gill-opening near lower fourth in body depth, slightly inclined, about long as eye. Pharynx well swollen, with number of obsolete grooves below. Skin smooth, tough. Six pores on each upper lip, first close to snout tip, second just behind nasal tube, third midway in snout, fourth below front eye edge, fifth behind hind eye edge, sixth midway in mouth behind eye. Nearly opposite along lower lip similar row of six pores on each side. Pair of pores between nasal tubes and two more pores posteriorly, last just before hind nostril. Lateral line of simple inconspicuous pores along side of body medially.

Dorsal origin at last third in space between rictus and gill-opening, fin of moderate height and continuous with small caudal. Latter slightly pointed, equals interorbital. Anal like dorsal, slightly lower. Vent close before anal.

Color in alcohol uniform olive to natal brown above. Snout, upper lip and mandible pale grayish-olive. Dorsal, anal and caudal margined with dusky to blackish. Gill opening pale. Iris pale slaty. Length, $1,032 \mathrm{~mm}$. Cebu.

\section{GYMNOTHORAX MELEAGRIS (Shaw).}

One from Zamboanga, $177 \mathrm{~mm}$. long (caudal end damaged). Its color pattern is somewhat like the nominal $G$. ercodes Jenkins, except that dark reticulations are more or less waved or variable, also showing more tendency to form narrow vertical lines. Median upper teeth opposite eyes, in two rows, rather short or bluntly conic.

ECHIDNA NEBULOSA (Ahl).

One from Zamboanga. Length $205 \mathrm{~mm}$.

\section{Family PEGASIDAE.}

\section{PARAPEGASUS NATANS (Linnaeus).}

Snout tip to vent contained in tail, measured from vent to base of caudal fin, $\frac{7}{8}$ to 1 . D. 5 ; A. 5 . Tail with 12 rings. Snout about $2 \frac{1}{8}$ to $2 \frac{1}{5}$ to vent; lateral edges denticulate, posterior denticles longer and directed backward; about 6 to 8 ridges, mostly complete, longitudinally and above. Color in alcohol general tint above clay color or tawny-olive, with five dusky obscurely defined transverse bands, first at nape, second above vent and others on tail. Upper surface, dorsal, pectoral and caudal all finely dotted with dusky. Lower surface immaculate, pale brown to whitish. Twenty-one examples from Takao; largest, $44 \mathrm{~mm}$. 
We have compared an example $95 \mathrm{~mm}$. long in the Academy from Padang, Sumatra, which agrees in every way.

\section{Family SOLENOSTOMIDAE.}

SOLENostomus PaRAdoxus (Pallas).

One example, $125 \mathrm{~mm}$. long, from Takao. D. V-20; A. 20 ; rings, $14+16$; depth of snout midway, $5 \frac{7}{8}$ in its length; caudal peduncle less than base of first dorsal.

Our example very closely resembles Solenostomus paradoxus Weber, ${ }^{4}$ which may really only represent a younger stage of $S$. paradoxus. Its caudal peduncle is shorter than that shown in Weber's figure. The spinous dorsal has the first two membranes with a black blotch like that shown in Jordan and Snyder's figures of $S$. cyanpterus and $S$. paradoxus. Moreover, our example has the spinous dorsal terminally and caudal both terminally and marginally dusky. It is a female and still retains a number of eggs between the ventrals.

\section{Family SYNGNATHIDAE.}

GASTROTOKEUS BIACULEATUS (Bloch).

One from Cebu. Length, $228 \mathrm{~mm}$.

\section{HIPPOCAMPUS KUDA Bleeker.}

Rings, $10+37$ or 38 . D. 18 . Tubercles prominent, rather spinescent and a few filaments present. Supraorbital spine variable, simple, usually with broad base. Preorbital spine obsolete or absent. Coronet moderate. Snout $2 \frac{1}{8}$ to $2 \frac{1}{5}$ to gill opening. Low or obsolete median spine at base of snout before eye, usually scarcely distinguishable. Color in alcohol dull tawny-olive above to paler or whitish below. Back and sides all penciled, streaked, and speckled with dusky, mostly longitudinally. Brood-pouch of males similarly marked to opaque. Eye with six or more conspicuous white lines which radiate on adjacent ocular area. Four examples, three of which males with brood-pouches. Takao. Largest about $125 \mathrm{~mm}$. long.

\section{HIPPOCAMPUS LONGIROSTRIS Cuvier.}

Rings, $10+35$. D. 18. Tubercles rather conspicuous, without filaments. Supraorbital spine simple, slightly curved backward or obliquely truncated terminally, length half of eye. Preorbital spine well developed, though shorter than supraorbital. Coronet low. Snout nearly long as space from front eye edge to gill-opening. Well developed spine medianly just before preorbital at snout base.

'Siboga Exped., Fishes, vol. 65, 1913, p. 103, fig. 33c. Arafura Sea. 
Color in alcohol nearly dark bone-brown, with largely uniform appearance. Under a lens minute crowded paler dots, very numerous. Lower surface of head, tail and trunk cinnamon-buff. Many

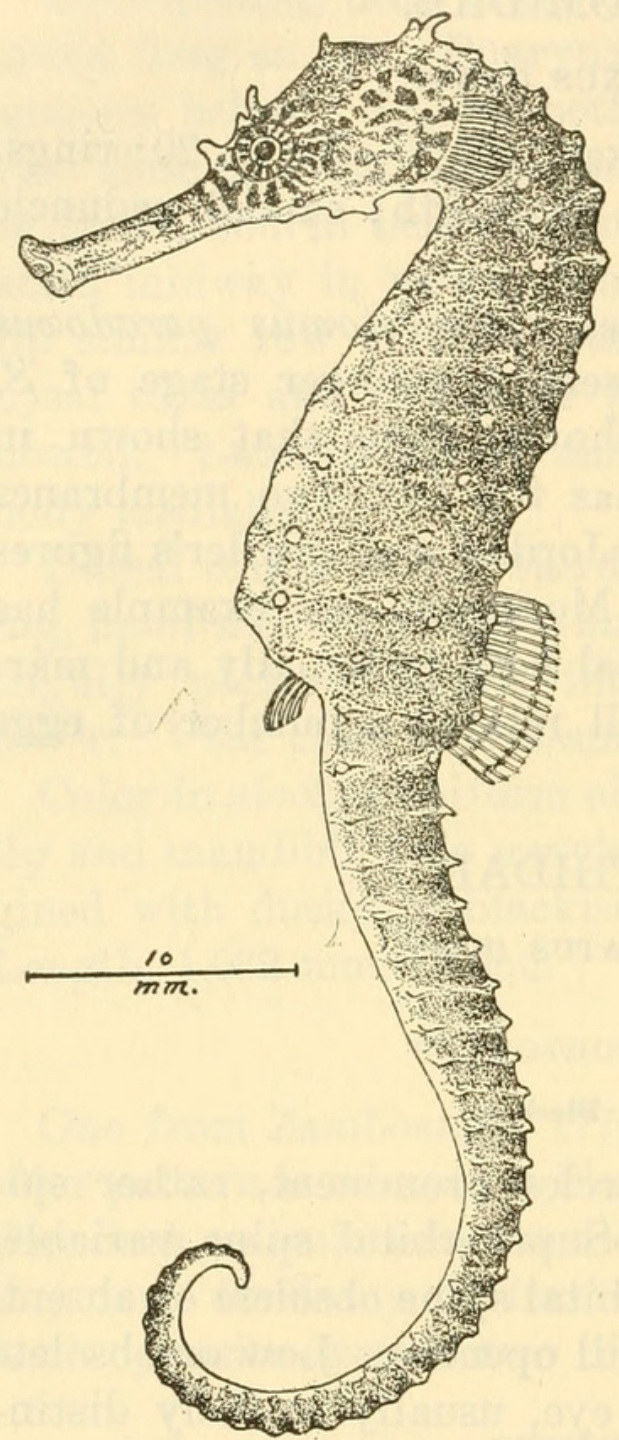

Fig. 2. - Hippocampus LONGIROStris Cuvier. narrow bone-brown bands radiate from eye. Cebu. Length about $140 \mathrm{~mm}$.

\section{Family FISTULARIIDAE. FISTULARIA PETIMBA Lacépède.}

Two from Takao. Compared with Hawaiian and Philippine examples in the Academy, they agree in most every particular. The body is broadly depressed in comparison with $F$. serrata, the snout much shorter and less serrate and the posterior sides of the body are smooth. In the younger example the body has a velvet-like appearance. Length to tips of outermost caudal rays, 128 to $308 \mathrm{~mm}$.

FISTULARIA SERRATA Cuvier.

Head, $2 \frac{1}{2}$; D. 16 ; A. 16 ; snout, $1 \frac{1}{4}$ in head; eye, $1 \frac{1}{4}$ in postorbital; interorbital, 17. Body moderately depressed. Denticles along lateral rostral edges moderate, though extend about hind two-thirds of snout. Lateral line armed with a row of denticles, quite conspicuous along side of tail. Keels on upper surface of snout as in preceding species, except their distension less anterior. According to Gunther's figure, ${ }^{5}$ their distension would occur medially. One from Takao, $335 \mathrm{~mm}$. long.

\section{Family CENTRISCIDAE.}

\section{CENTRISCUS STRIGATUS (Bleeker).}

Head, $2 \frac{2}{5}$ to origin of soft dorsal fin; depth, $5 \frac{1}{2} ;$ D. IV, $10 ;$ A. 12 ; snout, $1 \frac{1}{3}$ in head; eye, $1 \frac{3}{5}$ in postorbital; interorbital, 2. Body extremely compressed, thin, and narrowly convex above, constricted below as broad thin trenchant edge. Head and body cuirassed with finely striate bony plates. Snout formed as compressed bony beak, but moderately recurved. Space between front eye edge and hind edge of gill-opening slightly less than space between gill-opening and pectoral origin. Pectoral extended downward seven-eighths to

¿ Rep. Voy. Challenger, vol. 1, 1880, pl. 32, fig. C. 
ventral origin. Color in alcohol with brown streak along upper half of snout posteriorly about wide as pupil and indistinct behind eye. Body largely transparent brownish. Iris silvery-white. Length, $107 \mathrm{~mm}$. (dorsal spine damaged). Takao.

We have compared this with an example in the Academy, without locality, $120 \mathrm{~mm}$. long (tips damaged), which agrees in having four dorsal spines. The pectoral origin is, however, a little more posterior.

\section{Family EXOCOETIDAE.}

CYPSELURUS NIGRIPENNIS (Valenciennes).

Head, $3 \frac{3}{4}$; depth, $5 \frac{1}{2}$; D. I, 9 or 10 ; A. I, 9 or 10 ; snout, $3 \frac{1}{3}$ to $3 \frac{4}{5}$ in head from upper jaw tip; eye, $2 \frac{1}{2}$ to $2 \frac{3}{5}$; maxillary, $3 \frac{1}{8}$ to $3 \frac{1}{5}$; interorbital; $2 \frac{1}{2}$ to $2 \frac{2}{3}$. Snout tip to hind preopercle edge equals length of head depth. Snout, two-thirds of eye. Interorbital slightly concave. Gill-rakers, $7+14$, lanceolate, nearly long as filaments, which $2 \frac{1}{2}$ in eye. Scales with 4 or 5 short basal striae, edge scalloped, circuli moderately fine. Pectoral reaches middle of dorsal base. Ventral inserted midway between front eye edge and caudal base, reaches second branched anal ray base. Dorsal origin little before that of anal, fin rounded and median rays nearly long as head. Color in alcohol largely silvery-white. Back neutral-gray, with portions of dorsal, pectoral and ventral black, though last one or two caudal rays whitish and pectoral base pale. Caudal and anal pale or whitish. Three examples, 57 to $70 \mathrm{~mm}$. long. Takao.

\section{CYPSELURUS BRACHYSOMA (Bleeker).}

Head, 4; depth, 5; D. I, 10; A. I, 8; snout, 4 in head from upper jaw tip; eye, 3 ; maxillary, 4 ; interorbital, $2 \frac{2}{5}$. Body well compressed. Head width, $1 \frac{3}{4}$ its length. Snout depressed, length $\frac{2}{3}$ its width, $\frac{3}{4}$ of eye. Maxillary about opposite middle in nostril. Interorbital very slightly concave. Head depth equals space between snout tip and hind preopercle edge. Gill-rakers, $5+16$, lanceolate, about threefourths of filaments which $1 \frac{3}{4}$ in eye. Scales mostly fallen, about 24 between hind eye edge and dorsal origin. Scales with 2 or 3 basal radiating striae, circuli fine. Pectoral reaches about eighth branched dorsal ray base. Ventral inserted midway between hind pupil edge and caudal base, reaches about opposite middle in depressed anal length. Last dorsal ray long as eye. Color in alcohol apparently faded brownish. Pectoral blackish, edges pale or whitish. Dorsal and caudal brown. Ventral and anal whitish. Length, $153 \mathrm{~mm}$. (caudal tips damaged). Cebu.

Our example agrees largely with Bleeker's figure, ${ }^{6}$ except its ventral is inserted slightly more backward.

- Atlas Ichth., vol. 6, 1866-72, pl. 1, fig. 1. 
Family HEMIRAMPHIDAE.

HEMIRAMPHUS FAR (Forskål).

Head from upper jaw tip, $4 \frac{2}{3}$; depth, $6 \frac{1}{8}$; D. II, 11, occasionally II, 12 ; A. II, 9, rarely II, 10; scales, 50 in lateral line to caudal base; 38 to 40 predorsal scales; snout, $2 \frac{3}{4}$ to $2 \frac{7}{8}$ in head from upper jaw tip; eye, $3 \frac{3}{4}$ to 4 ; maxillary, $3 \frac{1}{4}$ to $3 \frac{3}{5}$; interorbital, $3 \frac{1}{3}$ to $3 \frac{3}{5}$. Five examples, 288 to $500 \mathrm{~mm}$. Takao.

\section{DERMOGENYS PUSILLUS Kuhl and Van Hasselt.}

Head from upper jaw tip, 4 ; depth, $6 \frac{2}{5}$; D. II, 8 ; A. II, 13; P. I, 9; V. I, 5 ; scales, 40 ? from gill-opening above to caudal base and 4 more or latter; 32 ? predorsal scales; snout, $3 \frac{2}{5}$ in head; eye, 32 ; maxillary, $2 \frac{4}{5}$; interorbital, $2 \frac{3}{4}$; first branched dorsal ray, $2 \frac{1}{8}$; longest anal ray, $1 \frac{1}{2}$; least depth of caudal peduncle, $2 \frac{2}{3}$; caudal, $1 \frac{2}{5}$; pectoral $1 \frac{1}{8}$; ventral, $2 \frac{1}{6}$.

Body moderately long, well compressed, deepest about midway in length. Caudal peduncle long as deep.

Head well compressed, flattened, sides narrowly convergent below, width $2 \frac{1}{4}$ in its length from upper jaw tip. Upper jaw depressed, short or broadly triangular, length about four-fifths its width at front of eyes. Eye large, slightly less than snout, impinges on upper profile and hind edge slightly behind middle in head length as measured from snout tip. Mouth with short horizontal gape, about two-thirds of eye. Maxillary largely concealed by preorbital, reaches eye. Narrow series of small uniform conic teeth in lower jaw basally, none in upper. Nostrils minute. Interorbital slightly concave.

Gill-opening extends forward opposite front pupil edge. Gillrakers, $2+16$ ? , short weak points, about one-fourth of gill-filaments, which half length of eye. Isthmus narrow slender frenum.

Scales rather large, cycloid, moderately imbricated, basal striae 5 and circuli about 17, complete. Head scaly, single row of large scales on cheek, and opercles scaled. Caudal base with 5 rows of scales. Lateral line incomplete, at least tubes obsolete or irregular behind ventrals.

Dorsal origin at last fourth in space between hind edge of gill. opening and caudal base, and last ray reaches latter. Anal inserted a little in advance of dorsal origin, larger than dorsal, though last ray falling well short of caudal base. Caudal rounded (edges damaged). Pectoral high, reaches three-fifths to ventral. Ventral placed midway between preopercle ridge and caudal base, reaches slightly less than half way to anal. Vent about last fourth in space between ventral and anal origins.

Color in alcohol, faded dull brownish, nearly uniform. Upper surface of head and down middle of back dusted with dusky specks 
or minute dots. Predorsal with two parallel dusky lines, close set, formed of dusky dots. Median lateral line of dusky from shoulder to caudal base medianly. No silvery lateral band. Iris slaty gray. Fins all pale brownish.

Length, $45 \mathrm{~mm}$. (ends damaged).

One from Zamboanga.

Among the examples of Philippine fishes studied in the Commercial Museum of Philadelphia were several specimens of this species which we have not since located. Of this lot, nine examples presented to the Academy were listed as Dermatogenys viviparus (Peters). ${ }^{7}$ This is wrong, and we find them to be Hyporhamphus neglectus. They agree with an example from Sumatra, though all are a little smaller, besides in very poor preservation. Likely all may eventually be united with Hyporhamphus unifasciatus (Ranzani) as contended by Gunther and Bleeker.

Hemiramphus viviparus Peters, ${ }^{8}$ judging from its description, appears inseparable from Dermogenys pusillus Kuhl and Van Hasselt.

\section{RHAMPHODERMOGENYS, new subgenus.}

Type.-Dermogenys bakeri, new species.

Distinguished from subgenus Dermogenys Van Hasselt by its long upper jaw and advanced ventrals.

One species.

Both Hemiramphus brachijnotopterus Bleeker ${ }^{9}$ and Hemiramphus sumatranus Bleeker ${ }^{10}$ appear to belong to the subgenus Dermogenys.

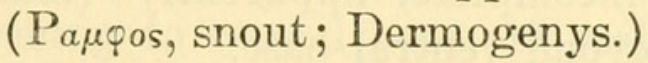

\section{DERMOGENYS BAKERI, new species.}

Head from upper jaw tip, $3 \frac{1}{4}$; depth, $6 \frac{1}{2}$; D. II, 8 ; A. II, 13; P. I, 10 ; V. I, 5 ; scales from gill-opening at shoulder 39 to caudal base; 4 scales above lateral line to dorsal origin, and 5 below to anal origin; 33 ? predorsal scales to head; snout, $2 \frac{1}{4}$ in head as measured from its own tip; eye, $4 \frac{1}{5}$; maxillary, $2 \frac{1}{8}$; interorbital, $3 \frac{3}{5}$; first branched dorsal ray, $2 \frac{7}{8}$; second simple anal ray, $1 \frac{7}{8}$; least depth of caudal peduncle, $3 \frac{1}{2}$; caudal (tip damaged), $1 \frac{3}{4}$; pectoral, $1 \frac{1}{2}$; ventral, $2 \frac{4}{5}$.

Body moderate, strongly compressed, or back broad and flattened sides well converging below. Caudal peduncle about as long as deep.

Head well compressed, sides flattened and narrowly converging below; width, $2 \frac{4}{5}$ in its length from upper jaw tip. Upper jaw depressed, lanceolate, width $1 \frac{3}{5}$ in its length. Eye large, slightly im-

${ }^{7}$ Proc. Acad. Nat. Sci., Phila., 1919, p. 10.

- Monatsb. Akad. Wiss. Berlin, 1865, p. 132. Samar and Luzon.

- Verh. Batav. Genoot. (Bengal) vol. 25, 1853, p. 146. River Hooghly, Calcutta.

${ }^{10}$ Nat. Tijds. Ned. Indie, vol. 5, 1853, p. 526. Lake Meninju, Western Sumatra. 
pinging in upper profile, and eye center very little behind middle in head length as measured from snout tip. Mouth with long gape, reaches five-sixths to eye. Maxillary،small, concealed by preorbital, reaches eye. Row of moderately small and nearly uniform conic simple teeth in each jaw. Front upper teeth form somewhat horseshoe-shaped pattern, contiguous each side with lateral row. Lower teeth in rows not approximated forward, graduated slightly, and obsolete little before tip of depressed upper jaw. Nostrils minute. Interorbital concave.

Gill-opening extends forward little before front pupil edge, though not to front eye edge. Gill-rakers, $2 ?+17$ short weak points, about one-fourth of gill-filaments, which about 3 in eye. Isthmus narrow slender frenum.

Scales large, cycloid, moderately imbricated, basal striae 5 to 12 anal circuli complete, 18 to 20. Head scaly. Single row of large scales on cheek. Caudal base with five rows of scales. Anal base

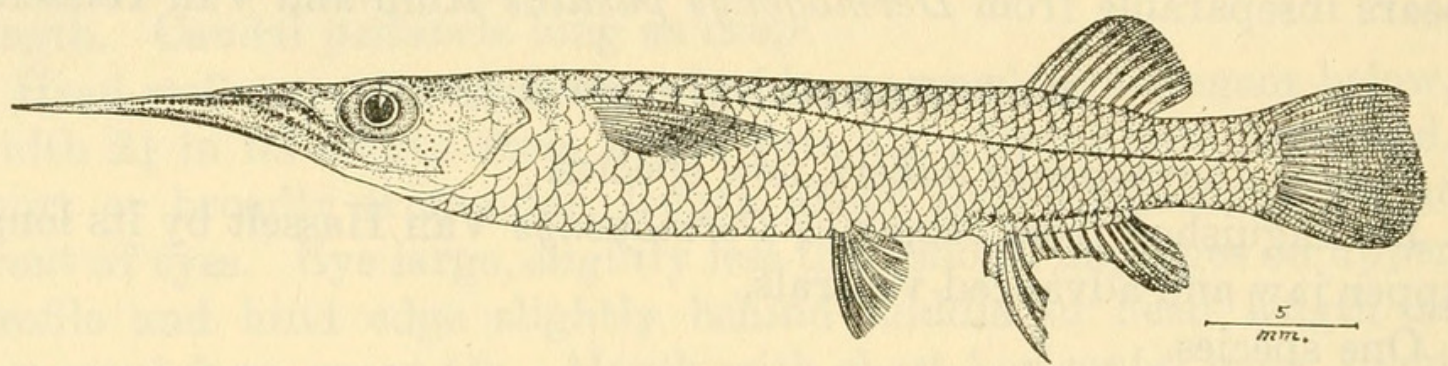

Fig. 3.-Deriogenys bakeri, NeW species.

scaly, also opercles. Lateral line incomplete, apparently (many scales fallen) not extending much beyond ventral base.

Dorsal origin little behind last third in space between hind edge of gill-opening and caudal base, and depressed fin not quite reaching latter. Anal inserted little before dorsal origin, fin larger than dorsal, though when depressed falls well short of caudal base. Caudal rounded (edges damaged). Pectoral high, fin reaches threefourths to ventral origin, nearly midway between hind eye edge and caudal base, reaches two-thirds to anal. Vent about last fourth in space between ventral and anal origins.

Color in alcohol, faded dull isabella-brown, nearly uniform. Upper surface of head and down middle of back dusted with dusky specks or minute dots. Predorsal with two close-set parallel lines, formed of dusky dots. Median lateral line of dusky from shoulder to caudal base, ending at latter medially, though no silvery lateral band. Iris gray-white. Fins pale brown.

Length, $43 \mathrm{~mm}$. (caudal ends damaged).

Type.-Cat. No. 84275, U.S.N.M. Zamboanga, Philippine Islands. Dr. Fred Baker.

Only the above example known.

(Named for its discoverer, Dr. Fred Baker.) 


\section{Family SPHYRAENIDAE.}

SPHYRAENA AUREOFLAMMEA Seale.

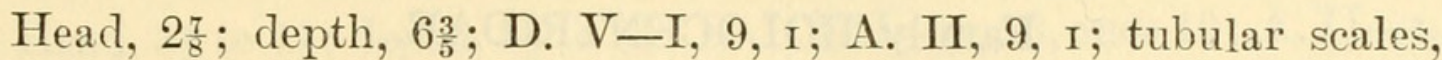
81 in lateral line (mostly fallen) to caudal base, and about 8 more on latter; 10 scales above lateral line to spinous dorsal origin, 10 below to spinous anal origin; 26 (pockets) predorsal scales to occiput; snout, $2 \frac{1}{4}$ in head from upper jaw tip; eye, $5 \frac{1}{8}$; maxillary, $2 \frac{3}{5}$; interorbital, 6 $\frac{1}{2}$. Gill-rakers, 2, lanceolate, on cerato-branchial, about two-thirds of filaments or 3 in eye. Scales with 28 to 34 basal parallel striae, circuli fine. Maxillary reaches nostril, but not quite to eye. Spinous dorsal begins opposite tip of pectoral. Ventral origin nearer pectoral base than spinous dorsal origin. Color in alcohol, brownish above, paler below. Length, $163 \mathrm{~mm}$. (caudal damaged). Cebu.

Our example agrees in most every way with Seale's account. In the short maxillary not extending to the eye it is certainly near Sphyraena langrar Bleeker and S. brachygnathus Bleeker. Of these the former is said to have the snout nearly twice as long as the eye and larger scales. In the latter the body is much more slender and the eye larger.

\section{Family MUGILIDAE.}

MUGIL TROSCHELII Bleeker.

Head, $3 \frac{3}{4}$; depth, 4t D. IV-I, 8 ; A. III, 9, I; scales, 33 from gillopening to caudal base; 12 scales transversely between soft dorsal and anal origins; 20 predorsal scales; snout, $3 \frac{1}{2}$ in head; eye, $3 \frac{3}{4}$; mouth width, 3 ; interorbital, $2 \frac{2}{5}$. Gill-rakers about $31+50$, finely lanceolate, $1 \frac{1}{2}$ in filaments or $1 \frac{3}{4}$ in eye. Scales with 5 radiating basal striae, and circuli very fine. Five scales between depressed spinous dorsal tip and soft dorsal origin. Preorbital scaly, with fine denticles. Pectoral axillary scale slightly less than half of fin. Soft dorsal largely scaled, anal likewise and its fron' fourth before soft dorsal origin. Maxillary reaches level of lower preorbital edge, slightly uncovered. Spinous dorsal slightly higher than soft fin, its origin midway between front pupil edge and caudal base. Least depth of caudal peduncle, $2 \frac{2}{5}$ in head; pectoral length, $1 \frac{2}{5}$. Caudal emarginate. Color in alcohol, dull brownish, mostly uniform. Caudal with slight wash of pale dusky. Length $148 \mathrm{~mm}$. Cebu.

Evermann and Seale have noted and figured this species as Liza troschetii ${ }^{11}$ from Manila. They say the origin of the anal is under the origin of the soft dorsal, though their figure shows it well in advance and as found in our example. Also, they say the pectoral is long as 
the head, though they figure it much shorter. The axillary pectoral spot they mention is hardly evident in our example.

\section{Family HOLOCENTRIDAE.}

HOLOCENTRUS RUBER (Forskå1).

Head to hind edge of opercular membrane, $2 \frac{7}{8}$ to $3 \frac{1}{8}$; depth, $2 \frac{2}{3}$ to $2 \frac{5}{6}$; D. XI, 13; A. III, 9, r; tubular scales, 33 to 35 in lateral line to caudal base; 3 scales above lateral line to soft dorsal origin, 7 or 8 below to spinous anal origin; 6 predorsal scales; snout, 4 in head; eye, $2 \frac{4}{5}$ to $3 \frac{1}{4}$; maxillary, $2 \frac{2}{3}$ to $2 \frac{3}{4}$; interorbital, $3 \frac{2}{5}$ to $3 \frac{1}{2}$. Gill-rakers, vI, $1+6$, Ix, lanceolate, seven-eighths of filaments, 2 in eye. Preopercle spine long as eye, serrae along hind edge of preopercle variable. Color in alcohol, pale brown generally, with silvery reflections. Obscure brown blotch at bases of soft dorsal and anal, posteriorly on latter, also on caudal, though extending slightly along upper and lower edges of fin lobes. Ventral tip and first anal ray brownish. Two examples, 235 to $265 \mathrm{~mm}$. (caudal damaged). Zamboanga.

Our examples appear to agree with Holocentrum melanospilum Bleeker, ${ }^{12}$ which has been placed as a synonym of the present species.

\section{Family SCOMBRIDAE.}

\section{SCOMBER KANAGURTA Rüppell.}

Head, $3 \frac{3}{4}$; depth, 4 to $4 \frac{1}{6}$; D. X-II, 11 I, 5; A. II, 10, 5: snout, $3 \frac{1}{3}$ to $3 \frac{2}{5}$ in head; eye, 4 ; maxillary, $2 \frac{1}{2}$; interorbital, $3 \frac{2}{5}$ to $3 \frac{4}{5}$. Gillrakers about $13+21$, firmly and slenderly clavate, very slightly less than filaments, which equal eye. Scales with circuli vertical, fine, all more or less parallel, only slightly diverging at scale center, and circuli about 80 to 88 in horizontal or transverse count. Color in alcohol, back dark greenish or blue-gray to slaty, sides and lower surface whitish with silvery tints. Back marked with several rows of slightly darker spots. Fins pale brown, hind edge of spinous dorsal dusky. Iris whitish. Length, 230 to $238 \mathrm{~mm}$. Two from Takao.

These agree with Sumatran examples in the Academy. We accept Bean and Weed's conclusions ${ }^{13}$ from their study of Javan material. We take exception, however, to Russell as the authority for the species, as he is nonbinomial, and must be replaced by Rüppell. Rastrelliger, with the single species $R$. brachysomus, has increased gillrakers, $23+44$.

12 Atlas Ichth., vol. 9, 1877, pl. (5), 359, fig. 1.

1s Proc. U. S. Nat. Mus., vol. 42, 1912, p. 602. 


\section{Family CARANGIDAE.}

\section{SCOMBEROIDES TOL (Cuvier).}

Head, $3 \frac{2}{5}$ to $4 \frac{1}{2}$; depth, $3 \frac{1}{3}$ to $3 \frac{2}{3}$; D. I, VII-II, 20 , once 19 ; A. II-I, 19, occasionally 18; snout, 3 in head from upper jaw tip; eye, $3 \frac{1}{4}$; maxillary, 2 ; interorbital, $3 \frac{1}{2}$. Gill-rakers, 6 or $7+18$ or 19 . Color in alcohol, back bluish-gray, sides and below silvery-white. Row of seven obscure small spots along side of back. Membranes of spinous dorsal blackish, also apex of soft dorsal, though rest of fin gray. Caudal pale, grayish behind. Other fins pale. Iris silverywhite. Length, 45 to $163 \mathrm{~mm}$. Eight from Takao.

All agree with examples in the Academy from Sumatra and the Philippines, the latter recorded as $S$. tala by Fowler. ${ }^{14}$ Some of the same also have the pronounced external conic canines, but all have linear scales. On the contrary, Bean and Weed, they doubtless having examined the type, place Eleira phitippina as a synonym of Scomberoides tysan. ${ }^{15}$ Jordan and Seale do not describe or indicate in any way the nature of the scales. Such characters as they give would point to its association with $S$. tala (Cuvier), with which it is included by Jordan and Richardson. ${ }^{16}$ However, a small Philippine example, $83 \mathrm{~mm}$. long, in the Academy, which we believe to be the young of $S$. Tysan (Forskål), has the maxillary reaching a little beyond the hind eye edge. Now, the type of Eleira philippina, 121 $\mathrm{mm}$. long, is said to have the maxillary reaching only to the last third of the eye, which is apparently correctly indicated by the figure.

\section{CARANX MATE Cuvier.}

Head, $3 \frac{3}{4}$; depth, $3 \frac{1}{10}$; D. VIII-I, 24; A. II-I, 20; scales, 40 in curve of lateral line, 53 in straight section, of which last 10 on caudal base; snout, $3 \frac{1}{8}$ in head; eye, $3 \frac{1}{2}$; maxillary, $2 \frac{3}{4}$; interorbital, $3 \frac{3}{5}$. Gill-rakers, $11+28$, lanceolate, slightly less than filaments, or $1 \frac{4}{5}$ in eye. Scales with circuli vertically parellel, 44 basal and 33 apical, confluent down vertical axis. Pectoral about equals arch of lateral line, which $1 \frac{1}{2}$ in straight section. Large dark blotch on hind opercle edge, little smaller than eye. Length, $120 \mathrm{~mm}$. Cebu.

Though smaller, this agrees in most respects with Sumatran examples in the Academy. We note that Caranx mate Cuvier ${ }^{17}$ has priority over L. affinis Rüppell, ${ }^{18}$ which latter is mostly in use.

14 Proc. Acad. Nat. Sci., Phila., 1918, p. 14.

${ }^{15}$ Proc. U. S. Nat. Mus., vol. 42, 1912, p. 602.

${ }^{10}$ Philippine Journ. Sci., vol. 2, 1910, p. 19.

${ }^{17}$ Hist. Nat. Poiss., vol. 9, 1833, p. 40. Pondichery, Seychelles, New Guinea, Anjer.

ss Neue Wirbelth., 1835 (March, 1838), p. 49, pl. 14, fig. 1. Red Sea. 
CARANX MALABARICUS (Schneider).

Head, $2 \frac{7}{3}$ to 3 ; depth, 2 to $2 \frac{1}{10}$; D. VIII-I, 21 to 23 , I; A. II-I, 17 , I ; snout, $2 \frac{2}{3}$ to $2 \frac{7}{8}$ in head from upper jaw tip; eye, $3 \frac{2}{5}$ to 4 ; maxillary, $2 \frac{1}{5}$ to $2 \frac{1}{4}$; interorbital, $3 \frac{1}{3}$ to $3 \frac{2}{3}$; scales, 66 to 70 in curve of lateral line, 30 to 40 in straight section. Gill-rakers, 7 to $10+20$ to 27 , about $1 \frac{2}{3}$ in eye, or little longer than filaments. Scales with circuli vertically parallel, about 48 basal and 38 apical, confluent down median vertical axis. Pectoral slightly less than arch of lateral line. Straight section of lateral line $1 \frac{1}{3}$ to $1 \frac{3}{4}$ in arch, latter greater with age. All show a dark blotch on hind preopercle edge, which equals pupil in largest example. Length, 150 to $175 \mathrm{~mm}$. Three from Takao.

We have compared two younger examples in the Academy from Sumatra, which agree in every way, with allowance for age.

CARANX MANDIBULARIS Macleay.

Head, $4 \frac{1}{4}$; depth 17 ; D. VIII-I, 22; A. II-I, 17; scales, 54 in curve of lateral line, 40 in straight section; snout, $3 \frac{2}{5}$ in head from upper jaw tip; eye, $3 \frac{4}{5}$; maxillary, $2 \frac{1}{5}$; interorbital, $3 \frac{2}{5}$. Gill-rakers, $25+48$, slender, lanceolate, little longer than filaments, or $1 \frac{1}{4}$ in eye. Scales with 22 to 25 vertical parallel circuli apically or basally, confluent down median axis. Pectoral very long, curved, $1 \frac{3}{4}$ to caudal base. No opercular spot. Blackish blotch in pectoral axilla. Length, $212 \mathrm{~mm}$. Takao.

Our specimen undoubtedly represents an early stage of Uhua richardsoni Jordan and Snyder, ${ }^{19}$ the type of which is said to be $451 \mathrm{~mm}$. long. From their figure it differs at once in the prolonged dorsal and anal lobes, the former depressed backward far as tips of median caudal rays, and latter depressed backward opposite base of last anal ray. The contour of our example is deeply ovoid. Its maxillary extends back opposite front pupil edge, and the least preorbital widt:. is only half the eye. It is undoubtedly allied with the species of Ciivla in its broadly naked breast, but may stand as a distinct subgenus, Ulua, on account of the great increased gill-rakers.

We may also note that Caranx formosanus Jordan and Snyder ${ }^{20}$ is evidently a synonym of Caranx malabaricus (Schneider). Likewise Caranx rastrosus Jordan and Snyder ${ }^{21}$ is probably a synonym of Caranx plumbeus (Quoy and Gaimard). Though the authors of C. rastrosus show their figure with a dark or blackish opercle, no mention of this is found in their description.

${ }^{19}$ Mem. Carnegie Mus., vol. 4 (2), 1908, p. 39, pl. 53.

${ }^{20}$ Idem, p. 38, pl. 52. Takao.

${ }^{21}$ Idem. p. 37, pl. 1. Takao and Cavite. 
Caran $x$ mandibutaris Macleay ${ }^{22}$ appears to be the earliest name for the present species. It was based on examples about a foot in length. Though some minor differences may appear in comparing the originaI description, we doubt not that they are a condition of age or individual variation. For instance, the scutes are given as $60+45$ and the long dorsal ray about equals the body depth.

CARANX ATROPOS (Forskăl).

Head, $2 \frac{3}{5}$; depth, $1 \frac{2}{5} ;$ D. VIII-II, $20 ;$ A. II-II, 16 ; snout, $3 \frac{1}{3}$ in head; eye, $2 \frac{2}{3}$; maxillary, 2 ; interorbital, $2 \frac{3}{4}$. Gill-rakers, $7+18$, lanceolate, little longer than filaments, or $1 \frac{7}{8}$ in eye. Breast naked. First dorsal ray elongate, slender, depressed backward opposite caudal base. First anal ray elongate, extends backward little beyond caudal base. Pectoral obtuse, $1 \frac{1}{6}$ in head. Ventral blackish, reaches soft dorsal origin. No opercular spot. One, $43 \mathrm{~mm}$. Takao.

Our example is identical with the Sumatran figured by Fowler as Citula atropos and which had the first branched dorsal and anal rays with broken tips. Just how much they may have been prolonged we can not determine. The same specimen was later wrongly associated with Caranx armatus (Forskål). ${ }^{23}$ Our comparison with the Sumatran specimen shows it to belong as originally identified. The species is distinguished by its blackish ventrals.

SCYRIS INDICA Rüppell.

One, $168 \mathrm{~mm}$. Takao. Agrees with Sumatran material in the Academy upon comparison.

\section{Family SCORPIDAE.}

\section{MONODACTYLUS ARGENTEUS (Linnaeus).}

Head, $3 \frac{1}{10}$; depth, $1 \frac{1}{3}$; D. VIII, 29, I; A. III, 29, I; scales, 53 in lateral line to caudal base and 5 more in latter; about 15 scales above lateral line to soft dorsal base; 40 scales below lateral line to spinous anal origin; snout, $4 \frac{1}{5}$ in head; eye, $2 \frac{3}{4}$; maxillary, $3 \frac{1}{10}$; interorbital, $2 \frac{9}{10}$. Gill-rakers, $9+17$, lanceolate, $1 \frac{1}{2}$ in filaments or 3 in eye. Scales each with single basal stria, circuli very fine, and minute apical denticles very numerous. Color in alcohol pale brownish generally, front lobes of soft dorsal and anal dusky, that of latter nearly blackish. Other fins pale, hind caudal edge grayish. Iris dark. Length, $147 \mathrm{~mm}$. Cebu.

${ }^{22}$ Proc. Linn. N. S. Wales, vol. 7, 1882, p. 356. New Guinea.

${ }^{23}$ Proc. Acad. Nat. Sci. Phila., 1905, p. $\$ 3$. 


\section{Family LEIOGNATHIDAE.}

\section{LEIOGNATHUS VIRgatUS Fowler.}

Head, $3 \frac{1}{4}$ to $3 \frac{1}{2}$; depth, $1 \frac{5}{6}$ to 2 ; D. VIII, 16 ; A. III, 14 ; snout, 3 to $3 \frac{1}{10}$ in head; eye, $2 \frac{1}{2}$ to $2 \frac{7}{8}$; maxillary, $2 \frac{1}{10}$ to $3 \frac{1}{10}$; interorbital, $2 \frac{3}{4}$ to $2 \frac{7}{8}$. Gill-rakers 5 or $6+17$ to 20 . Length, 80 to $108 \mathrm{~mm}$. Two from Takao.

Our examples agree in most every respect with the types in the Academy, with which we compared them.

LEIOGNATHUS EQUULA (Forskål).

Head, $3 \frac{1}{8}$; depth, 2 to $2 \frac{1}{10}$; D. VIII, 16; A. III, 14; P. II, 16; V. I, 5 ; tubular scales (damaged), about 53 in lateral line to caudal base; about 12 scales (mostly pockets) in vertical series above lateral line to spinous dorsal origin, 22 ? below to spinous anal origin; head width, $1 \frac{7}{8}$ in its length; head depth at occiput equals its length; second dorsal spine, $1 \frac{1}{3}$; first dorsal ray, $3 \frac{1}{5}$; first anal spine, $1 \frac{5}{6}$; first anal ray, $2 \frac{3}{5}$; upper caudal lobe, $1 \frac{1}{10}$; pectoral, $1 \frac{1}{5}$; ventral, 2 ; snout, 3 to $3 \frac{1}{5}$ in head; eye, $2 \frac{4}{5}$ to $2 \frac{7}{8}$; maxillary, $2 \frac{3}{4}$ to $2 \frac{9}{10}$; interorbital, 245 to 3 ; least depth caudal peduncle, $4 \frac{2}{5}$.

Body somewhat elongate, contour ovoid, compressed, deepest about spinous dorsal origin, profiles alike. Caudal peduncle compressed, long as deep.

Head deep, compressed, profiles similar, flattened sides converging moderately below. Snout obtuse, somewhat pyramidal, very slightly protruding beyond lower jaw; length four-fifths its width. Eye large, close to upper profile, hind pupil edge midway in head length. Mouth small, short and horizontal, gape about three-fifths to eye. Lips thin, narrow. Mandible profile slightly concave to articulation below, which is opposite front pupil edge. Mouth protractile downward. Teeth very small, weak, uniform, brushlike, single row in each jaw. No teeth on mouth roof or on tongue. Inner buccal folds rather narrow. Tongue thick, fleshy, adnate. Maxillary hangs down from preorbital about two-thirds an eye diameter below eye, its expension 4 in eye. Nostrils together, close before eye, about level with upper pupil edge. Interorbital concave. Two short sharppointed spines above nostrils. Supraocular ridge finely serrated. Lower preopercle edge well serrated, largest serrae posterior and hind edge entire. Supraocular spine almost meets spine of predorsal process.

Gill-opening extends forward nearly opposite eye center. Gillrakers, $8+22$, slightly longer than filaments, or 3 in eye. Pseudobranchiae slightly longer than gill-filaments. Shoulder girdle edge within gill-opening with two firm low processes, upper trifle above 
and lower level with bases of lower pectoral rays. Isthmus width about $2 \frac{1}{2}$ in eye.

Scales small, narrowly imbricated, caducous, entirely cover chest. Well-developed scaly sheaths along bases of spinous dorsal and anal. Soft dorsal and anal with series of inconspicuous spines each side basally, fin ray between each pair and all directed evenly backward. Axillary scaly ventral flap three-fifths of fin, three-fourths length of spine. Caudal base finely scaled. Abdomen narrowly compressed, lower face of preanal spine with median groove, forward about last two-fifths in space between ventral and anal origins. Chest with firm median keel. Two small keels extend forward from ventral bases, parallel. Lateral line convex, extends to caudal base. Tubes simple, well exposed, and largely continuous.

Spinous dorsal inserted opposite pectoral origin, second spine longest, others graduated down behind to uniformly low soft dorsal. Spinous anal inserted midway between snout tip and caudal base, first spine little less than third of second and third but slightly shorter. Soft anal like soft dorsal. Caudal well forked, pointed lobes about equal. Pectoral pointed, reaches third anal spine base. Ventral origin below that of pectoral, fin five-sixths to anal. Front basal edges of third dorsal and anal spines finely serrated.

Color in alcohol largely pale brownish, with blue-gray reflection on back. Latter also with number of deeper gray-brown vertical bars or streaks. Snout and interorbital dusted with deep brown dots, finer on occiput. Sides, lower surface, and iris silvery-white. Upper two-thirds of spinous dorsal over first three membranes jet black, rest of fin, together with others, pale brown. Slaty-gray line parallel with dorsal base close below basal spinous joints. Pectoral axil dusted with brown dots.

Length of largest, $80 \mathrm{~mm}$.

Three examples. Takao.

We have compared Sumatran examples in the Academy and found all in agreement.

\section{LEIOGNATHUS LEUCISCUS (Gunther).}

Head, $3 \frac{1}{2}$ to $3 \frac{5}{6}$; depth, $2 \frac{3}{4}$ to $2 \frac{4}{5}$; D. VIII, 16; A. III, 14 ; snout, $2 \frac{7}{8}$ to 3 in head; eye, 3 to $3 \frac{1}{8}$; maxillary, $2 \frac{2}{5}$; to $2 \frac{1}{2}$; interorbital, $2 \frac{3}{4}$ to $2 \frac{4}{5}$. Preopercle smooth. Gill-rakers, 7 or $8+11$ to 13 . Second dorsal spine little greater than body depth, or $2 \frac{3}{5}$ in combined head and trunk without caudal. Color in alcohol, back vinaceous-gray or bluish-gray, with brown tinge in some lights, mottled with deeper or brownish specks or blotches. Sides and lower surface silverywhite. Snout edge blackish-brown. Iris white. Fins pale brownish. Seven examples, 68 to $135 \mathrm{~mm}$. Takao. 
L. edwardsi Evermann and Seale ${ }^{24}$ we think a synonym. The characters of distinction, such as the smooth preopercle, supraocular spine, and less developed first dorsal spine are hardly of specifis value, and all are covered by our examples.

Quite likely L. stercorarius Evermann and Seale ${ }^{25}$ may be another synonym. A comparison of the paratype in the Academy shows no characters worthy of distinction from our series, as the prolonged second dorsal spine is quite variable.

GAZZA ARgENTARIUS (Schneider).

Head, $2 \frac{2}{5}$ to 3 ; depth, $2 \frac{1}{5}$ to $2 \frac{2}{5}$; D. VIII, 16 ; A. III, 14 ; snout, $3 \frac{1}{8}$ to $3 \frac{2}{5}$ in head; eye, $3 \frac{1}{10}$ to $3 \frac{1}{8}$; maxillary, $3 \frac{7}{8}$ to 4 ; interorbital, $2 \frac{7}{8}$ to $3 \frac{1}{5}$. Gill-rakers, $5+15$, lanceolate, slightly longer than filaments, or about 2 in eye. Color in alcohol, back bluish-gray, with vertical lines, often broken, as specks or bars. Upper jaw edge dusky-brown. Spinous dorsal dusky. Other fins pale brown. Side, lower surface, and iris silvery-white. Pectoral axil dusky. Length, 115 to $130 \mathrm{~mm}$. Five from Takao.

Our examples agree entirely with Sumatran and Philippine material in the Academy reported as G. tapeinosoma Bleeker.

\section{Family CHEILODIPTERIDAE.}

\section{AMIA BIFASCIATA (Rüppell).}

Head, $2 \frac{1}{2}$; depth, $2 \frac{3}{4}$; D. VII-I, 9, I; A. II, 8, I; tubular scales about 19 in lateral line to caudal base and 4 more on latter; 2 scales above lateral line to soft dorsal origin, 7 below to spinous anal origin; 5 predorsal scales; snout, $3 \frac{7}{8}$ in head from upper jaw tip; eye, $3 \frac{1}{10}$; maxillary, $2 \frac{1}{6}$; interorbital, 5. Gill-rakers III, $3+9$, Iv, lanceolate, seven-eighths of filaments, or 4 in eye. Scales with 13 to 17 basal radiating striae, often 2 or 3 incomplete auxilliaries, apical denticles 70 to 121, and circuli moderate. First and second membranes of spinous dorsal blackish, others dusky, also soft dorsal. Blackish caudal blotch basally, little smaller than eye. Length, $105 \mathrm{~mm}$. Cebu.

Compared with a Philippine example in the Academy. The median brown longitudinal band from the snout tip nearly to caudal base present in both, though less conspicuous in the Cebu example, doubtless on account of its poor preservation. A larger example of A pogon snyderi Jordan and Evermann, from the Hawaiian Islands, in the Academy agrees in every way and indicates that nominal species to be a synonym.

\section{AMIA SEALEI Fowler.}

Head, 22 ; depth, 3; D. VII-I, 9, I; A. II, 8, I; tubular scales, about 21 in lateral line to caudal base and 4 more on latter; 3 scales

${ }^{24}$ Bull. Bur. Fish., vol. 26, 1906 (1907), p. 68, fig. 7. San Fabian, Philippines.

${ }^{25}$ Idem, p. 67, fig. 6 . Bulan. 
above lateral line to soft dorsal origin; 3 predorsal seales; snout $4 \frac{1}{10}$ in head from upper jaw tip; eye, 3 ; maxillary, $2 \frac{1}{8}$; interorbital, $4 \frac{1}{2}$. Gill-rakers, II. $3+11$, Iv, lanceolate, filaments seven-eighths of gillrakers, which 3 in eye. Scales with 14 to 18 basal radiating striae, 128 to 148 apical denticles, and circuli coarse. Dorsals dusted with dull brownish. At upper caudal base small deep brown round spot, little less than pupil. Length, $98 \mathrm{~mm}$. (caudal damaged). Cebu.

We compared this example, though poorly preserved and much larger, finding it agrees with the types in the Academy.

\section{AMIA Lineata (Schlegel).}

Head, $2 \frac{1}{3}$ to $2 \frac{1}{2}$; depth $2 \frac{3}{4}$ to 3 ; D. VII-I, 9, I; A. II, 8 , I; tubular scales, 20 in lateral line to caudal base and 4 more on latter; 2 scales above lateral line to soft dorsal origin, 5 below to spinous anal origin; 5 predorsal scales; snout, 5 to $5 \frac{1}{2}$ in head; eye, $3 \frac{1}{5}$ to $3 \frac{1}{2}$; maxillary, $1 \frac{3}{4}$ to 2 ; interorbital, $3 \frac{1}{4}$ to $3 \frac{7}{8}$. Gill-rakers II, $3+11$, lanceolate, twice filaments, or 2 in eye. Scales with 10 to 16 basal radiating striae, 2 or 3 auxiliaries, apical denticles 93 to 104, and circuli rather fine. Color in alcohol with ten pale brown vertical bars, wide or narrower as whitish interspaces on trunk. Back pale brown. Dorsals and caudal dusted with blackish dots, more crowded and darker marginally or terminally. Pale subbasal dusky band on soft dorsal. Anal pale, dusted with blackish marginally. Paired fins pale. Length, 38 to $75 \mathrm{~mm}$. Eight from Takao.

An example in the Academy from Nagasaki compared and agrees. We believe the narrower vertical dark bands described by Jordan and Snyder are largely due to conditions of preservation. Our specimens, which are much fresher, at least in appearance, show more dark pigment dots under a lens and the dark areas they form are of greater extent. No structural differences can be found.

AMIA ELLIOTI (Day).

Head, $2 \frac{1}{3}$ to $2 \frac{2}{5}$; depth, $3 \frac{1}{4}$ to $3 \frac{2}{5}$; D. VII-I, 9, I; A. II, 8, I; tubular scales 22 in lateral line to caudal base and 4 more on latter; 2 scales above lateral line to spinous dorsal origin, same to soft dorsal origin, 6 below to spinous anal origin; 4 or 5 predorsal scales; snout 5 to $5 \frac{1}{5}$ in head from upper jaw tip; eye, $3 \frac{2}{5}$ to $3 \frac{3}{5}$; maxillary 2 ; interorbital, $3 \frac{1}{4}$ to $4 \frac{2}{5}$. Gill-rakers III, I+9, III, lanceolate, filaments fourfifths of gill-rakers, which $2 \frac{1}{8}$ in eye. Scales with 11 or 12 basal radiating striae, often 1 to 4 auxiliaries incomplete, apical dentricles 69 to 83 and circuli coarse. Color in alcohol dull brown with silvery reflections. Seven broad brown vertical bands, pale interspaces one-third width of bands. Iris slaty, with coppery tints. Upper half of spinous dorsal black, basal half white. Soft dorsal white, with margin and median horizontal band black. Caudal 60466-23-Proc.N.M.vol.62-10 
with submarginal dusky band behind. Length, 91 to $100 \mathrm{~mm}$. Four from Takao.

Jordan and Snyder place Apogon marginatus Döderlein as a species distinct from the present. As Apogon ellioti Steindachner, however, originally records the species correctly from Kagoshima and Kobi. Jordan and Snyder had but a single example, obtained at Wakanoura. All of our examples show the preopercle ridge with a blackish line.

\section{AMIA KцENSIS (Jordan and Snyder).}

Head, $2 \frac{1}{2}$ to $2 \frac{3}{4}$; depth, $2 \frac{7}{8}$ to $3 \frac{1}{4}$; D. VII-I, 9, I, or 10 , I; A. II, $8, \mathrm{I}$; tubular scales, 23 or 24 in lateral line to caudal base, and 2 to 4 more on latter; 2 scales above lateral line to soft dorsal origin, 6 below to spinous anal origin; 4 or 5 predorsal scales; snout, $4 \frac{1}{5}$ to $4 \frac{3}{5}$ in head from upper jaw tip; eye, 3 to $3 \frac{1}{2}$; maxillary, $1 \frac{7}{8}$ to 2 ; interorbital, $4 \frac{1}{3}$ to $4 \frac{1}{2}$. Gill-rakers III, $3+11$, III, lanceolate, one third longer than filaments, or $2 \frac{1}{4}$ in eye. Scales with 13 to 17 radiating basal striae, apical denticles 112 to 116 , and circuli rather few. Color in alcohol pale brown above, paler to whitish beneath, with silvery reflections, especially on opercle. Narrow deep brown line, not wide as pupil, from snout tip to caudal base and out over fin to its hind edge. Another, similar, parallel, begins above eye and ends on upper surface of caudal peduncle. Outer dorsal edges dusted with dusky. Both soft dorsal and anal with dusky line subbasally.

In very small brightly colored examples, upper dark lines arise at snout tip, extend over eye, and finally disappear at caudal. Also these show an additional median dark predorsal line arising over middle of eye and a paler one from upper hind eye edge, between supradorsal and mediolateral bands. It is much less conspicuous, only indicating the lateral line and not extending beyond soft dorsal. Length, 45 to $90 \mathrm{~mm}$. Twenty-four examples from Takao.

Compared with a Philippine example in the Academy and agrees.

\section{Family PRIACANTHIDAE.}

PRIACANTHUS TAYENUS Richardson.

Head, $2 \frac{5}{6}$ to 3 ; depth, $2 \frac{3}{5}$ to $2 \frac{4}{5}$; D. X, 12 , I; A. III, 13 , I; scales 70 along lateral line to caudal base and 5 more on latter, 10 scales. above lateral line to spinous dorsal, 9 above to soft dorsal origin, 30 below to spinous anal; 43 predorsal scales; snout, $3 \frac{2}{5}$ to $3 \frac{3}{4}$ in head from upper jaw tip; eye, 2 to $2 \frac{1}{4}$; maxillary, $1 \frac{4}{5}$ to $1 \frac{7}{8}$; interorbital, $4 \frac{1}{5}$ to $4 \frac{1}{3}$. Gill-rakers, $4+18$, lanceolate, one-fourth longer than filaments, or $2 \frac{3}{4}$ in eye. Scales with four basal lobes, irregular apical denticles 12 to 20 , and circuli moderate. Soft dorsal ends in 
point reaching middle of caudal. Caudal emarginate, lobes end in rather long points. Color in alcohol faded pale brown, pale or whitish below, sides silvery-white. Fins pale, spinous dorsal edge, upper soft dorsal marginally, lower anal edge and hind caudal edge dusky. Ventral white, membranes spotted finely with dusky to blackish and innermost membranes marginally with large black blotch. Length, 147 to $180 \mathrm{~mm}$. Three from Takao.

\section{PRIACANTHUS MACRACANTHUS Cuvier.}

Head, 3 ; depth, $2 \frac{3}{4}$; D. XI, 13, I; A. III, 14, I; scales, 94 along lateral line to caudal base and 7 more on latter; tubular scales in lateral line 62 to caudal base and 5 more on latter; 10 scales above lateral line to spinous dorsal origin, 12 to soft dorsal origin, 39 below to spinous anal origin; 50 predorsal scales; snout, $3 \frac{1}{2}$ in head from upper jaw tip; eye, $2 \frac{1}{2}$; maxillary, 2 ; interorbital, $3 \frac{1}{3}$. Gillrakers, $5+18$, lanceolate, equal filaments, or 3 in eye. Scales with four basal lobes, irregular apical denticles 20 to 23, and circuli fine. Caudal truncate. Color in alcohol dull brown above, pale below, with silvery reflections. Fins with dull ground color, spinous dorsal tinged dusky. Soft dorsal, anal, and caudal finely lined or streaked with dusky. Ventral pale, marked with few dusky dots. Length, $213 \mathrm{~mm}$. Zamboanga.

\section{PRIACANTHUS HAMRUR (Forskål).}

Head, 3 ; depth, 3 ; D. X, 13, I; A. III, 14, I; scales, 93 along lateral line to caudal base and 6 more on latter; tubular scales 74 in lateral line to caudal base and 6 more on latter; 12 scales above lateral line to spinous dorsal origin, 10 to soft dorsal origin, and 30 below to spinous anal origin; predorsal scales, 55 ; snout, $3 \frac{3}{4}$ in head from upper jaw tip; eye, $2 \frac{1}{2}$; maxiallary, 2 ; interorbital, $4 \frac{1}{8}$. Gill-rakers III, $3+18$, lanceolate, one-fifth longer than filaments, or 3 in eye. Scales with four basal lobes, 15 to 24 irregular apical denticles, and circuli moderate. Fins not produced, hind caudal edge emarginate. Color in alcohol pale brown, silvery-white below. Spinous dorsal with pale dusky tinge marginally. Ventral largely whitish, membranes dusted with dusky, more intense marginally. Length, 183 $\mathrm{mm}$. One from Takao.

\section{Family, SERRANIDAE.}

\section{EPINEPHELUS SUMMANA (Forskål).}

Heal, $2 \frac{2}{5}$ to $2 \frac{2}{3}$; depth, $2 \frac{4}{5}$ to $2 \frac{9}{10}$; D. XI, 16 , I; A. III, 8 , I; scales, 98 to 100 in lateral line to caudal base, tubular scales, 53 or $54 ; 13$ or 14 scales above lateral line to soft dorsal origin, 33 or 34 below to spinous anal origin; 90 or 92 predorsal scales; snout, about $4 \frac{3}{4}$ to 5 
in head from upper jaw tip; eye, about $4 \frac{2}{3}$ to $4 \frac{4}{5}$; maxillary, $2 \frac{1}{4}$ to $2 \frac{2}{5}$; interorbital, $6 \frac{7}{8}$ to 8 . Rakers vi, $2+10, \mathrm{v}$, lanceolate, equal filaments, or $2 \frac{1}{2}$ in eye. Teeth triserial along middle of lower jaw laterally. Preopercle edge finely serrate. Scales with 4 or 5 basal radiating striae, moderately numerous apical denticles rather slender, and circuli rather coarse. Maxillary half scaled apically above. Caudal rounded. Color in alcohol back gray-brown, belly and under surface pale to light brownish-drab. Above and on sides many small crowded and mostly rounded gray-white spots or bars, often broken and irregular, much smaller on head. Under surface of head, breast and belly nearly uniform. Fins dusky, with many minute pale or gray-white crowded dots and spots. Edges of soft dorsal, anal and . caudal narrowly whitish. Length, 245 to $252 \mathrm{~mm}$. Two from Zamboanga.

\section{EPINEPHELUS FUSCOGUTTATUS (Forskål).}

Head, $2 \frac{1}{3}$; depth, 3; D. XI, 14, I; A. III, S, I; scales, 104 in lateral line to caudal base, tubular scales about 55 and about 8 more on caudal basally; 16 scales above lateral line to soft dorsal origin, 35 below to spinous anal origin; 82 predorsal scales; snout 42 in head

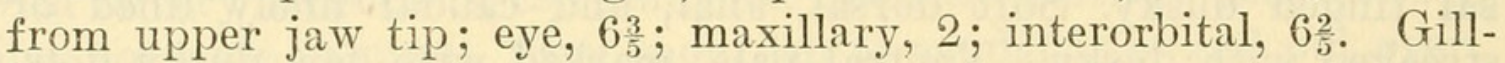
rakers $\mathrm{II}, 3+10$, vII, lanceolate, three-fourths of filaments, which $1 \frac{2}{5}$ in eye. Mandible with 3 lateral series of teeth. Preopercle edge finely serrated. Scales with 6 to 9 basal radiating striae, often 2 or 3 more auxiliaries, small weak apical denticles clustered as little patch subapically, and circuli rather coarse. Maxillary with upper half of apical expansion finely scaled. Caudal rounded. Color in alcohol with back warm sepia with deeper to dusky-brown marblings. Two dark or dusky predorsal blotches, four at dorsal base and black saddle on middle of caudal peduncle above. Four transverse dark-brown blotches across mandible. Body most everywhere with small illdefined dark spots, crowded and numerous on head. Dark blotches along dorsal base extending up on fin. Spinous dorsal with margin of each membrane blackish. Soft dorsal, anal, and caudal and paired fins with large deep brown blotches, more or less as transverse rows. Length, $218 \mathrm{~mm}$. One from Cebu.

\section{EPINEPHELUS MERRA Bloch.}

One from Zamboanga, $78 \mathrm{~mm}$. long. Two rows of tecth along each side of lower jaw. Gill-rakers, v, $3+11$, Iv, lanceolate, longer than filaments, or $2 \frac{1}{2}$ in eye. No maxillary scales. Color in alcohol, body with large deep rounded dusky spots, nearly large as eye, smaller on fins and under surface of head. Narrow interspaces or reticulations pale or whitish, especially on under surface of body. 


\section{EPINEPHELUS AREOLATUS (Forskål).}

Head, $2 \frac{1}{2}$; depth, $2 \frac{7}{8}$; D. XI, 16, I; A. III, 8, I; scales, 110 in lateral line to caudal base, tubular scales about 50 and 3 more on caudal base; 16 scales above lateral line to soft dorsal origin, 38 below to spinous anal origin; 67 predorsal scales; snout, $3 \frac{4}{5}$ in head from upper jaw tip; eye, $5 \frac{1}{4}$; maxillary, $2 \frac{1}{3}$; interorbital, $6 \frac{2}{5}$. Gill-rakers $7+13$, II, lanceolate, $1 \frac{3}{4}$ in eye, or slightly longer than filaments. Teeth biserial along sides of lower jaw. Preopercle edge finely serrate, produced at angle into 5 or 6 enlarged spines. Scales with 3 to 5 basal radiating striae, apical denticles in about 36 rows, and circuli complete. Maxillary two-thirds scaled apically above. Caudal emarginate. Color in alcohol with back deep brownishdrab, paler to nearly avellaneous on belly and lower surface. Vertical fins and ventrals dusky blackish. Body marked with large deep brownish-drab spots, though all smaller than eye. On fins all spots smaller, more numerous and crowded. Margin of soft dorsal narrowly pale to whitish, that of pectoral broadly so. Pectorai palest of fins. Length, $292 \mathrm{~mm}$. Takao.

\section{CROMILEPTES ALTIVELIS (Valenciennes).}

Head, $2 \frac{1}{2}$; depth, $2 \frac{3}{4} ;$ D. XI, 19 ; A. III, 10 ; scales, 102 in lateral line to caudal base, tubular scales 54 , and 8 more on caudal base; 18 scales above lateral line to soft dorsal origin, 40 below to spinous anal origin; about 70 predorsal scales; snout, $4 \frac{1}{2}$ in head from upper jaw tip; eye, $5 \frac{2}{3}$; maxillary, $2 \frac{7}{8}$; interorbital, $9 \frac{1}{5}$. Gill-rakers, vI, $1+9$, v, lanceolate, $1 \frac{3}{4}$ in gill-filaments, which 2 in eye. Scales with 6 or 7 basal radiating striae, small weak apical denticles few or absent, and circuli moderate. Color in alcohol nearly pale purpledrab, spotted sparsely, though evenly, with dusky-brown. Spots became much smaller on front of head, largest on back, not quite size of eye. Pectoral and ventral become dusky terminally, with rather numerous dusky spots. Length, $178 \mathrm{~mm}$. Cebu.

\section{Family LUTJANIDAE.}

\section{LUTJANUS KASMIRA (Forskål).}

Head, $2 \frac{2}{3}$; depth, $2 \frac{2}{3}$; D. XI, 13, I; A. III, 7, I; scales, 85 in lateral line to caudal base, tubular scales 50 , and 7 more on caudal base; 8 scales above lateral line to soft dorsal origin, 21 below the spinous anal origin; 13 predorsal scales to occiput; snout, $3 \frac{1}{8}$ in head from upper jaw tip ; eye, $3 \frac{3}{4}$; maxillary, $2 \frac{2}{3}$; interorbital, 5. Gill-rakers, $7+13$, Iv, lanceolate, slightly less than filaments, or 3 in eye. Preopercle with deep notch, serrae strong below and around angle. Scales 
with 9 basal radiating striae, apical denticles 70 to 84 , and circuli extremely fine. Color in alcohol, back dull brown, below much lighter. Four blue-gray horizontal bands, lowest median, above pectoral axil to caudal base medianly and widest, each with dark marginal line. Fins all pale. Length, $173 \mathrm{~mm}$. Zamboanga.

LUTJANUS VITTA (Quoy and Gaimard).

Head, $2 \frac{3}{4}$ to $2 \frac{4}{5}$; depth, $2 \frac{3}{5}$ to $2 \frac{4}{5}$; D. X, 13 , I; A. III, 8 , I; scales, 53 to 60 in lateral line to caudal base, tubular scales 50 and 5 more on caudal base; 7 scales above lateral line to soft dorsal origin, 16 or 17 below to spinous anal origin; 13 to 16 predorsal scales to occiput; snout, 3 to $3 \frac{1}{6}$ in head from upper jaw tip; eye, $4 \frac{2}{3}$; maxillary, $2 \frac{2}{5}$ to $2 \frac{1}{2}$; interorbital, $4 \frac{1}{2}$ to 5 . Often slight notch on hind preopercle edge above angle. Gill-rakers, v, $1+9$, III, to 11, II, lanceolate, about seven-eighths of filaments, or 2 in eye. Scales with 11 to 14 basal radiating striae, apical denticles 90 to 127 , and circuli extremely fine. Color in alcohol, dull brussels-brown on back to lateral line, below pale orange-yellow. Each row of scales above lateral line with dark median line following courses of scales, thus oblique after curve of lateral line. Below lateral line pale horizontal lines like those above, fading on belly. Fins dull brownish, like back. Anal, pectoral, and ventral pale like lower surface of body. Length, 223 to $295 \mathrm{~mm}$. Two examples, from Cebu and Takao, respectively.

Dark median dusky olive band from snout tip to base of upper caudal lobe, in larger example expanded slightly as in Bleeker's Mesoprion ophuysenii below front of soft dorsal.

\section{LUTJANUS MALABARICUS (Schneider).}

Head, $2 \frac{1}{2}$; depth, $2 \frac{1}{4}$; D. XI, 14, I ; A. III, 9, I ; scales, 60 in lateral line to caudal base, tubular scales 46 and 7 more on caudal base; 10 scales above lateral line to soft dorsal origin, 20 below to spinous anal origin; 12 predorsal scales; snout, $2 \frac{2}{3}$ in head; eye, $5 \frac{1}{6}$; maxillary, $2 \frac{3}{5}$; interorbital, 6 . Preopercle with very slight notch above angle. Gill-rakers, v $2+11$, Iv, lanceolate, little longer than filaments, or $1 \frac{3}{5}$ in eye. Scales with 18 to 21 basal radiating striae; apical denticles 83 to 86 , and circuli very fine. Color in alcohol with back nearly dull avellaneous, sides and below pale to silvery-white. Along each row of scales medianly very slightly darker streak. Upper edge of caudal peduncle with white blotch below last dorsal rays, adjoins an olive-brown saddle, behind which at caudal base slightly paler blotch. Fins pale. Upper dorsal and hind caudal edges slightly dusky-gray. Length, $253 \mathrm{~mm}$. Takao. 
LUTJANUS DECUSSATUS (Cuvier).

Head, $2 \frac{2}{5}$; depth, $2 \frac{3}{5}$; D. X, 13, I; A. III, 8, I; scales, 60 in lateral line to caudal base, tubular scales $50 ; 8$ scales above lateral line to soft dorsal origin, 14 below to spinous anal origin; 13 predorsal scales to occiput; snout, $3 \frac{1}{8}$ in head; eye, $4 \frac{2}{5}$; maxillary, $2 \frac{2}{5}$; inter-

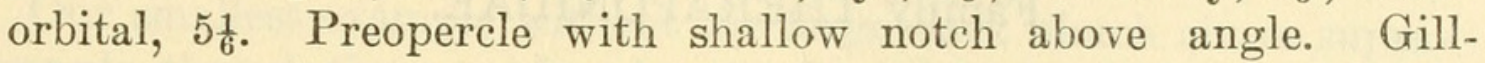
rakers vi, $1+7$, Iv, lanceolate, equals filaments, or $2 \frac{1}{5}$ in eye. Scales with 12 to 14 radiating basal striae, apical denticles 72 or 73 , and circuli extremely fine. Color in alcohol, back dull brown, pale below. Five longitudinal pale brown bands. On back across upper three seven vertical dark streaks. Blackish blotch size of eye at caudal base medianly. Fins all dull brown. Length, $115 \mathrm{~mm}$. Cebu.

LUTJANUS FULVIFLAMMA (Forskăl).

Head, $2 \frac{1}{2}$ to $2 \frac{2}{3}$; depth, $2 \frac{3}{4}$; D. X, 12 , I or 13 , I; A. III, 8 , I; scales, 49 to 54 in lateral line to caudal base, tubular scales 44 to 47 , and 5 to 8 more on caudal base; 7 or 8 scales above lateral line to soft dorsal origin, 11 to 14 below to spinous anal origin; 10 to 14 predorsal scales to occiput; snout, $3 \frac{1}{5}$ to $3 \frac{1}{3}$ in head; eye, $3 \frac{7}{8}$ to 4 ; maxillary, $2 \frac{1}{3}$ to $2 \frac{1}{2}$; interorbital, $4 \frac{2}{5}$ to $5 \frac{1}{3}$. Preopercle with shallow notch above angle, latter well denticulated. Gill-rakers iv to vI, 1 or $2+9$, Iv, lanceolate, nearly long as filaments, or 2 in eye. Scales with 10 to 12 basal radiating striae, apical denticles 67 to 92 , and circuli very fine. Color in alcohol, back drab-gray to natal-brown on head above. Sides and lower surface whitish. Ellipsoid dusky-brown blotch, obscurely defined, on lateral line, longer than eye and below front of soft dorsal. Obscure pale yellowish lines, oblique above and horizontal below lateral line, one medianly in each scale course. Length, 126 to $156 \mathrm{~mm}$. Two from Zamboanga and two from Cebu.

LUTJANUS SEBAE (Cuvier).

Head, $2 \frac{2}{5}$; depth, $2 \frac{1}{8}$; D. XI, 15, I; A. III, 10, I; scales about 66 in lateral line to caudal base, tubular scales 50 , and 5 more on caudal base; 10 scales above lateral line to soft dorsal origin, 24 below to spinous anal origin; 15 predorsal scales to occiput; snout, $2 \frac{1}{3}$ in head; eye, $5 \frac{1}{8}$; maxillary, 3 ; interorbital, $5 \frac{2}{3}$. Preopercle edge notched above angle. Gill rakers, v, $1+8, \mathrm{Iv}$, lanceolate, equal filaments, or $2 \frac{1}{8}$ in eye. Scales with 9 to 15 basal radiating striae, apical denticles 70 to 82 and circuli very fine. Color in alcohol, generally nearly ivoryyellow. Broad oblique dark sepia band along side of snout to spinous dorsal origin. Another transversely from front of spinous dorsal to behind pectoral base, then obliquely till before spinous anal origin. Third band from last dorsal spines obliquely back and 
broadly over caudal peduncle to end of lower caudal lobe. End of upper caudal lobes and ventral blackish. Upper edges of soft dorsal and lower edges of soft anal white with black submarginal band. Length, $210 \mathrm{~mm}$. Zamboanga.

\section{Family THERAPONIDAE.}

THERAPON JARBUA (Forskål).

Head, $3 \frac{1}{5}$; depth, $2 \frac{3}{5}$; D. XII, 10 , I ; A. III, 9, I; scales, 100 in lateraI line to caudal base, tubular scales 90 , and 4 more on caudal base; 15 scales above lateral line to soft dorsal origin, 18 above to spinous dorsal origin, 30 below to spinous anal origin; 25 predorsal scales; snout, $3 \frac{1}{3}$ in head; eye, $4 \frac{3}{5}$; maxillary, $2 \frac{3}{5}$; interorbital, 3 . Gill-rakers $7+14$, short thick strong points, $1 \frac{2}{3}$ in filaments, which $1 \frac{1}{2}$ in eye. Scales with 10 to 12 basal radiating striae, apical denticles 16 to 24 , and circuli moderately coarse. Color in alcohol, dull brownish above, with some light blue-green reflections. Lower surface whitish. Body marked everywhere with bright silvery-white. Fins all pale. Spinous dorsal with large black blotch on upper three-fifths of front elevation and another on last three spines. Smaller black blotches, three on soft dorsal marginally. Above and behind suprascapula large dusky blotch, little larger than eye. Three parallel longitudinal dark or dusky-brown bands on back, upper close along dorsal bases, second begins as broad dark blotch on predorsal narrowing along lateral line and reflected obliquely across upper caudal lobe. Lowest band from below suprascapula, back medianly to caudal, extends medianly over caudal fin to its edge. Except upper tip of caudal fins otherwise pale. Length, $252 \mathrm{~mm}$. Takao.

THERAPON QUADRILINEATUS (Bloch).

Head, $3 \frac{1}{4}$ to $3 \frac{3}{5}$; depth, $2 \frac{3}{5}$ to $3 \frac{1}{8}$; D. XII, 10, I; A. III, 10, I; scales, 80 to 92 along close above lateral line to caudal base, tubular scales in lateral line 63 to 67 , and 6 to 8 more on latter; 13 to 15 scales above lateral line to soft dorsal origin, 14 to 16 above to spinous dorsal origin, 22 to 26 below to spinous anal origin; snout, $2 \frac{3}{4}$ to 3 in head; eye, $3 \frac{1}{5}$ to 4 ; maxillary, $3 \frac{1}{5}$ to $3 \frac{1}{2}$; interorbital, $3 \frac{1}{2}$ to $3 \frac{7}{8}$. Gillrakers, $17+22$ or 23 , lanceolate, slightly less than filaments, which 2 in eye. Scales with 7 to 18 basal radiating striae, apical denticles 16 to 30, and circuli coarse. Color in alcohol, dull brownish above, pale below, most of body overshot with silvery reflections. Spinous dorsal with blackish edge and black elevated blotch forward. Soft dorsal and anal largely dusky marginally, also caudal. Four longitudinal deep brown parallel bands, uppermost from hind interorbital to front of soft dorsal basally, and second from above nostrils to soft dorsal base medianly. Third band from snout tip through 
eye to base of upper caudal lobe and lowest from pectoral axil to lower caudal lobe medianly, though obscure. Large dark brown round spot above and behind suprascapula rests on inception of lateral line. Length, 117 to $163 \mathrm{~mm}$. One from Cebu and two from Takao.

Our smallest example without the large dark blotch above suprascapula, though there are four longitudinal dark lines or bands above front of lateral line. Also another, indistinct, along each side of body.

\section{Family HAEMULIDAE.}

\section{PLECTORHINCHUS PALYTAENIA (Bleeker).}

Head, $3 \frac{1}{4}$ to $3 \frac{2}{5}$; depth, $2 \frac{5}{6}$ to $2 \frac{7}{8}$; D. XII or XIII, 21 , I; A. III, 7, I; 102 or 103 scales counted along close above lateral line to caudal base; 59 or 60 tubular scales in lateral line to caudal base and 9 more on latter; 16 or 17 scales above lateral line to soft dorsal origin, 21 below to spinous anal origin; 50 to 57 predorsal scales; snout, $2 \frac{1}{3}$ to $2 \frac{2}{5}$ in head; eye, $3 \frac{1}{2}$ to 4 ; maxillary, $2 \frac{7}{8}$ to 3 ; interorbital, $3 \frac{2}{3}$ to $3 \frac{7}{8}$. Gill-rakers, $10+18$, lanceolate, $1 \frac{2}{3}$ in filaments, which $1 \frac{2}{3}$ in eye. Scales with 3 or 4 basal radiating striae, apical denticles, 52 to 62 , and circuli very fine. Color in alcohol, pale brownish, generally with nine white longitudinal lines, broadest along middle of side. Between white lines each brown line or band narrowly bordered with darker. Fins uniform dull brown. Iris yellowish. Length, 295 to $301 \mathrm{~mm}$. Two from Zamboanga.

\section{PLECTORHINCHUS GOLDMANNI (Bleeker).}

Head, $3 \frac{1}{3}$; depth, $2 \frac{2}{3}$; D. XIII, 19 , I ; A. III, 7 , I; scales, 95 counted close above along lateral line to caudal base, tubular scales 58, and 18 more on latter; 14 scales above lateral line to soft dorsal origin, 21 below to spinous anal origin; 62 predorsal scales; snout, $2 \frac{1}{2}$ in head; eye, $3 \frac{1}{6}$; maxillary, $3 \frac{1}{8}$; interorbital, $3 \frac{3}{5}$. Gill-rakers, $8+20$, lanceolate, 2 in filaments, which $1 \frac{3}{4}$ in eye. Scales with 5 basal radiating striae, apical denticles 42 to 50 , and circuli very fine. Color in alcohol, pale brownish generally. Six deep blackish-brown longitudinal bands on back, lowest from pectoral axil and less distinct. Spinous dorsal whitish, with two rows of blackish spots, one row marginal and other median. Soft dorsal with two or three irregular rows of smaller blackish spots. Soft anal and caudal with black spots, larger on latter. Pectoral and ventral dull brown. Iris pale olive-slate. Length, $218 \mathrm{~mm}$. Cebu.

Our example without the black spot at pectoral base indicated i1. Bleeker's figure, or the two longitudinal dark lines below the baso of same fin, as he shows. 


\section{PLECTORHINCHUS PUNCTATUS (Rïppell).}

Head 3 ; depth, 22 ; D. X, 24, I; A. III, 7, I; tubular scales, 57 in lateral line to caudal base and 12 more on latter; 13 scales above lateral line to soft dorsal origin, 17 above to spinous dorsal origin, 20 below to spinous anal origin; 62 predorsal scales; snout, $2 \frac{2}{5}$ in head; eye, $3 \frac{1}{2}$; maxillary, 3 ; interorbital, 4 . Gill-rakers, $6+13$, lanceolate, $2 \frac{1}{4}$ in filaments, which $1 \frac{2}{3}$ in eye. Scales with 6 to 8 basal radiating striae, apical denticles 30 to 46, and circuli moderate. Color in alcohol, largely olive-brown, little paler on breast and belly below, back, and sides, with irregular large close-set spots of slightly darker color than general body color. Dorsals with similar large blackish closeset spots, also caudal, ventral, and anal blackish. Pectoral pale brown. Length, $145 \mathrm{~mm}$. Cebu.

Agrees largely with Day's figure, except it does not show the dark circles on lower and posterior side of head.

\section{PLECTORHINCHUS CHAETODONTOIDES (Lacépède).}

Head, $2 \frac{7}{8}$; depth, $2 \frac{1}{8}$; D. XII, 19, I; A. III, 8, I; about 65 scales counted close along lateral line to caudal base, tubular scales 59, and 6 more on caudal base; 12 scales above lateral line to soft dorsal origin, 12 above to spinous dorsal origin; 52 predorsal scales; snout, $2 \frac{3}{4}$ in head; eye, $3 \frac{1}{4}$; maxillary, 3 ; interorbital, $3 \frac{2}{5}$. Gillrakers, $10+24$, lanceolate, half of filaments and latter $1 \frac{3}{4}$ in eye. Scales with 5 or 6 basal radiating striae, with 1 to 4 auxilliaries, apical denticles 36 to 38 , and circuli fine. Color in alcohol, dull brown generally, with pale blotch on snout and front of mandible. Another below eye over branchiostegal region and front of breast. One also from before pectoral base to that of ventrals. Pale blotch behind pectoral base, one at occiput, another on back includes hind dorsal spines. One above and at front of spinous anal and finally one obliquely over caudal peduncle. All these markings in dark area bordered slightly with narrow dark line. Fins dusky brown except for extension of pale blotch. Soft dorsal with two whitish obliquely longitudinal lines. Soft anal blackish, with little whitish blotch in front and behind, first spine largely pale. Caudal whitish, with blackish transverse band, also base of fin. Pectoral and ventral blackish. Length, $150 \mathrm{~mm}$. Cebu.

Our example differs a little from Bleeker's figure of the young in that it has no dark round spots within the pale areas and its lower fins with more or less blackish. It has the predorsal and front spinous dorsal regions of the back uniformly dark, likewise the entire region of the soft dorsal and the region of the caudal base. 
PLECTORHINCHUS PICTUS (Thunberg).

Head, 3 ; depth, $2 \frac{1}{2}$ to $2 \frac{3}{4}$; D. X, 21, I, to $24, \mathrm{I}$; A. III, 7, I; about 95 to 98 scales counted close along and above lateral line to caudal base, tubular scales 54 to 68 and 11 to 14 more on caudal base; 14 to 16 scales above lateral line to soft dorsal origin, 19 or 20 above to spinous dorsal origin, and 21 to 23 below to spinous anal origin; 47 to 55 predorsal scales; snout, $2 \frac{3}{5}$ to 3 in head; eye, $3 \frac{1}{8}$ to $3 \frac{1}{3}$; maxillary, $2 \frac{7}{8}$ to $3 \frac{1}{10}$; interorbital, $4 \frac{1}{8}$ to $4 \frac{1}{4}$. Gill-rakers, $8+12$ lanceolate. $1 \frac{1}{2}$ in gill filaments, which 2 in eye. Scales with 5 to 8 basal radiating striae, rather long and slender apical denticles 15 to 19 , and circuli moderately coarse. Color in alcohol, blackish-brown above with white longitudinal lines or bands. Margin of dorsals white, broadly black basally. White median line from middle of predorsal forward, where broadening to snout end, forks to end line each side along front of back until about opposite base of ninth dorsal spine. From over eye white band back to last two dorsal rays along upper caudal peduncle edge, then obliquely over upper caudal lobe to its hind edge. Another white band parallel from lower eye edge includes pectoral base and extends similarly along lower caudal peduncle edge and fin lobe. Rest of under surface pale. Pectoral whitish. Ventrals and anals largely blackish. Length, 87 to $102 \mathrm{~mm}$. Three from Takao and one from Cebu.

The three smaller examples, from Takao, largely resemble Bleeker's figure, ${ }^{26}$ except the bands of our specimens are much more broadly white and contrasted. An indistinct dark longitudinal streak from below pectoral base to beginning of caudal peduncle, not shown by Bleeker. Our examples with more blackish on soft anal, also outer terminal caudal edges blackish and basal front of spinous dorsal white. Our largest example differs in the marginal dark band of the back broken into five dark blotches.

\section{POMADASIS HASTA (Bloch).}

Head, 3; depth, 27 ; D. XII, 14; A. III, 7, I; tubular scales 51 in lateral line to caudal base and 9 more on latter; 4 scales above lateral line to soft dorsal origin, 7 above to spinous dorsal origin, 10 below to spinous anal origin; 13 predorsal scales to occiput and 24 more forward on cranium; snout, 3 in head; eye, $5_{5}^{2}$; maxillary, $3 \frac{2}{3}$; interorbital, $3 \frac{7}{8}$. Gill-rakers, $5+11$, lanceolate, short, $2 \frac{1}{2}$ in gill-filaments, which $1 \frac{3}{5}$ in eye. Scales with 9 or 10 radiating basal striae, apical denticles 70 or 71 , and circular fine. Color in alcohol, dull olivebrown above, paler below. On back and predorsal about seven irregular series of deep brown spots continue back until only half as many

${ }^{26}$ Atlas Ichth., vol. 8, 1876-77, pl. 55 (333), fig. 2. 
rows below soft dorsal. Dorsals dull gray-brown with four longitudinal rows of blackish spots. Caudal and soft anal with dusky tints, otherwise fins pale. Length, $262 \mathrm{~mm}$. Takao.

\section{POMADASIS MACULATUS (Bloch).}

Head, 3 to $3 \frac{1}{8}$; depth, $2 \frac{3}{5}$ to $2 \frac{3}{4}$; D. XII or XIII, 13, I, or 14 , I; A. III, 7 , I; tubular scales 50 or 52 in lateral line to caudal base and 8 to 10 more on latter; 5 scales above lateral line to soft dorsal origin, 8 or 9 above to spinous dorsal origin and 13 or 14 below to spinous anal origin; 30 to 38 predorsal scales. Gill-rakers, 4 or $5+14$, lanceolate, $2 \frac{1}{4}$ in gill-filaments, which $1 \frac{3}{4}$ in eye. Scales with 9 to 14 basal radiating striae, apical denticles 48 to 73 , circuli fine. Color in alcohol with back saccardo-umber, sides and below paler to whitish. Back with four obscure deep dusky vertical broad bands, often broken above where more or less alternate, and scarcely extending below level of eye. Spinous dorsal largely dusky to blackish. Caudal and soft dorsal paler. Dorsal and anal spines burnished with silvery. Other fins like belly. Oblique short dusky line below nostril. Length, 51 to $220 \mathrm{~mm}$. Seven from Takao.

\section{Family SPARIDAE.}

\section{NEMIPTERUS MULLOIDES (Bleker).}

Head, $3 \frac{1}{6}$ to $3 \frac{3}{4}$; depth, 3 to 4 ; D. X, 9, I; A. III, 7, I; tubular scales 45 to 48 in lateral line to caudal base and 2 more on latter; 3 scales above lateral line to soft dorsal origin, 4 above to spinous dorsal origin, 10 below to spinous anal origin; 12 or 13 predorsal scales; snout, $2 \frac{1}{2}$ to 4 in head; eye, $2 \frac{3}{4}$ to $3 \frac{1}{2}$; maxillary, $2 \frac{3}{5}$ to $2 \frac{4}{5}$; interorbital, $3 \frac{1}{2}$ to 5 . Gill-rakers, $3+6$ short broad tubercles, much shorter than filaments, which $1 \frac{3}{4}$ in eye. Scales with 7 to 11 basal radiating striae, often 2 or 3 incomplete, apical denticles 96 to 102, and circuli very fine. Color more or less faded dull uniform brownish in alcohol, paler below and with silvery reflections. Length, 68 to $255 \mathrm{~mm}$. Seventeen from Takao.

This species appears to be known previously only from Sumatra, and its occurrence in Formosa is therefore of interest. A comparison with Bleeker's figure shows our specimen with slightly shorter dorsal spines, though all with the marginal membranes deeply incised. In appearance the squamation is quite compact, so that the specific name is certainly well selected with reference to the general resemblance to certain of the goat-fishes.

\section{GYMNOCRANIUS LETHRINOIDES (Bleeker).}

Head, $2 \frac{7}{8}$ to 3 ; depth, $2 \frac{1}{2}$; D. X, 10 ; A. III, 10, I; tubular scales 47 or 48 in lateral line to caudal base and 2 or 3 more on latter; 6 
scales above lateral line to soft dorsal origin, 8 above to spinous dorsal origin, 15 or 16 below to spinous anal origin; 14 or 15 predorsal scales; snout, $2 \frac{3}{5}$ to $2 \frac{4}{5}$ in head; eye, $2 \frac{7}{8}$ to 3 ; maxillary, $3 \frac{1}{5}$ to $3 \frac{1}{4}$; interorbital, $3 \frac{1}{3}$ to $3 \frac{2}{5}$. Gill-rakers, $5+5$, short low tubercles; gill-filaments, $2 \frac{3}{4}$ in eye. Scales with 15 or 16 basal radiating striae, 65 to 97 blunt apical denticles and circuli moderately fine. Color in alcohol, back brown, lower surfaces whitish. About five or six rather irregular narrow vertical cross bands of darker brown than body color. Dorsals with two longitudinal dark bands or lines and each caudal lobe with fine transverse dark bands. Other fins pale. Length, 207 to $210 \mathrm{~mm}$. Two from Zamboanga.

\section{CAESIO LUNARIS Cuvier.}

Head, 3 to $3 \frac{1}{8}$; depth, $2 \frac{1}{2}$ to $2 \frac{3}{4}$; D. X, 13 , I; A. III, 9, I; tubular scales 48 to 50 in lateral line to caudal base and 6 more on latter; 7 scales above lateral line to soft dorsal origin, 14 below to spinous anal origin; 24 or 25 predorsal scales; snout, $3 \frac{3}{5}$ to 4 in head; eye, $2 \frac{4}{5}$ to $3 \frac{7}{8}$; maxillary, $2 \frac{4}{5}$ to 3 ; interorbital, $3 \frac{1}{2}$ to 4 . Gill-rakers, $11+23$, lanceolate, $1 \frac{1}{2}$ in eye; gill-filaments, four-fifths of gill-rakers. Scales with 12 to 15 basal radiating striae, pointed apical denticles 60 to 70 , and circuli fine. Color in alcohol with black dusky-drab, paler on sides and whitish on under surfaces. Dorsals dusky, other fins pale, except deep brownish axillary blotch of pectoral. Mandible tip brownish like maxillary. Length, 143 to $150 \mathrm{~mm}$. Six from Zamboanga.

Our examples differ from Bleeker's figure and account in that the caudal tips are not blackish, but pale like the rest of the fin.

\section{CAESiO COERUlaUReUS Lacépède.}

Head, $3 \frac{2}{5}$; depth, $3 \frac{1}{3}$; D. X, 15, I; A. III, 12, I; tubular scales 60 in lateral line to caudal base and 6 more on latter; 7 scales above lateral line to soft dorsal origin, 14 below to spinous anal origin; 24 predorsal scales; snout, $3 \frac{2}{5}$ in head; eye, $4 \frac{1}{3}$; maxillary, 3 ; interorbital, $2 \frac{7}{8}$. Gill-rakers, $11+26$, lanceolate, $1 \frac{1}{3}$ in filaments or $1 \frac{7}{8}$ in eye. Scales with 11 to 17 basal radiating striae, tuberculate apical denticles 83 to 70 and circuli fine. Color in alcohol faded olivaceous above to pale brown below. Beginning over eye and following along lateral line close above, obscure dull olive band, $2 \frac{1}{2}$ scales wide and bordered narrowly above and below slightly darker than general color of back. Dorsals like back. Caudal with median portion of each lobe dull olive-dusky, borders all paler. Dusky blotch at pectoral origin, axil broadly dusky. Other fins all pale. Length, 205 $\mathrm{mm}$. Cebu. 


\section{CAESIO PISANG Bleeker.}

Head, $3 \frac{1}{3}$; depth, $4 \frac{4}{5}$; D. X, 14, I; A. III, 12 ; tubular scales, 62 ? in lateral line to caudal base and 5 more on latter; 6 scales above lateral line to soft dorsal origin; predorsal scales, 25 ?; snout, 4 in head from upper jaw tip; eye, 4; maxillary, 3 ; interorbital, $3 \frac{7}{8}$. Gill-rakers, $10+25$, lanceolate, equal gill-filaments, or $1 \frac{1}{2}$ in eye. Scales with 12 basal radiating striae, moderately pointed apical denticles 68 to 77 and circuli fine. Cheek with 4 rows of scales. Color in alcohol faded nearly dark purplish-gray on back, sides and lower surface pale brownish. Iris slaty. Mandible and snout tips brownish. Dorsals gray-brown. Other fins all pale, tips of caudal lobes slightly dusky to blackish. Length, $140 \mathrm{~mm}$. Cebu.

PTEROCAESIO MULTIRADIATUS Steindachner.

Head, $3 \frac{2}{5}$ to $3 \frac{1}{2}$; depth, $3 \frac{3}{4}$ to 4 ; D. XII, occasionally XI, 20, I; A. III, 13, I; tubular scales 71 to 75 in lateral line to caudal base and 7 more on latter, occasionally $6 ; 7$ scales above lateral line to soft dorsal origin, 15 or 16 below to spinous anal origin; predorsal scales 20 to 21 to occiput and 6 or 7 more forward on cranium; snout, $3 \frac{4}{5}$ to $4 \frac{1}{6}$ in head from upper jaw tip; eye, $3 \frac{2}{5}$ to 4 ; maxillary, $2 \frac{7}{8}$; interorbital, $3 \frac{1}{8}$ to $3 \frac{1}{3}$. Gill-rakers, $11+27$, lanceolate, slightly less than gill-filaments or $1 \frac{3}{4}$ in eye. Scales with 11 to 13 basal radiating striae, rather tuberculate apical denticles 53 to 58 and circuli fine. Color in alcohol, back dull olivaceous. From over eye olive band to suprascapula, along lateral line till below last dorsal rays when continued straight to base of upper caudal lobe. Above lateral line each scale with small dull bluish median basal spot, these forming longitudinal lines. From upper hind half of eye broad blue band back to caudal base medianly, four scales wide below spinous dorsal and narrowing posteriorly. Dorsals dusky-olive. Caudal with longitudinal dusky-brown band in each lobe, borders pale. Lower surface of body whitish, also fins, except axial and blotch at pectoral origin, which blackish. End of mandible brownish, like snout. Eye pale yellowish. Length, 134 to $140 \mathrm{~mm}$. Four from Zamboanga.

This handsome species does not appear to have been noticed since Steindachner originally described it from Amboina. Pterocaesio Bleeker is here admited to generic rank, chiefly on account of the increased dorsal spines and rays. It is, however, more closely allied allied with Caesio than with Pinjalo.

\section{PENTAPUS CANINUS (Cuvier).}

Head, $3 \frac{1}{5}$ to $3 \frac{1}{4}$; depth, 3 to $3 \frac{1}{8}$; D. X, 9, I; A. III, 7, I; tubular scales 43 in lateral line to caudal base and 7 or 8 more nontubular on latter; 3 scales above lateral line to soft dorsal origin, 11 below 
to spinous anal origin; 27 predorsal scales; snout, $2 \frac{7}{8}$ in head; eye, $3 \frac{1}{2}$ to $3 \frac{3}{5}$; maxillary, $2 \frac{2}{3}$; interorbital, $2 \frac{7}{8}$ to 3 . Gill-rakers, $5+6$, short tubercles, greatly less than gill-filaments, which 2 in eye. Scales with 8 to 13 basal radiating striæ, and 3 or 4 incomplete auxiliaries, apical denticles 111 to 119 , circuli very fine. Four upper canines curved downward; two lower more wide set and greatly divergent. Cheek with 6 rows of scales to preopercle ridge. Color in alcohol dull brown, pale to whitish below. Obsolete pale band from suprascapula backward, usually along lateral line until below soft dorsal when fading out, or sometimes sloping gradually up below front arch of lateral line, crossing latter and continued on back to last dorsal ray bases. From above axilla broad pale band to caudal base medianly, pale sulphury over hind coastal region. Iris pale yellowish. Fins all dull, lower ones ocharceous. Length, 164 to $176 \mathrm{~mm}$. Two from Zamboanga.

As shown in Bleeker's figure, the narrow pale line above the lateral line, extending upward from above the eye, is not evident in our examples.

PENTAPUS NEMURUS (Bleeker).

Head, $3 \frac{2}{3}$; depth, $3 \frac{2}{5}$; D. X, 9, I; A. III, 7, I; tubular scales 50 in lateral line to caudal base and 9 nontubular on latter; 3 scales above lateral line to soft dorsal origin, 15 below to spinous anal origin; 36 predorsal scales; snout, $2 \frac{4}{5}$ in head ; eye, $4 \frac{1}{4}$; maxillary, $2 \frac{9}{10}$; interorbital, 3. Gill-rakers, $5+5$ short tubercles, greatly less than gillfilaments, which $1 \frac{2}{3}$ in eye. Scales with 9 to 12 basal radiating striae, apical denticles 125 to 150, circuli fine. Five upper canines forward; 2 lower more wide set and divergent. Cheek with 7 rows of scales to preopercle ridge. Color in alcohol dull brown, paler to whitish below. Narrow sulphury line from above eye over suprascapula and lateral line to last dorsal ray base. Broader and brighter sulphury band from each side of snout tip from lower hind half of eye over pectoral axil to caudal base and over median caudal rays. Fins all pale brownish, lower ones whitish. Length, $212 \mathrm{~mm}$. to median caudal ray tips; $314 \mathrm{~mm}$. to end of upper caudal filaments. One from Zamboanga.

Also two younger examples, 108 to $110 \mathrm{~mm}$. from Cebu. Head, 3 to $3 \frac{1}{5}$; depth, $3 \frac{1}{4}$ to $3 \frac{1}{3}$; D. X, 9 , I ; A. III, 7, I; tubular scales 40 to 42 in lateral line to caudal base and 1 more on latter; 2 or 3 scales above lateral line to soft dorsal origin, 3 or 4 above to spinous dorsal crigin, 11 or 12 below to spinous anal origin; 31 to 35 predorsal scales; snout, 3 to $3 \frac{1}{5}$ in head; eye, $3 \frac{1}{8}$ to $3 \frac{2}{5}$; maxillary, $2 \frac{7}{8}$ to 3 ; interorbital, $3 \frac{1}{3}$ to $3 \frac{1}{2}$. Gill-rakers, $5+4$, short low tubercles; gillfilaments, $2 \frac{3}{5}$ in eye. Scales with 9 to 11 basal radiating striae, apical denticles 90 to 92 and circuli fine. Color in alcohol largely 
faded dull brown. Pale median band from lower hind eye edge to caudal base medianly, narrow at first and little wider behind. Narrow pale band along back parallel and above lateral line, rather obscure.

PAGRUS SPINIFER Forskâl.

Head, 3 ; depth, $1 \frac{3}{4}$; D. XI, 10, I; A. III, 8, I; tubular scales 50 in lateral line to caudal base and 1 more on latter; 7 scales above lateral line to soft dorsal origin, 18 below to spinous anal origin; 45 predorsal scales forward till over nostrils; snout, $1 \frac{2}{3}$ in head; eye, $3 \frac{2}{5}$; maxillary, 3 ; interorbital, $3 \frac{1}{8}$. Gill-rakers, $7+10$, strong obtuse points, little less than one-third of gill-filaments, which $1 \frac{1}{2}$ in eye. Scales with 9 to 11 basal radiating striae, rather obtuse apical denticles 80 to 90 and circuli fine. Dorsal filaments long and slender, reach little beyond caudal base. Pectoral extends back opposite tip of depressed second anal spine. Color in alcohol with back drab, below whitish, everywhere overshot with silvery-white. Fins pale. Length, $210 \mathrm{~mm}$. Takao.

\section{LETHRINUS HARAK (Forskål).}

Head, 3; depth, 3; D. X, 9, I; A. III, 8, I; tubular scales 44 in lateral line to caudal base and 4 more on latter; 5 scales above lateral line to soft dorsal origin, 14 below to spinous anal origin; 9 predorsal scales; snout 2 in head; eye 4 ; maxillary $2 \frac{2}{5}$; interorbital $3 \frac{2}{5}$. Gill-rakers, $5+5$, obtuse, knob-like, 2 in gill-filaments, which $2 \frac{1}{5}$ in eye. Scales with 13 to 16 basal radiating striae, and 4 incomplete auxiliaries, 108 to 140 apical denticles, circuli very fine. Color in alcohol dull olive-brown, faded pale below. Each row of scales medianly with slightly darker streak than body color. Just below lateral line, under last dorsal spines dusky-brown obscure blotch, much larger than eye. Soft dorsal and caudal with very faint traces of darker bands, as about three longitudinally on former and four transversely on latter. Length, $280 \mathrm{~mm}$.

Also two smaller, 140 to $146 \mathrm{~mm}$. long. Zamboanga. Head, $2 \frac{4}{5}$ to $2 \frac{7}{3}$; depth, $2 \frac{1}{2}$ to $2 \frac{2}{3}$; D. X, 9 , I ; A. III, 8, I ; tubular scales 46 in lateral line to caudal base and 1 or 2 more on latter; 6 rows of scales above lateral line to spinous dorsal origin, 5 above to soft dorsal origin, 14 or 15 below to spinous anal origin; 9 or 10 predorsal scales; head width, $2 \frac{1}{8}$ to $2 \frac{1}{5}$ in its length; snout, $2 \frac{1}{8}$ to $2 \frac{1}{5}$; eye, $3 \frac{2}{5}$ to $3 \frac{2}{3}$; maxillary, $2 \frac{2}{3}$ to $2 \frac{3}{4}$; interorbital, $4 \frac{1}{8}$ to $4 \frac{1}{4}$; pectoral, $1 \frac{1}{10}$ to $1 \frac{1}{5}$. Snout conic, width $1 \frac{1}{3}$ to $1 \frac{1}{2}$ in its length. Jaws about even or lower very slightly included. Maxillary opposite hind nostril. Teeth conic, even hind ones, which hardly molar. Gill-rakers, 5 or $6+5$ or 6 , half of gill-filaments, which $2 \frac{1}{3}$ in eye. Scales small and crowded 
along anal base, smaller on breast than on predorsal. Basal radiating striae 14 or 15 , apical denticles 80 to 88 , circuli fine. Dorsals and anals low. Second and third anal spines about equal.

Color in alcohol dull olive brown above, paler to whitish beneath. Each scale with paler center or spot, obsolete, yet suggesting lengthwise streaks. Opposite outer half of depressed pectoral and slightly beyond borders or bases of scales darker or more deeply brownish so as to form an ill-defined large dark blotch below lateral line, though much greater than eye in extent. Cheek tinged with natal-brown. Iris very pale yellowish. Under surface of head whitish. Dorsals grayish, with pale dusky-gray shading marginally on spinous fin, and soft fin with three dark gray longitudinal bands. Caudal with four transverse bands. Outer portions of ventrals dusky-gray. Brownish spot in pectoral axil.

We believe these two young examples to represent an adolescent stage, but have not yet found the obscure dark bands on the soft dorsal and caudal noticed previously. In some respects they are suggestive of $L$. carinatus Weber, ${ }^{27}$ a much deeper species. L. bonhamensis Gunther ${ }^{28}$ appears to be synonymous. L. atkinsoni Seale ${ }^{29}$ may antedate $L$. carinatus Weber. It is not described with markings on the soft dorsal and caudal, though its ventrals are said to be dusky on their posterior third.

\section{Family GERRIDAE.}

\section{GERRES KAPAS Bleeker.}

Head, 3 to $3 \frac{1}{8}$; depth, $2 \frac{1}{2}$ to $2 \frac{3}{4}$; D. IX, 10, I; A. III, 7, I; scales about 38 ? in lateral line to caudal base (squamation damaged); 4 scales above lateral line to spinous dorsal origin, 8 ? below to spinous anal origin; 14 predorsal scales to frontal fontanelle; snout, 3 to $3 \frac{1}{3}$ in head; eye, 3 to $3 \frac{1}{6}$; maxillary, $2 \frac{1}{2}$ to $2 \frac{2}{3}$; interorbital, $2 \frac{4}{5}$ to $2 \frac{7}{8}$. Gill-rakers, III, $1+8$, lanceolate, about 2 in filaments or 4 in eye. Scales with 6 to 10 basal radiating striae, fine circuli very largely parallel and vertical. Premaxillary groove broadly naked. Color in alcohol largely pale brown on back. Sides and below bright silvery-white. Fins pale brown. Brown spot on membranes of last half of spinous dorsal and on all of soft dorsal. Length, 133 to 138 $\mathrm{mm}$. Three from Zamboanga.

Three young examples in the Academy from the Philippines agree, except in such differences as are due to age, like larger eye, etc.

${ }^{27}$ Siboga Exped., Fish., vol. 65, 1913, p. 289, pl. 2, fig. 1. Seget, Western New Guinea ; Tual, Medrig Kei.

${ }^{28}$ Journ. Mus. Godeffroy, vol. 2 (1) 1873-1875, p. 65, pl. 47. Bonham Island.

29 Philippine Journ. Sci., vol. 4 (6) 1909, p. 515, pl. 11. Balabae Island 60466-23-Proc.N.M.vol.62-11 
GERRES FILAMENTOSUS Cavier.

Head, 3 ; depth, $2 \frac{1}{2}$; D. IX, 10, I; A. III, 7, I; scales, 40 in lateral line to caudal base and 3 more on latter; 6 scales above lateral line to spinous dorsal origin, 9 below to spinous anal origin; 13 predorsal scales to frontal fontanelle; snout, $3 \frac{1}{5}$ in head; eye, $3 \frac{2}{5}$; maxillary, $2 \frac{3}{4}$; interorbital, 3 . Gill-rakers, vi +7 , lanceolate, 3 in gill-filaments, which $2 \frac{2}{5}$ in eye. Scales with 6 to 10 basal radiating striae, circuli extremely fine. Second dorsal spine filamentous, extends back opposite base of last soft ray. Color in alcohol with back pale brownish, with about ten to twelve pale dusky vertical lines. Sides, lower surface and iris bright silvery-white. Spinous dorsal blackish on membranes terminally. Row of dark spots, one on each membrane below middle. Edge of snout dusky. Length, $114 \mathrm{~mm}$. Takao.

Two examples in the Academy from Sumatra compared, which do not show the dark vertical streaks, doubtless a condition of preservation.

\section{PENTAPRION LONGIMANUS (Cantor).}

Head, $3 \frac{1}{2}$; depth, $2 \frac{3}{5}$; D. IX, 15 ; A. V, 13 ; scales mostly fallen; snout, $3 \frac{1}{4}$ in head; eye, $2 \frac{7}{8}$; maxillary, $2 \frac{1}{2}$; interorbital, $2 \frac{2}{3}$. Gillrakers, $5+13$, lanceolate, four-fifths of gill-filaments or 4 in orbit. Scales with 1 to 3 basal radiating striae, circuli fine, and apical circuli extremely fine and numerous. Color in alcohol with scales largely bright silvery-white. Median bright silvery vertebral streak laterally. Iris silvery-white. Fine pale, membranes of spinous dorsal grayish terminally. Length, $127 \mathrm{~mm}$. Takao.

\section{Family MULLIDAE.}

\section{UPENEOIDES BELAQUE Fowler.}

Head, $3 \frac{1}{3}$; depth, $3 \frac{3}{5}$; D. VIII-I, 8, I; A. I, 6, r; scales 32 in lateral line to caudal base and 2 more on latter; 3 scales above lateral line to soft dorsal origin; 7 below to spinous anal origin; 16 (pockets) predorsal scales; snout, $2 \frac{4}{5}$ in head; eye, 4; maxillary, $2 \frac{2}{5}$; interorbital, $3 \frac{1}{4}$. Bands of fine teeth in jaws, on vomer and palatines. Gill-rakers, $9+19$, lanceolate, $1 \frac{1}{4}$ in gill-filaments, which $1 \frac{1}{3}$ in eye. Scales with 5 or 6 basal radiating striae, apical denticles 60 to 62 and circuli very fine. Color in alcohol faded dull brownish generally. Spinous dorsal pale or whitish, with two horizontal dark brown bands and broad jet black apical blotch. Soft dorsal similar, only basal and lower bands appear slightly oblique across fin, owing to its inclination, and apical leaves fin tip pale. Upper caudal lobe with four oblique dark bands, about wide as interspaces and lower lobe with but three oblique bands. Length, $108 \mathrm{~mm}$. Zamboanga. 
Compared with the types in the Academy and found in agreement. The types, owing to preservation, do not now show any traces of dark caudal bars, and we think it quite likely they were obliterated by the strong preserving fluid. There is also variation in the dark bands on the dorsals, some of which are the exact pattern of the Zamboanga specimen.

\section{UPENEOIDES BENSASI (Schlegel).}

Head, $3 \frac{2}{5}$; depth, $4 \frac{3}{5}$ to $4 \frac{3}{4}$; D. VII, once V-I, 8, I; A. I, 6, I; scales, 28 or 29 in lateral line to caudal base and 2 or 3 more on latter; 2 scales above lateral line to soft dorsal origin, 2 above to spinous dorsal origin, 7 below to spinous anal origin; 6 predorsal scales; snout, $2 \frac{1}{2}$ to $2 \frac{3}{4}$ in head ; eye, $3 \frac{1}{3}$ to $3 \frac{7}{8}$; maxillary, $2 \frac{2}{5}$; interorbital, $3 \frac{1}{4}$ to $3 \frac{3}{4}$. Gill-rakers, III, $5+12$, iv, lanceolate, about as long as gill-filaments or 2 in eye. Scales with 4 to 6 basal radiating striae, apical denticles 70 to 75 and circuli very fine. Color in alcohol brown, paler to whitish below. All specimens show muzzle and edges of preopercle more or less blotched with reddish-brown. Iris silvery-white. Dorsals marked much as in $U$. belaque, each with three horizontal dark bands. Each caudal lobe with four oblique dark bands, terminal jet black. Length, 68 to $102 \mathrm{~mm}$. Twentyone examples from Takao.

\section{UPENEOIDES TRAGULA (Richardson).}

Head, $3 \frac{1}{5}$ to $3 \frac{3}{5}$; depth, 4 to $4 \frac{1}{8}$; D. VIII-I, 7, I; A. I, 6, I; scales, 30 in lateral line to caudal base and 2 more on latter; 3 scales above lateral line to soft dorsal origin, 6 below to spinous anal origin; 4 predorsal scales; snout, $2 \frac{1}{5}$ to $2 \frac{1}{2}$ in head; eye, $4 \frac{1}{2}$ to $4 \frac{3}{4}$; maxillary, $2 \frac{1}{3}$ to $2 \frac{1}{2}$; interorbital, $3 \frac{1}{3}$ to $3 \frac{2}{5}$. Gill-rakers III or Iv, 1 to $3+11$ or $12, v$ or vi, lanceolate, 1 to $1 \frac{2}{3}$ in gill-filaments, which $1 \frac{1}{3}$ to $1 \frac{7}{8}$ in eye. Scales with 5 or 6 basal radiating striae, apical denticles 138 to 153 and circuli very fine. Color in alcohol with back dull brown, sides and below whitish, everywhere more or less variably speckled with darker spots. Dark brown band from snout tip through eye and back along side to middle of upper caudal lobe basally. Spinous dorsal dusky apically, with six dark transverse bands, upper black. Soft dorsal similar, only with less black and most transverse bands paler. Caudal barred like dorsal, upper lobe with five and lower with seven transverse black bands. Other fins much paler, also cross bars, of which six on pectoral and five on ventral and anal. Length, 128 to $233 \mathrm{~mm}$. One from Cebu and Zamboanga, respectively.

The Cebu specimen, although in poor preservation, agrees better with Day's figure. It has the outer caudal and soft dorsal bars similarly broader. 
UPENEUS BARBERINUS (Lacépède).

Head, 3 ; depth, $3 \frac{1}{3}$ to $3 \frac{2}{5}$; D. VIII-I, 8, I; A. I, 6, I; scales, 28 in lateral line to caudal base and 3 more on latter; 2 or 3 scales above lateral line to soft torsal origin, 6 below to spinous anal origin; 13 predorsal scales; snout, $1 \frac{3}{4}$ to $1 \frac{4}{5}$ in head; eye, 5 to $5 \frac{1}{6}$; maxillary, $3 \frac{1}{6}$ to $3 \frac{1}{2}$; interorbital, 4 to $4 \frac{1}{4}$. Gill-rakers, $6+21$, lanceolate, $1 \frac{1}{2}$ in gill-filaments, which $1 \frac{1}{5}$ in eye. Scales with 5 basal radiating striae, apical denticles 140 to 142 and circuli fine. Color in alcohol pale brown, sides and below, whitish. Dorsal darker apically, fins otherwise mostly pale. Deep brown band from each side of snout tip to eye, then back to suprascapula and along lateral line till opposite soft dorsal, when continued upward to upper surface of caudal peduncle. Round, deep brown spot, size of eye, in lateral line at caudal base. Length, 163 to $173 \mathrm{~mm}$. Two from Zamboanga.

\section{UPENEUS MULTIFASCIATUS (Quoy and Gaimard).}

Head, $3 \frac{1}{8}$ to $3 \frac{1}{5}$; depth, $3 \frac{1}{5}$; D. VIII-I, 8 , I; A. II, 6, I; scales, 27 in lateral line to caudal base and 3 more on latter; 2 scales above lateral line to soft dorsal origin, 3 above to spinous dorsal origin, 7 below to spinous anal origin; 14 predorsal scales; snout, $1 \frac{4}{5}$ to $1 \frac{5}{6}$ in head; eye, 5 to $5 \frac{2}{3}$; maxillary, $2 \frac{3}{5}$ to $2 \frac{3}{4}$; interorbital, $3 \frac{3}{5}$ to $3 \frac{3}{4}$. Gill-rakers, $7+28$, lanceolate, about as long as filaments or $1 \frac{3}{5}$ in eye. Scales with 7 radiating basal striae, apical denticles 139 to 141 and circuli very fine. Color in alcohol, pale brown above, still paler to whitish below. Deep brown blotch close behind eye, about its equal. Another, much larger, at front two-thirds of soft dorsa? base and finally one saddle like on upper surface of caudal peduncle. Pale vertical streak at soft dorsal origin and interspace between soft dorsal and caudal dark blotches, pale-like belly. Spinous dorsal grayish. Soft dorsal blackish medianly and basally, including all of last ray. Upper half of soft dorsal with two closely set submarginal parallel lines. Anal pale, with four or five longitudinal brownish lines. Other fins all pale. Ventrals margined externally with brownish, also upper and lower edges of caudal lobes narrowly brownish. Length, 168 to $190 \mathrm{~mm}$. Two from Zamboanga.

\section{MULLOIDES AURIFLAMMA (Forskăl).}

Head, $3 \frac{1}{3}$ to $3 \frac{1}{2}$; depth, $3 \frac{7}{8}$ to $4 \frac{1}{5}$; D. VII-I, 8 , I; A. II, 6, I; scales, 35 in lateral line to caudal base and 2 more in latter; 3 scales above lateral line to soft dorsal origin, 3 above to spinous dorsal origin, 6 below to spinous anal origin; 14 predorsal scales; snout, $2 \frac{1}{5}$ in head; eye, 4 ; maxiallary, $3 \frac{2}{5}$ to $3 \frac{2}{3}$; interorbital, $3 \frac{1}{2}$ to $3 \frac{3}{4}$. Gill-rakers, $7+18$, lanceolate, 2 in gill-filaments, which $1 \frac{1}{2}$ in eye. Scales with 6 or 7 basal radiating striae, apical denticles 105 and circuli very fine. Color in alcohol pale olive above, sides and below lighter to whitish. 
with slight yellowish tint. Dorsals and caudal little darker than other fins. Length, 163 to $170 \mathrm{~mm}$. Two from Zamboanga.

\section{Family POLYNEMIDAE.}

\section{POLYDACTYLUS TETRADACTYLUS (Shaw).}

Head, $3 \frac{1}{2}$; depth, $4 \frac{1}{4}$; D. VIII-I, 14, I; A. III, 15, I; scales, 90 in lateral line to caudal base and about 35 more out on caudal along upper portion of lower lobe to hind edge of fin; 16 scales above lateral line to soft dorsal origin, 20 below to spinous anal origin; about 56 predorsal scales; snout, $6 \frac{7}{8}$ in head; eye, $4 \frac{7}{8}$; maxillary, $1 \frac{5}{6}$; interorbital, $4 \frac{1}{3}$. Gill-rakers, $6+7$, lanceolate, about one-fourth longer than gill-filaments or $1 \frac{2}{5}$ in eye. Scales with 1 to 3 basal radiating striae, apical denticles 40 to 55 and circuli moderate. Pectoral filaments 4, reach about five-sixths in fin. Color in alcohol olivebrown above, paler to whitish below, with silvery reflections. Fins brownish. Pectoral and anal dark apically. Ventral pale, also pectoral filaments. Length, $303 \mathrm{~mm}$. Takao.

POLYDACTYLUS INDICUS (Shaw).

Head, $3 \frac{1}{2}$; depth, $3 \frac{1}{3} ;$ D. VIII-I, 13, I; A. III, 12, I; scales, 70 in lateral line to caudal base, where forking and sending off two branches, one along each inner portion of emargination of caudal to its edge; 9 scales above lateral line to spinous dorsal origin, 9 above to soft dorsal origin, 11 below to spinous anal origin; 35 predorsal scales; snout, 5 in head; eye, $4 \frac{1}{3}$; maxillary, 2 ; interorbital, $3 \frac{3}{4}$. Gillrakers, $13+17$, lanceolate, little over twice gill-filaments or $1 \frac{1}{5}$ in eye. Scales with 5 to 7 radiating basal striae, apical denticles 43 to 48 and circuli moderate. Pectoral filaments 5, some reach anal origin. Suprascapular spine distinct and slightly larger one at preopercle angle. Color in alcohol with back nearly olive-brown, sides and below pale to whitish. Fins dark like back, except outer apical whitish borders of ventral. Length, $182 \mathrm{~mm}$. Takao.

\section{Family POMACENTRIDAE.}

\section{POMACENTRUS PROSOPOTAENIA Bleeker.}

Head, $2 \frac{5}{6}$ to 3 ; depth, 2 to $2 \frac{1}{8}$; D. XII, 15 I; A. II, 13, I; tubular scales 16 or 17 in upper arch of lateral line, 7 pores in hind section to caudal base; 3 scales above lateral line to spinous dorsal origin, 10 below to spinous anal origin; 20 or 21 predorsal scales; snout, $2 \frac{1}{2}$ in head; eye, $4 \frac{2}{5}$ to $4 \frac{2}{3}$; maxillary, $3 \frac{2}{5}$; interorbital, $3 \frac{1}{8}$ to $3 \frac{1}{3}$. Teeth uniserial, truncate. Gill-rakers, $13+17$, weakly lanceolate, 3 in gillfilaments, which equal eye. Scales with 8 or 9 basal radiating striae, apical denticles 146 to 215 and circuli very fine. Color in alcohol blackish-brown above, becoming nearly bay on breast and belly. 
Head with a number of small gray spots around eye, on cheeks and opercles. Obscure or obsolete small spots above anal and behind pectoral. Fins all more or less dusky, only pectoral paler. Axilla pale. Traces of pale line, linking nostrils across snout. Length, 147 to $165 \mathrm{~mm}$. Two from Zamboanga.

POMACENTRUS FORNOSANUS, new spccies.

Head, $3 \frac{1}{3}$; depth, $2 \frac{2}{5}$; D. X, 12, I; A. II, 12, I; P. III, 17; V. I, 5; tubular scales 29 in upper arch of lateral line and 15 pores in horizontal section, of which last one on caudal base; 47 scales between suprascapula and caudal base; 7 scales above lateral line to spinous dorsal origin, 13 below to spinous anal origin; 18 predorsal scales; head width, $1 \frac{3}{4}$ in its length; head depth about equals its length; snout, $4 \frac{1}{3}$; eye, 3 ; maxillary, $2 \frac{1}{2}$; interorbital, 3 ; first dorsal spine, $3 \frac{3}{4}$; tenth, 2 ; fourth dorsal ray, $1 \frac{3}{4}$; second anal spine, $2 \frac{1}{5}$; fifth anal ray, 2 ; least depth of caudal peduncle, $2 \frac{1}{5}$; caudal, 1 ; pectoral, $1 \frac{1}{6}$; ventral, $1 \frac{1}{3}$.

Body elongately ellipsoid, deepest about midway in its length, well compressed and edges convexly rounded. Caudal peduncle well compressed and least depth about equals its length.

Head moderate, rather robust, well compressed, flattened sides very slightly converging below, profiles alike. Snout convex over surface and in profile, length three-fifths its width. Eye large, circular, little elevated and hind pupil edge nearly midway in head length. Mouth moderately wide, gape short, oblique, closed jaws about even. Lips fleshy, rather narrow. Maxillary large, well inclined and exposed, reaches well beyond front eye edge, only narrow upper edge slipping below little differentiated preorbital. Teeth moderately small, uniserial, somewhat compressed, pointed and not forming cutting edge, also slightly larger in front of jaws. Greater portion of maxillary edge with finer similar teeth. No teeth on mouth roof or tongue. Inner buccal folds moderately wide. Tongue depressed, moderate, free. Nostril small pore little behind middle in eye. Pseudobranchiae slightly less than gill-filaments. Branchinarrow, width little less than that of maxillary. Hind preopercle edge roughly serrate. Opercle with two spines, lower little more backward.

Gill-opening extends forward about opposite front eye edge. Gillrakers, $8+19$, lanceolate, slightly shorter than gill-filaments or $2 \frac{1}{2}$ in eye. Pseudobranchiae slightly less than gill-filaments. Branchiostegal membrane short, forms very short fold across narrow constricted isthmus.

Scales finely ctenoid, become little smaller about body edges and in lengthwise rows parallel with lateral line. All larger scales rather 
narrowly imbricated. Soft dorsal, anal, caudal and pectoral bases with small scales. Scale between ventral bases nearly half length of fin. Axillary ventral scale about two-fifths of fin. Cheek with 4 rows of scales, completely covering infraorbitals. Snout, including front of interorbital, maxillary, lips, and mandible naked. Scales with 5 to 9 basal radiating striae, apical denticles 38 to 52 , and circuli fine. Upper section of lateral line formed of rather broad tubes, mostly with small bifurcations extended backward behind middle in dorsal base. Pores of straight hind section small, inconspicuous, simple.

Spinous dorsal origin slightly before that of pectoral, anterior median spines highest, fin edge slightly notched and cutaneous

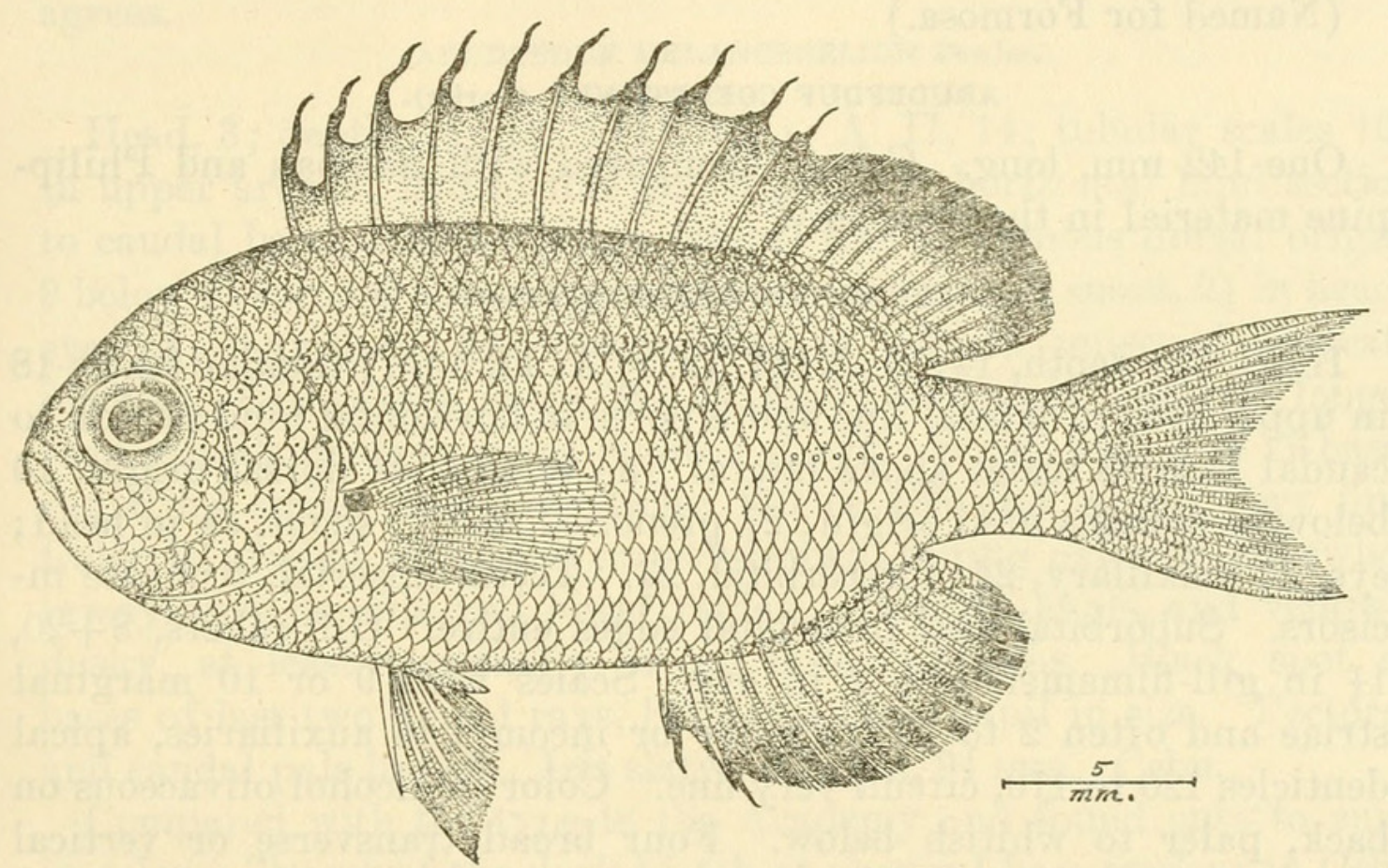

Fig. 4.-Pomacentrus formosanus, new species.

pointed flap behind tip of each spine. Soft dorsal inserted near last third in space between front pupil edge and caudal base, fin slightly rounded or with median rays little longest. Spinous anal inserted little nearer pectoral origin than caudal base, first spine three-fifths of second. Caudal deeply emarginate, lobes pointed, upper longer and ends in cutaneous point. Pectoral broad, fin rounded. Ventral inserted nearly opposite first fourth in depressed pectoral, well behind base of latter, reaches vent, spine two-thirds length of fin. Vent close before anal.

Color in alcohol nearly mars-brown, sides paler or almost dull saccardo-umber, and lower surface with tinges nearly cinnamon-bluff and tawny, latter especially along belly. Dorsals and anals dusky on outer portions. Pectoral and caudal dull or pale brown, likewise ventral, except latter with tips of soft rays tinged dusky. Con- 
spicuous black blotch, little smaller than pupil, at origin of pectoral fin and adjoining forward pale or whitish area of nearly equal extent. Iris dull bluff-yellow.

Length, $70 \mathrm{~mm}$.

Type.-Cat. No. 76644, U.S.N.M. Takao, Formosa. Dr. Fred Baker.

Only the type known. In some respects the species superficially resembles Pomacentrus jerdoni Day, of which we have compared a Philippine example in the Academy. This is largely in general coloration of the preserved examples and the black blotch at the pectoral origin. The structural characters of distinction for $P$. formosanus are the shorter body and greatly smaller scales.

(Named for Formosa.)

\section{ABUDEFDUF COELESTINUS (Cuvier).}

One $142 \mathrm{~mm}$. long. Cebu. Compared with Samoan and Philippine material in the Academy.

\section{ABUDEFDUF CURACAO (Bloch).}

Head, $3 \frac{1}{8}$; depth, $1 \frac{1}{2}$; D. XIII, 12, I; A. II, 13, I; tubular scales 18 in upper arch of lateral line and 8 pores in horizontal hind section to caudal base; 3 scales above lateral line to spinous dorsal origin, 10 below to spinous anal origin; 27 predorsal scales; snout, $3 \frac{4}{5}$ in head; eye, 3 ; maxillary, $2 \frac{3}{4}$; interorbital, $2 \frac{1}{2}$. Teeth uniserial, truncate incisors. Suborbital and preorbital edges entire. Gill-rakers, $8+20$, $1 \frac{1}{4}$ in gill-filmaments or 2 in eye. Scales with 9 or 10 marginal striae and often 2 to 10 irregular or incomplete auxiliaries, apical denticles 120 to 170, circuli very fine. Color in alcohol olivaceous on back, paler to whitish below. Four broad transverse or vertical bands of olivaceous-dusky; first at predorsal and front of spinous dorsal to pectoral base and postventral region; second from middle of spinous dorsal to spinous anal; third from last dorsal spines; fourth on caudal peduncle. Spinous dorsal dusky, fins otherwise pale. Pectoral and ventral pale yellowish. Length, $110 \mathrm{~mm}$. Zamboanga.

Our example differs a little from Bleeker's colored figure of Glyphidodon trifasciatus in that its bands are less sharply defined. $\mathrm{He}$ shows two dark bands from the front of the spinous dorsal, whereas in our example they largely appear as one. The species is variable. Three Philippine examples in the Academy, though structurally in agreement, show the first and second dark transverse bands quite diverse.

\section{ABUDEFDUF LEUCOGASTER (Bleeker).}

Head, $3 \frac{2}{5}$; depth, $1 \frac{5}{6}$; D. XIII, 11, I ; A. II, 12; tubular scales 17 in upper arch of lateral line and 8 pores in horizontal hind section 
to caudal base; 3 scales above lateral line to spinous dorsal origin, 9 below to spinous anal origin; 22 predorsal scales; snout, 3 in head; eye, 3 ; maxillary, 3 ; interorbital, 22 . Teeth uniserial, with slight notch on median margin so as to form bilobate pattern. Gill-rakers $7+15$, lanceolate, seven-eighths of gill-filaments or 3 in eye. Scales with 3 to 7 radiating marginal striae, apical denticles 34 to 137 and circuli very fine. Caudal well emarginated. Color in alcohol faded largely dull brownish, sides with brassy tinge below. Small obscure irregular gray spots on sides and about head. Vertical fins graybrown. Paired fins dull brown. Iris pale greenish-yellow. Length, $96 \mathrm{~mm}$. Zamboanga.

Compared with an example in the Academy from Sumatra and agrees.

\section{ABUDEFDUF MELANOPSELION Fowler.}

Head, 3 ; depth, 17 ; D. XIII, 13, I; A. II, 14; tubular scales 16 ? in upper arch of lateral line and 6 pores in horizontal hind section to caudal base; 5 scales above lateral line to spinous dorsal origin, 9 below to spinous anal origin; 22 predorsal scales; snout, $2 \frac{7}{8}$ in head; eye, $3 \frac{4}{5}$; maxillary, $3 \frac{3}{5}$; interorbital, $2 \frac{3}{4}$. Teeth uniserial truncate incisors. Gill-rakers, about $33+35$, finely lanceolate, one-fifth longer than gill-filaments or seven-eighths of eye. Scales with 8 to 11 basal radiating striae, apical denticles 110 to 185 and circuli very fine. Color in alcohol with back prout's-brown, fading paler or somewhat tawny-olive on side and lower region. Dorsals, anals, and ventrals dusky, at least terminally or on outer portions. Black spot at bases of last two dorsal rays, little less than pupil in size. Pectoral and caudal pale brown. Iris slaty. Length, $94 \mathrm{~mm}$. Cebu.

Compared with the type in the Academy and found only to vary in color. Traces of the dark blotch at pectoral base evident in Cebu example, though much more faded on right side. The type is much more contrasted, as shown in the original figure. This does not show the black blotch at bases of last dorsal rays, though it is still evident on the specimen, but more distinct on the right than on the left side.

DASCYLLUS ARUANUS (Linnaeus).

Seven from Zamboanga. Length, 35 to $67 \mathrm{~mm}$.

Family LABRIDAE.

\section{HEMIPTERONOTUS SPILONOTUS (Bleeker).}

Head, 3 to $3 \frac{1}{8}$; depth, $2 \frac{1}{2}$ to $2 \frac{4}{5}$; D. II, VII, 12 , I or 13 , I; A. III, 12 ; scales 20 in upper section of lateral line, 5 in lower hind section to caudal base and 1 more on latter; 2 scales above lateral line to third dorsal spine base, 9 below to spinous anal origin; snout, $1 \frac{3}{4}$ to 2 in 
head; eye, $4 \frac{3}{4}$ to $5 \frac{4}{5}$; maxillary, $3 \frac{2}{5}$ to $3 \frac{1}{2}$; interorbital, $6 \frac{1}{5}$ to 7 . Gillrakers, $6+15$, conic, firmly lanceolate, about two-thirds of gill-filaments, which 12 in eye. Scales with 61 to 65 basal radiating striae, and about 3 to 7 short auxiliary marginals, 60 to 68 apical radiating weak striae and circuli moderately fine. Color in alcohul, large example generally same as $H$. pentadactylus. Pale blue-gray line along median keel of snout front. Mandible with four blue-gray vertical lines each side. Lateral line with eighth scale jet black. Humeral scale with blue-gray line, also cluster of several scales about end of depressed pectoral with blue-gray bases, line of demarcation from rest of scale showing them sharply vertical. Gray line across pectoral base. Iris buff-yellow. Soft dorsal and anal grayish, with oblique whitish lines, more or less broken into small spots toward deeper terminal part of soft dorsal. Caudal grayish, with seven or eight vertical pale or whitish cross bands. Pectoral brownish above and terminally, otherwise pale like ventrals. Two examples, 115 to 152 $\mathrm{mm}$. Takao.

Smaller example without blue-gray lines on head very distinct and black of eighth scales of lateral line extended upon base of one above. It certainly approaches $H$. evides Jordan and Richardson $^{30}$, which we think a synonym. There are no characters shown in the description or figure of $H$. evides to ever have allowed it distinct from $H$. spilonotus. Further, no discussion of its status, in comparison with other species, has ever been advanced.

\section{HEMIPTERONOTUS PENTADACTYLUS (Linnaeus).}

Head, $3 \frac{1}{8}$; depth, 24 ; D. II, VII, 12, I; A. III, 12, I; scales 20 in upper section of lateral line, 4 in lower hind section to caudal base and 1 more on latter; 3 scales above lateral line to third dorsal spine base, 10 below to spinous anal origin; snout, $2 \frac{1}{10}$ in head; eye, $5 \frac{1}{5}$; maxillary, $3 \frac{1}{3}$; interorbital, $5 \frac{3}{5}$. Gill-rakers, $6+12$, conic, firmly lanceolate, about three-fourths of gill-filaments and latter $1 \frac{3}{5}$ in eye. Scales with 56 or 57 basal radiating striae, and 2 to 5 auxiliary short ones, about 44 to 60 apical radiating weak striae, and circuli moderately fine. Color in alcohol faded pale brown, but slightly paler below. Pale blue-gray line from snout tip to dorsal along frontal keel. Front mandible edge and median cutaneous fold of branchiostegal region likewise. Each side of mandible with two blue-gray narrow lines, first little before middle and second little backward. Iris pale buff-yellow. Pale yellowish scale at suprascapula sprinkled slightly with blackish. Lateral line with second to fifth scales more or less pale yellowish, but second to fourth more blackish than suprascapular. Blotch of dull

${ }^{30}$ Mem. Carnegie Mus., vol. 4, No. 4, 1909, p. 196, pl. 72. 
brown extends about over four scales, one scale below lateral line and just before pectoral end. Dorsals grayish, spotted and blotched with white. Anals grayish, with about three whitish longitudinal narrow bands, more or less complete. Caudal little more dusky, upper and lower edges especially deeper but narrowly so, and fin with about five vertical pale or whitish narrow cross bands. Other fins pale. Pectoral slightly pale dusky terminally. Length, 145 mm. Takao.

Also three smaller examples, same data, but without the dark scales at the beginning of lateral line. In the largest they show only a smail whitish spot apically on scale. In the smaller example no blue-gray lines on head. Head, $3 \frac{1}{4}$; depth, $3 \frac{1}{8}$; D. II, VII, 12, I; A. III, 12, I; scales 21 in upper section of lateral line, 5 in lower hind section to caudal base and 1 more on latter; 3 scales above lateral line, 9 below ; snout, $2 \frac{1}{8}$ to $2 \frac{7}{8}$; eye, 4 to $5 \frac{1}{4}$; maxillary, $3 \frac{2}{5}$ to $3 \frac{1}{2}$; interorbital, $5 \frac{2}{3}$ to 6 ; length, 75 to $136 \mathrm{~mm}$.

Snyder has described $H$. jenkinsi from a young Hawaiian specimen, an inch long, which is shown without scales on the cheek and black blotch above the lateral line below front of soft dorsal. From this it appears to us it is probably an Iniistius, likely the young of I. aneitensis (Gunther).

\section{EPIBULUS INSIDIATOR (Pallas).}

Two examples, 162 to $222 \mathrm{~mm}$. Zamboanga. Neither of these specimens show the pectoral fin as contrasted, or pale, as in Bleeker's figure.

\section{CHEILINUS FASCIATUS (Bloch).}

Length, $325 \mathrm{~mm}$. Zamboanga. About the suprascapular region, postpectoral and humeral also, each scale marked with a decided and contrasted blackish-brown blotch basally.

\section{CHEILINUS TRILOBATUS Lacépède.}

Length, $307 \mathrm{~mm}$. Cebu. Agrees with Gunther's figure ${ }^{31}$ of a Samoan example. Our specimen shows both soft dorsal, anal, and caudal, with their elongated points more pronounced. In alcohol its breast and belly are spotted paler, and along the median line assume quite large pale blotches. Similar ones also occur on the lower surface of the head.

\section{Family CALLYODONTIDAE.}

\section{CALLYODON BALINENSIS (Bleeker).}

Head, $2 \frac{7}{8}$; depth, $2 \frac{3}{4}$; D. IX, 10, I; A. III, 8, I; scales, 18 in upper section of lateral line, 5 in lower section to caudal base and 2 more

s1 Journ. Mus. Godeffroy, vol. 15 (VII), 1881, pl. 131. 
on latter; 2 scales above lateral line to spinuus dorsal origin, 6 below to spinous anal origin; 5 predorsal scales; 3 rows of cheek scales; snout, $2 \frac{3}{5}$ in head; eye, $5 \frac{3}{4}$; maxillary, 5 ; interorbital, 3 . Single exposed posterior canine above each side. Gill-rakers, $11+24$, slender fine flexible points, $4 \frac{1}{2}$ in gill-filaments, which equal eye. Scales with 30 basal radiating striae, apical striae 28, parallel. Dorsal spines flexible. Caudal concave behind. Color in alcohol, back nearly sepia, below paler to nearly maize-yellow. Dorsals, anals, and caudal, also upper pectoral edge, brown like back, though outer portions of all darker. Obscure transverse band of brown across interorbital connecting eyes. Length, $190 \mathrm{~mm}$. Zamboanga.

\section{CALLYODON PRONUS (Fowler).}

Head, $2 \frac{4}{5}$; depth, $2 \frac{3}{4}$; D. IX, 10, I; A. III, 9, I; scales 18 in upper section of the lateral line, 5 in lower section to caudal base, and 2 more in latter; 2 scales above lateral line to spinous dorsal origin, 6 below to spinous anal origin; 4 predorsal scales; snout, 22 in head; eye, $6 \frac{2}{5}$; maxillary, $6 \frac{1}{3}$; interorbital, 3 . Two posterior canines each side above and one below each side. Gill-rakers, $12 ?+31$, slender, flexible, 4 in gill-filaments, which equal eye. Scales with 36 basal radiating striae, apical striae 32 . Color in alcohol now largely faded dull uniform brown. Lips pale. Pale line from rictus to lower edge of eye. Small blackish blotch, less than pupil in size, at pectoral origin. Dorsals and anals with submarginal dusky line, leaves fin edges pale yellow, though that of anals broader. Emarginated caudal also with similar dark line behind. Length, 203 mm. Cebu.

Compared with the type of Scarus pronus Fowler ${ }^{32}$ in the Academy and agrees. Slight differences, due to preservation and individual variation evident. In type two lower left canines, though only one right. While our Cebu example shows but two rows of cheek scales type has three, the lowest on the preopercular flange. We think in the case of the Cebu example they may have fallen. The front profile is less sinuous. Though the type has been varnished, the black spot at the pectoral origin is still apparent.

\section{CALLYODON MURICATUS (Valenciennes).}

Head, $2 \frac{4}{5}$ to 3 ; depth, $2 \frac{2}{5}$ to $2 \frac{3}{5}$; D. IX, 9 , I, or 10 , I, A. III, 9, I; scales, 16 or 17 in upper section of lateral line, 8 or 9 in lower section to caudal base and 2 more on latter; 2 scales above lateral line to spinous dorsal origin, 7 below to spinous anal origin; 5 predorsal scales; snout, 2 to $2 \frac{1}{6}$ in head; eye, 5 to $6 \frac{1}{3}$; maxillary, 4 to $4 \frac{1}{4}$; interorbital, 3 to $3 \frac{2}{5}$. No posterior canines. Upper lip covers at least half

32 Proc. Acad. Nat. Sci. Phila., 1899, p. 490, pl. 18, fig. 3. Thornton Island. 
of teeth. Gill-rakers, $7+9$ short weak flexible points, 5 in filaments, latter equal eye. Three rows of cheek scales. Scales with 37 basal radiating striae, apical striae 14 . Caudal rounded convexly. Color in alcohol with back deep benzo-brown to fuscous, becoming paler to dark ecru below. Dorsals, anals, caudal, and ventral blackish, more or less pale or slaty basally. Pectoral paler. Iris pale yellowish-white. Lips dusky. Teeth pale or whitish. Side of body with seven vertical series of nearly light cinnamon-drab spots, on trunk three of four spots in each series, though on caudal peduncle only one or two. All spots with slightly darker marginal edge. Length, 185 to $255 \mathrm{~mm}$. Two from Zamboanga.

Seale describes Callyodon albipunctatus from Sitanki Island, Jolo Archipelago, based on an example but $170 \mathrm{~mm}$. long. Its coloration suggests the present species, though it is said to have only two rows of scales on the cheek and the lower limb of the preopercle naked. Also the gill-rakers are said to be numerous, minute, and hairlike.

\section{PSEUDOSCARUS NUCHIPUNCTATUS (Valenciennes).}

Head, 3; depth, $2 \frac{3}{5}$; D. IX, 9, I; A. III, 9, I; scales 17 in upper section of lateral line, 3 in lower section to caudal base and 2 more on latter; 2 scales above lateral line to spinous dorsal origin, 6 below to spinous anal origin; 7 predorsal scales; snout, $2 \frac{1}{3}$ in head; eye, $7 \frac{1}{4}$; maxillary, $4 \frac{1}{4}$; interorbital, $2 \frac{3}{4}$. Two posterior upper cannies, hind one smaller and hidden. Gill-rakers about $15+45$, finely lanceolate, flexible, $3 \frac{1}{2}$ in gill-filaments, which nearly equal $1 \frac{1}{2}$ eye diameters. Three rows of scales on cheeks. Scales with 31 basal radiating striae, apical radiating striae 40. Color in alcohol deep seal-brown generally, more or less uniform over trunk. Teeth greenish. Upper lip pale to whitish, with submarginal yellowishcitrine parallel cross band. Lower jaw with two similar pale bands, followed by two streaks of same color over subopercle region. Edge of lower lip narrowly grayish, separated from yellow-citrine band by seal-brown line. Streak of yellowish-citrine across preorbital to rictus, and small blotches or spots of same color over rest of suborbitals. Several small yellowish-citrine spots above opercle and larger buff blotch in first scale of lateral line. Fins dark like general body color, margins of all except pectorals distinctly pale or buffy and on dorsals and anals separated from dark basal color by narrow dusky line. No basal pale bands, as shown in Bleeker's figure, though last ray of each fin with tinge of yellowish-citrine basally and externally. The black spots shown on the body scales of Bleecker's figure are not evident. Length, $273 \mathrm{~mm}$. Zamboanga. 
We agree with Gunther in admitting $P$. prasiognathus Jordan and Seale and $P$. maoricus Jordan and Seale, to the synonymy of this species.

PSEUDOSCARUS FORSTERI (Valenciennes).

Head, $2 \frac{3}{5}$ to $2 \frac{2}{3}$; depth, $2 \frac{1}{2}$ to $2 \frac{3}{4}$; D. IX, 10 , I; A. III, 9, I; scales 17 in upper section of lateral line, 5 or 6 in lower section to caudal base and 2 more on latter; 2 scales above lateral line to spinous dorsal origin, 6 below to spinous anal origin; 4 predorsal scales; snout, $2 \frac{1}{5}$ to $2 \frac{1}{4}$ in head from tip of upper tooth; eye, $6 \frac{3}{4}$ to 7 ; maxillary, $3 \frac{4}{5}$ to 4 ; interorbital, 3 to $3 \frac{1}{8}$. Two rows of scales on cheek. Last or most posterior denticle of cutting edge of upper teeth, little enlarged. Gill-rakers, $20+35$ ?, finely lanceolate, flexible, about onefourth of gill-filaments, which $1 \frac{1}{4}$ eye diameters. Scales with 38 basal radiating striae, apical striae nearly parallel, about 38. Color in alcohol more or less yellowish, back tinged brown. Citrine-yellow band across each lip with edge narrowly whitish, colors on upper lip separated by brownish line and behind rictus unite, then extend up to lower eye edge and back across preopercle. Above last deep brown band of equal width, though most conspicuous close to eye. Still above, from hind eye edge, two more citrine-yellow short bands radiate backward, each in turn separated by brownish. Dorsals with submarginal brownish or yellowish band, separated below by darker brownish line. Anal with outer three-fifths citrine, remaining basal portion whitish. Caudal pale; hind concave edge (folded) pale brown (when expanded convex). Pectoral pale brown, edge narrowly pale citrine followed with grayish band, and below that yellowish band. Ventral pale brownish. Jaws pale bluish. Interorbital pale forward. Length, 206 to $232 \mathrm{~mm}$. Zamboanga.

In the presence of only two rows of scales on the cheek our examples agree with the figures of Pseudoscarus capistratoides Bleeker ${ }^{33}$ and Gunther's figure of a Tahitian example. Though no projecting: canines are developed, there is apparently an obsolete one above each side, scarcely protruded and covered largely by the upper lip. Possibly with age they may become erect and project.

\section{Family ILARCHIIDAE.}

HARPOCHIRUS LONGIMANUS (Schneider).

Head, $2 \frac{4}{5}$ to 3 ; depth, $1 \frac{1}{8}$ to $1 \frac{1}{4}$; D. I, VIII, 20, I; A. III, 16, I, 17, I; scales, 75 or 76 close above and along lateral line to caudal base; tubular scales 45 to 49 in lateral line to caudal base; 18 or 19 scales above lateral line to second dorsal spine base, 37 to 42 scales below to spinous anal origin; snout, $2 \frac{1}{6}$ to $2 \frac{1}{5}$ in head; eye, $3 \frac{2}{5}$ to $3 \frac{1}{2}$;

as Atlas Ichth., vol. 1, 1863, pl. (1) 6, fig. 2. 
maxillary, $3 \frac{1}{4}$ to $3 \frac{1}{3}$; interorbital, $3 \frac{1}{3}$ to $3 \frac{4}{5}$. Gill-rakers, $5+9$, short conic points, 3 in gill-filaments, which $1 \frac{3}{4}$ in eye. Scales with 2 or 3 basal radiating striae, circuli fine, crescentic. Pectoral reaches at least to straight section of lateral line on caudal peduncle. Color in alcohol largely silvery. Back with light, obscure, slightly darker brown vertical bands, alternately wide and narrow. Two examples, 178 to $193 \mathrm{~mm}$. Takao.

\section{Family PLATACIDAE.}

PLATAX TEIRA (Forskål).

Head, $2 \frac{4}{5}$ to 3 ; length, $1 \frac{1}{5}$ in depth; D. V, 35 or 36 ; A. III, 26; scales about 70 counted close along and above lateral line to caudal base; tubular scales 48 to 51 in lateral line to caudal base; scales 53 to 55 from gill-opening to caudal base; 30 scales above lateral line to soft dorsal origin, 47 to 49 below to spinous anal origin; snout, $2 \frac{3}{4}$ to $2 \frac{7}{8}$ in head; eye, $2 \frac{4}{5}$ to 3 ; maxillary, $3 \frac{1}{3}$ to $3 \frac{2}{5}$; interorbital, $2 \frac{2}{3}$ to $2 \frac{3}{4}$. Gill-rakers, $9+9$, firmly lanceolate ceratobranchial 4 in gillfilaments, epibranchial uniformly obtuse. Scales with 4 or 5 basal radiating striae, also 1 to 3 auxiliary short marginals, apical 21 to 24 short denticles and circuli moderately fine. Color in alcohol nearly light quaker-drab, more or less uniform to brownish, long dorsal and anal lobes dark quaker-drab. Ventrals sooty. Iris pale yellowish. Pectoral and caudal pale brownish. Vertical band through eye dark quaker-drab, another includes pectoral base and a third just before caudal peduncle. Length, $128 \mathrm{~mm}$. Zamboanga.

Another, young example $33 \mathrm{~mm}$. long from same locality. Head, $2 \frac{2}{3}$; depth, 1 ; D. V, 37 ; A. III, 27 ; tubes 46 in lateral line to caudal base; snout, 3 in head; eye, $2 \frac{2}{5}$; maxillary, $3 \frac{1}{3}$; interorbital, $2 \frac{7}{8}$. Preopercle edge with 6 or 7 points. Color in alcohol with dark bands on body much narrower than in larger examples, second only distinct on back, third as narrow dark band connecting front of soft dorsal and anal, fourth as two dark blotches at last dorsal and last anal rays, and fifth as basal caudal band. Caudal and pectoral whitish.

\section{Family CHAETODONTIDAE.}

\section{CHAETODON CHRYSOZONUS Cuvier.}

Head, $3 \frac{2}{5}$; depth, $1 \frac{1}{2}$; D. XIII, 22, I; A. III, 18, I; 32 scales between between gill-opening and caudal base; 7 scales above lateral line to spinous dorsal origin, 15 scales below lateral line to spinous anal origin; snout, $2 \frac{7}{8}$ in head from upper jaw tip; eye, $3 \frac{1}{6}$; maxillary, 4 ; interorbital, $3 \frac{1}{2}$. Gill-rakers, $6+11$ weak, slender points, about onesixth of gill-filaments, which $1 \frac{7}{8}$ in eye. Scales with 11 basal radiating striae, apical denticles 106 to 105, circuli very fine. Color in alcohol 
faded dull brown, pockets of trunk showing obscure oblique streaks inclined posteriorly. Broad blackish band from close before spinous dorsal origin down including eye and across cheek. Upper soft dorsal edge and lower anal edge narrowly blackish. Caudal with broad white edge behind, with submarginal blackish band slightly lunate, close to broad pale yellowish band. Iris dark slaty. Length, $94 \mathrm{~mm}$. Cebu.

\section{CHAETODON PUNCTATO-FASCIATUS Cuvier.}

Head, $3 \frac{2}{5}$; depth, $1 \frac{1}{2}$; D. XIII, 22, I ; A. III, 18, I; 32 scales between gill-opening and caudal base; tubular scales 35 in lateral line to below last dorsal rays; 9 scales above lateral line to spinous dorsal origin, 16 below to spinous anal origin; snout, 3 in head from upper jaw tip; eye, 3 ; maxillary, $4 \frac{1}{3}$; interorbital, $3 \frac{1}{8}$. Gill-rakers, $6+14$ weak slender, points, about one-fifth of gill-filaments, which $1 \frac{1}{3}$ in eye. Scales with 11 to 13 basal radiating striae, apical denticles 78 to 109 , circuli very fine. Color in alcohol faded dull brown generally. About seven more or less deep blackish-brown vertical bands, median widest, extending on dorsals. Each scale of trunk with rounded dusky-brown spot. Small rounded black spot on predorsal close to spinous dorsal origin. Pale band from close above eye to its upper edge, margined with deep brown, also continued below eye across cheeks. Soft dorsal edge broadly pale, with submarginal white line, then blackish one and outer portion of fin dusky. Soft anal similar, only without dusky. Caudal broadly whitish behind, with outer submarginal blackish crescent. Iris slaty. Length, $93 \mathrm{~mm}$. Cebu.

CHELMON ROSTRATUS (Linnaeus).

Head, $2 \frac{1}{3}$; depth, $1 \frac{2}{3}$; D. IX, 26 ; A. III, 19 ; 48 scales between gillopening and caudal base; 38 tubular scales in lateral line to caudal base; 10 scales above lateral line to spinous dorsal origin, 23 below to spinous anal origin; snout, $1 \frac{7}{8}$ in head from upper jaw tip; eye, 5 ; maxillary, $2 \frac{2}{3}$; interorbital, $5 \frac{2}{3}$. Gill-rakers, $5+7$ short rudimentary points, barely one-sixth of gill-filaments, which $1 \frac{2}{5}$ in eye. Scales with 10 to 14 basal radiating striae, apical denticles 70 to 76 , circuli fine. Color in alcohol generally pale brown, with four slightly paler bands vertically. First from front preorbital through eye and narrow, and last from each soft vertical in broadest, all margined narrowly with dark brownish. Within last on soft dorsal round black spot, little less than eye. Deep blackish-brown band vertically on caudal peduncle margined in front and behind with paler. Soft dorsal and anal edges broadly grayish, inner portion of which area forming slightly deeper submarginal band. Ventral deep brown, edge pale behind. Pectoral and caudal pale. Length, $113 \mathrm{~mm}$. Cebu. 


\section{Family ACANTHURIDAE.}

HEPATUS MATOIDES (Valenciennes).

Head, 3 ; depth, $1 \frac{5}{6} ;$ D. VIII, 26 ; A. III, 24 ; snout, $1 \frac{5}{6}$ in head; eye, 3 ; maxillary, $3 \frac{2}{5}$; interorbital, 3 . Teeth uniserial, compressed, edge of each dentate. Color in alcohol with trunk nearly benzobrown. Dorsals, anals, and ventrals blackish. Caudal edges above and below, and base, pale brownish, pale vertical band basally, and rest of fin blackish brown. Pectoral pale. Iris slaty. Length, 80 mm. Cebu.

Compared with Hawaiian examples in the Academy.

CTENOCHAETUS STRIATUS (Quoy and Gaimard).

Head, $3 \frac{1}{5}$ to $3 \frac{2}{5}$; depth, $1 \frac{7}{8}$ to 2 ; D. VIII, 26 or 27 ; A. III, 25 or $2 €$; snout, $1 \frac{1}{3}$ to $1 \frac{2}{5}$ in head; eye, $3 \frac{1}{8}$ to $3 \frac{7}{8}$; maxillary, 3 to $3 \frac{1}{3}$; interorbital, 3 to $3 \frac{1}{6}$. Teeth slender, pediculate, apical expansion entire on inner edge, dentate on outer. Color in alcohol nearly uniform natal-brown on trunk, vertical fins darker to dusky. Trunk with numerous horizontal and slightly waved abscure dull blue-gray lines. Five examples, 125 to $155 \mathrm{~mm}$. Zamboanga.

ACANTHNURNS ANNULATUS (Quoy and Gaimard).

Head, $3 \frac{7}{8}$; depth, $2 \frac{2}{5}$; D. VII, 28, I ; A. II, 26, I; snout, $1 \frac{1}{2}$ in head; eye, $3 \frac{3}{4}$; maxillary, 4 ; interorbital, $3 \frac{1}{6}$. Color in alcohol with back sepia, fading to nearly tawny-olive below. Dorsals dusky sepia, become blackish submarginally, fin edge narrowly whitish. Anals paler dusky, with three longitudinal deeper lines, parallel and whole length of fin, edge narrowly whitish. Caudal with broad whitish edge behind. Pectoral brown, edged paler all around. Ventral brownish, paler basally. Iris dusky. Length, $245 \mathrm{~mm}$. Cebu.

This specimen agrees with Gunther's figure of $N$ aseus marginatus ${ }^{34}$ in the contour of its upper profile, based on an example from Aneiteum. The complete figure is from a Pelew example and its color pattern agrees in every respect with our specimen.

\section{Family SIGANIDAE.}

SIGANUS JAVUS (Linnaeus).

Head, $3 \frac{1}{3}$; depth, 2; D. I, XIII, 10, I; A. VII, 9, I; snout, 2 in head; eye, 3 ; maxillary, $3 \frac{2}{5}$; interorbital, 3 . Teeth rather elongate, upper slightly tridentate or with front prong only slightly smaller than median or main prong, while hind denticle very small or nearly obsolete, also more terminal on tooth. Lower teeth biserial, similar, except small terminal obsolete denticle not present and in each case median denticle forward. Scales minute, simple, elongate, circuli 
very fine, nonstriate. Color in alcohol dull brownish generally, scarcely paler below. Vertical fins and ventrals brownish, all with more or less dusky terminally. Pectoral pale. Length, $133 \mathrm{~mm}$. Cebu.

Compared with Philippine examples in the Academy.

\section{SIGANUS FUSCESCENS (Honttuyn).}

Head, $3 \frac{7}{8}$; depth, $2 \frac{2}{3}$; D. I, XIII, 10, I ; A. VII, 9, I; snout, $2 \frac{2}{5}$ in head; eye, $3 \frac{1}{5}$; maxillary, $3 \frac{1}{2}$; interorbital, 3 . Teeth and scales as in preceding. Color in alcohol faded dull brownish generally, scarcely paler on abdomen. Dorsals and anals dark gray, mottled or obscurely blotched with darker on membranes, also on caudal, though traces of about five outer marginal darker blotches on each lobe most distinct. Paired fins pale. Ventral membrane dusky. Length, $155 \mathrm{~mm}$. Cebu.

Agrees with Philippine material in the Academy.

SIGANUS ROSTRATUS (Valenciennes).

Head, $3 \frac{7}{8}$ to 4 ; depth, $2 \frac{3}{5}$ to $2 \frac{2}{3}$; D. I, XIII, once XII, 10, I; A. VII, 9, I; snout, $2 \frac{2}{5}$ to $2 \frac{3}{5}$ in head; eye, $3 \frac{1}{4}$ to $3 \frac{2}{5}$; maxillary, $3 \frac{7}{8}$ to 4 ; interorbital, 3 to $3 \frac{1}{4}$. Teeth and scales as in $S$. javus. Caudal strongly forked. Color in alcohol dusky-brown generally, often clouded white on ventral region and lower surface also frequently pale vinaceous-drab. Spinous dorsal grayish, blotched with purpledrab, likewise spinous anal and ventral. Other vertical fins grayish, with brownish cloudings or specklings. Pectoral pale olive. Iris yellowish-white. Length, 138 to $163 \mathrm{~mm}$. Four from Zamboanga.

Our examples apparently young. They agree fairly with Gunther's figure of Teuthis rostrata ${ }^{35}$ from an example obtained at Tahiti. Traces of the numerous gilded small spots are still evident. Quite characteristic are the 3 or 4 large dark blotches on the ventrals.

SIGANUS CORALINUS (Valenciennes).

Head, $3 \frac{2}{3}$ to $3 \frac{1}{2}$; depth, 2 to $2 \frac{1}{8}$; D. I, XII to XIV, 9, I, or 10 , I; A. VII, 8 , I; or $9 \mathrm{I}$; snout, $1 \frac{7}{8}$ to $1 \frac{9}{10}$ in head; eye, $3 \frac{2}{3}$; maxillary, $3 \frac{4}{5}$ to $3 \frac{7}{8}$; interorbital, $3 \frac{1}{6}$ to $3 \frac{1}{4}$. Teeth and scales as in preceding species. Inner ventral spine, as depressed, very slightly less than outer. Color in alcohol nearly brownish-drab above, little paler below. Head, breast, belly, and ventral edge with moderate crowded dark edged gray ocelli, which much smaller and more or less as dark dots on trunk. Fins olive-gray, sometimes few obscure small clouded blotches on rayed vertical ones basally. Iris pale yellowish white. Length, 188 to $790 \mathrm{~mm}$. Two from Zamboanga.

Compared with Sumatran example in the Academy.

25 Journ. Mus. Godeffroy, vol. 2-3 (5-6), 1874, p. 89, pl. 60. 
SIGANUS VULPINUS (Schlegel and Müller).

Head, $3 \frac{1}{4}$ to $3 \frac{3}{5}$; depth, $2 \frac{1}{6}$ to $2 \frac{1}{5}$; D. I, XIII, 11 , rarely 10 ; A. VII, 9 ; snout, $1 \frac{7}{8}$ to 2 in head; eye, $3 \frac{4}{5}$ to $4 \frac{3}{4}$; maxillary, 5 to $5 \frac{1}{5}$; interorbital, $3 \frac{2}{5}$ to $3 \frac{2}{3}$. Teeth and scales as in preceding. Inner ventral spine about seven-eighths of outer. Color in alcohol, with back nearly burnt-umber, fading pale brown below and behind, especially on dorsals, anals, and caudal. Upper half of head, including snout, from slightly below maxillary end to lower eye edge then to suprascapular and spinous dorsal origin bone-brown. All of breast and chest before pectoral and ventral bases deep bone-brown. Lower half of head pale lavender-gray, finely dotted with bone-brown and as gray color extends over front of back, gradually fading after pectoral, also finely dotted. Pectoral tinted olive-gray, upper edge dark and similar tints on rayed vertical fins. Iris pale yellowish white. Length, 193 to $230 \mathrm{~mm}$. Four from Zamboanga.

Jordan and Seale's figure ${ }^{36}$ does not show the fine dark dots on the lower surface of the head, evidently having faded out.

We give $L o$ Seale only subgeneric rank, as in dentition, gill-rakers, and scale structure it agrees with all the other species we have examined. Its sole distinction appears to be in the constricted lower branchial region. Jordan and Seale say ${ }^{37}$ it " is defined by the short tubular snout," which is not at all the case. The snout is, in fact, as long as most of the long-snouted species we have seen. From Siganus corallinus, for instance, its branchial construction is only a condition of slightly greater restriction.

\section{Family BALISTIDAE.}

\section{BALISTAPUS LINEATUS (Schneider).}

Head, $2 \frac{5}{6}$ to $2 \frac{7}{8}$; depth, $1 \frac{9}{10}$ to 2 ; D. III-II, 24 ; A. I, 22 or 23 ; scales, 46 between gill-opening and caudal base and 4 more on latter; 25 to 29 scales between soft dorsal and anal origins; 38 to 47 predorsal scales; snout, $1 \frac{1}{3}$ in head; eye, $5 \frac{3}{4}$ to 6 ; interorbital, 4 to $4 \frac{1}{8}$. Color in alcohol generally nearly bone-brown. Trunk with many inclined paler lines, extend from dorsal surface backwards toward anal and caudal. Several from muzzle with more or less yellowish white tinge. Spinous dorsal dark like back. Fins largely dull yellowish-white, narrow basal portion of each dorsal and anal ray, also of pectoral, bone-brown. Iris pale slaty. Length, 160 to $220 \mathrm{~mm}$. Two from Zamboanga.

The larger example shows three rows of antrorse spines on each side of caudal peduncle, the smaller has only two.

${ }^{36}$ Bull. Bur. Fish. U. S., vol. 25, 1905 (1906), p. 361, fig. 67.

${ }^{87}$ Idem, p. 360. 


\section{Family TRIACANTHIDAE.}

TRIACANTHUS BLOCHI Bleeker.

Head, $3 \frac{1}{6}$; depth, $2 \frac{2}{5}$; D. V-22 ; A. 16, I; snout, $1 \frac{1}{3}$ in head; eye, 3 ; interorbital, $3 \frac{1}{3}$; first dorsal spine, $2 \frac{1}{4}$ in combined head and trunk, greater than greatest body depth; second dorsal spine about $4 \frac{2}{3}$ in first; ventral spine $1 \frac{1}{10}$ in head, reaches anal; caudal peduncle length, $1 \frac{1}{5}$ in dorsal base. Color in alcohol faded dull brownish, little paler below. Iris pale slaty. Length, $74 \mathrm{~mm}$. Cebu.

Our example appears to agree best with Bleeker's figure. ${ }^{38}$

\section{Family TETRODONTIDAE.}

\section{SPHEROIDES SPADICEUS (Richardson).}

Head, $2 \frac{3}{4}$ to 3 ; depth (contracted), $3 \frac{1}{4}$ to $3 \frac{1}{3}$; D. II, 10 to 12 ; A. II, 9 to 11 ; snout, 2 to $2 \frac{1}{8}$ in head; eye, $3 \frac{1}{4}$ to $3 \frac{2}{5}$; interorbital, $2 \frac{1}{3}$ to $2 \frac{2}{5}$. Interorbital and front predorsal region until about overdepressed pectoral middle, also all of belly before vent and level with lower pectoral edge, spinescent, though spines on abdomen larger and less crowded. Color in alcohol with back grayish-olive, variably paler to dusky. Fins all pale brownish. Sides silvery-white from below eye, belly and lower surface white. Iris pale yellowish-white. Length, 50 to $160 \mathrm{~mm}$. Twenty-five from Takao.

\section{Family SCORPAENIDAE.}

\section{RHABDOSEBASTES, new genus.}

Type.-Sebastes stolicakae Day.

This genus is allied with the rose fishes, Sebastes, but differs in the possession of fifteen dorsal spines and the much smaller scales. Sebastopsis Gill has thirteen dorsal spines but no palatine teeth.

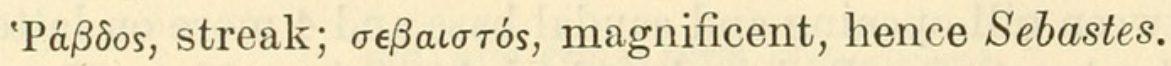

\section{RHABDOSEBASTES STOLICZKAE (Day).}

Head, $2 \frac{1}{8}$; depth, 3; D. XIV, 10; A. III, 5; P. 12; V. I, 5; scales along and close above lateral line 34 to caudal base and 4 more on latter; tubular scales 37 in lateral line to caudal base and 4 more on latter; 4 scales above lateral line to soft dorsal origin, 12 below to spinous anal origin; 22 predorsal scales; head width, about 2 in its length; head depth at occiput, $1 \frac{2}{5}$; mandible, $2 \frac{1}{3}$; third dorsal spine, $2 \frac{1}{3}$; second dorsal ray, 2 ; second anal spine, $1 \frac{3}{5}$, first branched anal ray, $2 \frac{1}{8}$; least depth of caudal peduncle, $4 \frac{1}{4}$; caudal fin, $1 \frac{7}{8}$; pectoral, $1 \frac{1}{2}$; ventral, $1 \frac{2}{3}$; snout, $5 \frac{1}{5}$ in head from upper jaw tip ; eye, $3 \frac{1}{3}$; maxillary, $2 \frac{3}{5}$; interorbital, $6 \frac{1}{8}$.

38 Atlas Ichth., vol. 5, 1865, p. 89, pl. (3) 217, fig. 1 . 
Body elongate, well compressed, deepest about midway in its length, back not elevated. Caudal peduncle well compressed, length about four-fifths its least depth.

Head large, compressed, slightly flattened sides converge moderately upward. Snout very short, convex over surface and slightly so in profile, length about three-fifths its width. Eye large, ellipsoid, hind edge about midway in head length. Maxillary oblique, extends down until about midway in eye length, expansion $2 \frac{1}{6}$ in eye. Mouth moderate, closed jaws about even. Bands of villiform teeth in jaws, on vomer and palatines. Upper inner buccal fold broad, lower very narrow. Tongue large, smooth, fleshy, depressed, pointed, free around edge and in front. Front nostril above eye, close before front eye edge, with cutaneous expanded fleshy fiap $2 \frac{2}{5}$ in eye, edge scarcely fringed. Hind nostril simply pore close above upper eye edge and slightly before front pupil edge. Interorbital slightly convex, little more than half of eye. Preorbital very narrow, much narrower than maxillary, which only partly slips below. Preopercle edge finely serrate and its lower edge with three moderately large antrorse spines. Opercle with strong flattened spine, $2 \frac{1}{2}$ in eye.

Gill-opening extends forward nearly opposite front eye edge. Gill-rakers, v+xII, low rudiments or tubercles, greatly lower than gill-filaments, which $2 \frac{1}{4}$ in eye. Pseudobranchiae long as gill-filaments. Isthmus narrowly constricted forward, scaled.

Scales large, in oblique rows on trunk, etenoid, with 10 or 11 basal parallel marginal striae, apical denticles about 58 to 74 and circuli fine. Slightly smaller scales on soft dorsal, anal, pectoral and caudal bases, though scarcely smaller along body edges. Head, except maxillary, lips and preorbital, covered with small scales. Seven rows of scales across cheek from lower eye edge to preopercle angle. Lateral line on small and largely concealed scales, with simple tubes, its course largely concurrent with dorsal profile.

Spinous dorsal inserted little before pectoral origin, though slightly behind hind preopercle edge. Dorsal spines graduated down from third, which highest, second and fourth about equal, and first very slightly shorter than fourteenth, fin membranes deeply notched marginally. Soft dorsal origin nearly midway between hind end of opercle flap and caudal base, second ray longest, first subequal and all others graduated shorter. Spinous anal origin near last third in space between ventral origin and caudal base, second spine longest, third much shorter though depressed slightly beyond caudal base and first about one-sixth of second. Soft anal with first ray longest, though much shorter than second anal spine, and rays graduated down to hindmost. Caudal rounded behind. Pectoral 
rounded, extends slightly over halfway to anal. Ventral inserted entirely behind pectoral base, depressed fin falling very slightly short of vent or about two-thirds to anal, spine about two-thirds of fin.

Color in alcohol largely snuff-brown, variegated with markings of deep to warm sepia. Lower surface of body paler. Head above marked with rather small obscure spots of sepia. Muzzle generally pale, with four deep sepia blotches on maxillary and about three on mandible each side. Nasal tentacle dark. Iris dull slaty. On trunk ill-defined blotch below front of spinous dorsal, another about midway in its length and third one below soft dorsal, though former two more or less reflected on fin. Spinous dorsal entirely blotched with sepia. Fewer, though larger sepia blotches on soft dorsal. Anal with three broad bands of sepia, four on caudal, five on pectoral, and four on ventral. Pectoral axil pale, also inside gill-opening. Length, $108 \mathrm{~mm}$. Cebu.

Our specimen agrees largely with Day's ${ }^{39}$ account and figure! No specimen other than ours appears to have been secured since, and as it shows some minor variations we have given the above description. Our example shows the dark bands and blotches on the soft vertical fins more pronounced and contrastedly wide on caudal. Its spots on the spinous dorsal are also quite distinct and numerous.

PTEROIS HETERURA Bleeker.

Head, $2 \frac{1}{2}$ to $3 \frac{3}{4}$; depth, $3 \frac{1}{5}$ to $3 \frac{1}{4}$; D. XII, I, 9, I; A. II, 7, I, rarely 6 ; scales, 43 mostly according to pockets counted along close to lateral line to caudal base and 3 more on latter; 6 scales above lateral line to front of spinous dorsal, 11 below to spinous anal origin; snout, $2 \frac{3}{5}$ to 3 in head from upper jaw tip; eye, 3 to $3 \frac{4}{5}$; maxillary, 2 to $2 \frac{1}{3}$; interorbital, 5 to 6 . Gill-rakers, Iv, $2+10$ II, lanceolate, longest equal gill-filaments or $2 \frac{3}{4}$ in eye. Scales with 9 to 11 basal radiating striae, apical denticles weakly 5 to 7 , circuli very fine. Color in alcohol largely faded dull brownish with traces of about five double sets of vertical slightly darker cross bands. On cheek three dark vertical bands from pupil. Dorsals light brownish, caudal and anals paler and all rayed portions finely spotted on rays with dark brown. Pectoral and ventral blackish, former with about eight to ten transverse pale vertical bands. Numeral blotch dusky-brown. Branchiostegal region tinged dusky. Length, 73 to $148 \mathrm{~mm}$. Thirteen from Takao.

Bleeker's figure does not show the very prominent cutaneous predorsal flap, in some of our smaller examples nearly twice the eye in length. In our largest specimen the produced long caudal filaments render the tail equal to the rest of the body with the exception of

Fishes of India, vol. 1, 1875, p. 148, pl. 36, fig. 1. Nicobars. 
the snout, thus greatly longer than Bleeker indicates. These two characters, together with the large scales, contrasted dark paired pale unpaired fins, constantly two anal spines and reduced radial formula, will serve to distinguish this species. It has not previously been recorded from Formosa.

\section{APISTUS CARINATUS (Schneider).}

Head, $2 \frac{2}{5}$; depth, $3 \frac{1}{3}$; D. XIV, I, 9, I; A. III, 7; scales (mostly fallen) about 55 ?, in lateral line to caudal base; 6 scales above lateral line to third dorsal spine base; 16 scales below lateral line to spinous anal origin; 6 predorsal scales to occiput; snout, $3 \frac{7}{8}$ in head; eye, $3 \frac{3}{4}$; maxillary, $2 \frac{1}{8}$; interorbital, $7 \frac{1}{2}$. Gill-rakers, III, $5+15$, II, lanceolate, $2 \frac{1}{2}$ in eye; gill-filaments three-fourths of gill-rakers. Scales with 4 or 5 basal radiating striae, strong apical denticles 3 with median largest, circuli moderate. Color in alcohol pale brownish generally to nearly whitish below. Dorsals pale brown with large black blotch on posterior half of fin and two black bands on soft fin. Caudal pale, with three transverse dusky bands. Pectoral largely black, its uppermost ray white. Ventral and anal dusky terminally. Length $57 \mathrm{~mm}$. Takao.

Quite likely $A$. evolans Jordan and Starks and $A$. venenans Jordan and Starks, each based on only one example, are simply variants of the present species. The elongated pectoral of our example, which reaches slightly beyond the caudal base, is doubtless a condition of youth.

\section{MINOUS TRACHYCEPHALUS (Bleeker).}

Head, $2 \frac{1}{8}$; depth, 3 ; D. IX, 9 ; A. III, 7 ; snout, $2 \frac{5}{6}$ in head from upper jaw tip; eye, $4 \frac{1}{4}$; maxillary, $2 \frac{1}{6}$; interorbital, $5 \frac{1}{6} ; 1 \frac{1}{4}$ in eye; pectoral, $2 \frac{1}{3}$ in combined head and trunk or about 3 in total length. Gill-rakers, $3+7$, robust, ends tuberculate, equal gill-filaments or $2 \frac{1}{2}$ in eye. Color in alcohol largely dull fuscous, marked obscurely with darker blotches. Under surface whitish, dusted in places with dots of drab or ecru, especially on sides of head. Fins dark, terminal portions of pectoral and ventral and anal, fuscous-black. Length $60 \mathrm{~mm}$. Takao.

Our example agrees with Bleeker's figures, ${ }^{40}$ the species having originally been obtained at Celebes. Our specimen shows the maxillary extending little more posteriorly, though not quite opposite the front pupil edge. Though it has the caudal base pale there are no dark bands as in his figure of $M$. monodactylus. ${ }^{41} M$. adamsi Richardson has been taken from the synonymy of $M$. monodactylus by 
Jordan and Starks, ${ }^{42}$ where it had been placed by Gunther, ${ }^{43}$ after a comparison of the type of $M$. monodactylus with adequate materials for the time, from Borneo and Madras, as well as China. We hardly feel this is justified, even in view of the contention for a different faunal area, unless Gunther's action can be properly shown to be unsound.

\section{Family DACTYLOPTERIDAE.}

\section{EBISINUS CHEIROPHTHALMUS (Bleeker).}

Head, $3 \frac{1}{3}$ to $3 \frac{3}{5}$; depth, $4 \frac{3}{4}$ to $4 \frac{5}{6}$; D. I-I-IV- 8 ; A. 6 ; scales, 44 to 46 in lateral series to caudal base and 2 more on latter; 22 or 23 scales between soft and dorsal and anal origins; snout, $2 \frac{2}{5}$ to 3 in head; eye, $2 \frac{4}{5}$ to 3 ; maxillary, 2 to $2 \frac{1}{3}$; interorbital, $1 \frac{5}{6}$ to 2 , deeply convex. Along each side of lower body edge posteriorly 3 projecting lobate keeled scales, first about midway in anal. Color in alcohol nearly hair-brown with six transverse obscure nearly chaetura-black blotches, fifth and sixth of which with paler centers. First band across interorbital, second on occiput and last on caudal peduncle. First dorsal spine and pectoral blackish, dorsals otherwise and caudal brownish. Ventral and anal paler. Caudal with three transverse dark bands, soft dorsal with about six. Few pale brown spots on each anal ray. Iris pale yellowish white. Length, 107 to $125 \mathrm{~mm}$. Three from Takao.

\section{Family PLATYCEPHALIDAE.}

\section{THYSANOPHRYS NEMATOPHTHALMUS (Gunther).}

Head, $2 \frac{7}{8}$; depth, $7 \frac{4}{5}$ to $8 \frac{1}{2}$; D. I, VIII-I, 10, i; A. 11, I; scales, 98 counted close along and above lateral line to caudal base, and 9 more on latter; tubular scales 53 or 54 in lateral line to caudal base and 2 more on latter, unarmed; 9 or 10 scales above lateral line to soft dorsal origin, 22 to 24 scales below to anal origin; 16 or 17 predorsal scales; 2 preopercle spines; snout, 3 to $3 \frac{1}{8}$ in head from upper jaw tip; eye, $5 \frac{1}{3}$ to 6 ; maxillary, $2 \frac{1}{2}$; interorbital, $6 \frac{1}{4}$ to $6 \frac{1}{2} ; 3$ supraorbital tentacles, median long at eye and single flat tentacle below preopercle angle. Gill-rakers, v, $1+5$, Ix, lanceolate, equal gill-filaments or 2 in eye. Scales with 16 to 20 radiating basal striae, apical denticles about 30 and circuli moderately fine. Color in alcohol dark vandyke-brown, with about eight obscure saddlelike blotches of darker, merging along lower side into many broken and incomplete reticulate blotches. Dusky vandyke-brown blotch belo weye across cheek. Dorsals like back, finely reticulated with pale or whitish, likewise caudal, which also with four obscure dark vertical bands. Pectorals like dorsals, but with blackish blotches basally. Ventral pale basally, dusky to 
blackish terminally, where also marked with whitish reticulating lines. Anal largely whitish, with dusky to blackish subterminal blotch on each membrane. Iris brownish, with dusky blotch above. Length, 230 to $257 \mathrm{~mm}$. One from Cebu and one from Zamboanga, respectively.

\section{THYSANOPHRYS MACRACANTHUS (Bleeker).}

Head, $2 \frac{1}{2}$ to $2 \frac{7}{5}$; depth 7 to $7 \frac{1}{2}$; D. I, VIII-I, 11 ; A. 12 ; scales, 82 or 83 counted close along and above lateral line to caudal base and 6 more on latter; tubular scales 51 or 52 in lateral line to caudal base and 3 more on latter; 19 to 22 spines anteriorly in lateral line; 7 or 8 scales above lateral line to soft dorsal origin, 14 or 15 below to soft anal origin; 10 or 12 predorsal scales; 2 spines at preopercle angle, lower equals eye and 2 more short ones below; snout, $3 \frac{1}{4}$ to $3 \frac{1}{2}$ in head from upper jaw tip; eye, $3 \frac{3}{4}$ to 5 ; maxillary, $2 \frac{1}{3}$ to $2 \frac{1}{2}$; interorbital, $3 \frac{3}{4}$ to $4 \frac{1}{3}$; bony interocular, 2 to 3 in eye. Gill-rakers v or vi, $1+5$ or 6 , vi, lanceolate, 2 in eye and gill-filaments about three-fourths of gill rakers. Scales with 5 to 8 basal radiating striae, 28 to 48 apical denticles and circuli moderately fine. Color in alcohol with back cinnamon-drab and about 5 obscure slightly darger blotches or saddles on back. Lower surface white. Dorsals brownish, spotted with dusky. Caudal dark brownish, dusky terminally. Lower pectoral rays and ventral terminally dusky-black, upper pectoral rays with six or more transverse dusky bands. Anal pale like belly. Iris yellowish-white. Length, 48 to $183 \mathrm{~mm}$. Five from Takao.

\section{THYSANOPHRYS TUBERCULATUS (Cuvier).}

Head, $2 \frac{1}{3}$ to $2 \frac{3}{5}$; depth, $5 \frac{1}{4}$ to $5 \frac{3}{4}$; D. I, VIII-I, 11 ; A. 11 ; scales, 60 counted close along and above lateral line to caudal base and 5 more on latter; 10 or 11 spinous scales along front part of lateral line, 22 in young; tubular scales 50 to 52 in lateral line to caudal base; 6 or 7 scales above lateral line to soft dorsal origin, 14 or 15 below to anal origin; 7 predorsal scales to occiput; snout, $3 \frac{1}{10}$ to $3 \frac{1}{3}$ in head from upper jaw tip; eye, $3 \frac{3}{4}$ to 4 ; maxillary, $2 \frac{1}{3}$ to $2 \frac{2}{5}$; interorbital, $4 \frac{1}{4}$ to $4 \frac{3}{4}$; bony interorbital, $2 \frac{1}{2}$ to $3 \frac{1}{2}$ in eye. Gill-rakers v, $1+6$, vII, lanceolate, 3 in eye and gill-filaments three-fourths of rakers. Scales with 4 or 5 basal radiating striae, apical denticles 18 or 19, strong and circuli moderate. Two spines at end of preoprecle. Color in alcohol nearly hair-brown above, with seven slightly darker obscure blotches, below whitish. Spinous dorsal with three blackish horizontal bands, soft dorsal with four, caudal with about five. Lower half of pectoral blackish, margin whitish, and upper half pale or whitish with five transverse blackish bands. Ventral largely blackish terminally, edge narrowly pale or whitish. Iris dull yellowish-white. Young much more spotted or speckled 
with dark brown above, and serrae and spinules on head much more prominent. Length, 62 to $105 \mathrm{~mm}$. Three from Takao.

Day's figure of Platycephalus tuberculatus ${ }^{44}$ shows the soft dorsal and anal with fine longitudinal or inclined narrow bands. In our specimens these are all very much broader and contrasted. Moreover, the preopercular spine is variably long in our examples and may or may not extend over the gill-opening to the pectoral base.

\section{Family PLEURONCETIDAE.}

PSEUDORHOMBUS CINNAMONEUS (Schlegel).

Head, $3 \frac{2}{3}$; depth, $2 \frac{1}{5}$; D. 77 ; A. 63 ; scales 88 counted close above along lateral line to caudal base and 5 more on latter; tubular scales 81 in lateral line to caudal base and 3 more on latter; 20 scales above lateral line arch to dorsal base, 36 below straight section anteriorly to anal base; snout 4 in head; lower eye, $5 \frac{1}{8}$; maxillary, $2 \frac{1}{6}$; pectoral, $1 \frac{3}{5}$. Gill-rakers, $5+9$ left, $3+8$ right, lanceolate, slightly less than gill-filaments, which 2 in lower eye. Scales ctenoid on both sides of body; with 13 to 16 basal radiating striae, 18 to 23 apical denticles, moderately long and strong on left side; 16 to 21 basal radiating striae and 17 to 21 apical denticles on right side; all circuli fine. Color in alcohol with left side nearly army-brown, and very slight dark cloudings. Blotch obscurely at beginning of lateral line nearly bone-brown. Right side nearly tilleul-buff, and vertical fins all grayish terminally. Length, $212 \mathrm{~mm}$. Takao.

Also ten young from the same locality. They show: Head, $4 \frac{1}{8}$ to $4 \frac{1}{4}$; depth, $2 \frac{1}{2}$ to $2 \frac{3}{5}$; D. 75 to 87 ; A. 65 or 66 ; scales fallen and pockets hardly distinguishable; snout to lower eye, 4 in head from upper jaw tip; lower eye, $3 \frac{1}{3}$ to $3 \frac{7}{8}$; maxillary, $2 \frac{1}{2}$ to $2 \frac{2}{3}$; pectoral, $1 \frac{1}{3}$ to $1 \frac{1}{2}$. Gill-rakers, left 2 or $3+7$ or 8 ; right 0 to $2+6$. Color in alcohol with left side pale brown, little variegated and right side pale to whitish. Length, 57 to $65 \mathrm{~mm}$.

\section{PSEUDORHOMBUS PENTOPHTHALMUS (Gunther).}

Head, $3 \frac{1}{4}$ to $3 \frac{1}{3}$; depth, $1 \frac{9}{10}$; D. 63 or 64 ; A. 47 to 49 ; scales, 70 or 71 counted close above along lateral line to caudal base and 5 more on later; 71 or 72 tubular scales in lateral line to caudal base and 18 more on latter; 13 or 14 scales above lateral line arch to dorsal base, 29 to 32 below to anal base; snout, 4 to $4 \frac{1}{3}$ in head; lower eye, $4 \frac{1}{3}$ to $4 \frac{3}{5}$; maxillary, $2 \frac{1}{8}$ to $2 \frac{1}{6}$; pectoral, $1 \frac{2}{5}$ to $1 \frac{3}{5}$. Gill-rakers, $4+14$ left, $5+15$ right, lanceolate, long as gill-filament, or about 2 in eye. Scales with 12 or 13 basal radiating striae; apical denticles 18 to 22 , left; right scales cycloid and basal radiating striae 10 to 17 ; circuli fine. Color in alcohol with left side nearly benzo-brown, mottled 
paler or slightly darker, many markings as rings. At least five rings nearly large as eye, two above and same below lateral line and posterior just before caudal peduncle. Also each sprinkled with minute white dots. Length, 108 to $130 \mathrm{~mm}$. Five from Takao.

$P$. ocellifer Regan ${ }^{45}$ is said to have the eye $3 \frac{1}{2}$ to $3 \frac{2}{3}$ in head, the main character of distinction from the present species.

SCAEOPS GRANDISQUAMA (Schlegel).

Head, $3 \frac{3}{4}$ to $3 \frac{4}{5}$; depth, $1 \frac{4}{5}$ to $1 \frac{5}{6}$; D. 81 to 83 ; A. 60 to 62 ; scales (pockets) about 42 ? in lateral line to caudal base; snout, $4 \frac{3}{4}$ to $5 \frac{1}{5}$ in head from upper jaw tip; eye, 3 to $3 \frac{1}{3}$; maxillary, $3 \frac{1}{5}$ to $3 \frac{1}{6}$; interorbital equals or slightly greater than eye; pectoral, $1 \frac{1}{6}$ to $1 \frac{1}{4}$. Gill-rakers, $0+6$ left, $0+5$ right, lanceolately robust, equal gill-filaments or about 3 in eye. Scales very caducous, with about 56 to 58 basal parallel fine striae, minute apical denticles 36 to 38 , circuli fine. Arch of lateral line about $3 \frac{3}{4}$ in straight section. Color in alcohol with left side nearly dull snuff-brown, obscurely speckled or clouded with darker or nearly bister tints. Fins grayish, speckled with darker. Right side very pale, tinted somewhat pinkish-buff. Fins grayish, with trace of a blackish blotch on each of upper and lower caudal rays medially. Length, 50 to $82 \mathrm{~mm}$. Seventeen from Takao.

Quite likely Scaeops kobensis Jordan and Starks ${ }^{46}$ based on a single example, $83 \mathrm{~mm}$. long, from Kobe, is synonymous.

\section{PARDACHIRUS PAVONINUS (Lacépède).}

Head, $4 \frac{1}{8}$; depth, $2 \frac{1}{2}$; D. 64 ; A. 50 ; tubular scales 80 in lateral line to caudal base; about 33 scales above lateral line to dorsal base, 37 below to anal base; snout measured to upper eye, $3 \frac{1}{3}$ in head; upper eye, $6 \frac{1}{4}$; maxillary, $2 \frac{1}{2}$; interorbital, 5 . Scales with 34 to 42 radiating basal striae, apical denticles 5 to 7 . Color in alcohol with right side nearly warm sepia, marked with innumerable dusky to blackish variable rings, many with black central dot. Rings smaller and more crowded along fins marginally. Left side pinkish-buff, fins becoming grayish marginally. Length, $180 \mathrm{~mm}$. Zamboanga.

\section{LIACHIRUS NITIDUS Gunther.}

Head, $3 \frac{5}{6}$ to $4 \frac{1}{5}$; depth, $2 \frac{1}{6}$ to $2 \frac{1}{5}$; D. 50 to $62 ;$ A. 45 to 48 ; tubular scales 72 to 80 in lateral line to caudal base; 22 to 25 scales above lateral line to dorsal base, 30 to 33 below to anal base; snout measured to upper eye, $3 \frac{1}{4}$ to $4 \frac{1}{3}$ in head; eye, $5 \frac{1}{2}$ to $6 \frac{3}{4}$; mouth gape, $3 \frac{1}{6}$ to $3 \frac{2}{5}$; interorbital, $4 \frac{1}{4}$ to 6 . Scales cycloid, with 37 to 44 basal radiating. striae and circuli moderately fine. Color in alcohol with right side nearly fuscous with innumerable fine close fuscous-black to black

${ }^{45}$ Ann. Mag. Nat. Hist. London (7), vol. 15, 1905, p. 25. Inland Sea, Japan.

${ }^{46}$ Proc. U. S. Nat. Mus., vol. 31, 1907, p. 170, fig. 2. 
blotches or specks. Spots rather sparsely on fins, at least terminally. Left side nearly opaque white, with few grayish cloudings. Fins all grayish. Length, 72 to $103 \mathrm{~mm}$. Three from Takao.

Though our examples differ greatly in their coloration from the figure given by Jordan and Evermann, ${ }^{47}$ it is evident their specimen was faded, leaving only a few blackish spots. Our examples show the upper eye slightly more advanced.

\section{CYNOGLOSSUS ROBUSTUS Gunther.}

Head, $4 \frac{1}{2}$ to $4 \frac{1}{3}$; depth, $3 \frac{7}{8}$ to $4 \frac{1}{3}$; D. 95 to 115 ; A. 75 to 82 ; scales, 56 ? to 60 (mostly fallen) in median lateral line from gill-opening to caudal base; 6 to 8 scales above median lateral line to uppermost lateral line; 10 or 11 scales below median lateral line to anal base; snout, $2 \frac{3}{4}$ to $3 \frac{1}{3}$ in head, as measured from upper eye; upper eye, $7 \frac{1}{4}$ to $10 \frac{3}{4}$. Scales with 26 to 60 basal radiating striae, apical denticles on left side, 22 to 27 ; scales on right side with about 66 basal radiating striae, and no denticles; all circuli fine. Color in alcohol with left side and fins nearly dull wood-brown, and very dull cloudings of darker. Right side pale, pinkish-buff to vinaceous-buff, fins pale. Length, 82 to $184 \mathrm{~mm}$. Three from Takao.

Cynoglossus diplasios Jordan and Evermann ${ }^{48}$ is certainly very closely related if not synonymous. It is said to be distinguished by the presence of two well developed complete lateral lines on either side. In our examples we can not confirm this character, as most of the scales have fallen, though there are enough present on the left side to show that both are there evident.

Jordan and Starks give D. 122 to 127 and A. 96 to 100 for $C$. robustus, ${ }^{49}$ and scales 69 to 71 as counted from the gill-opening and 10 between lateral lines at middle of the body. The figure of $C$. diplasios, as given by Jordan and Evermann, shows 13 between the lateral lines.

$C$. brunners Regan is another closely related species from the Inland Sea of Japan, though even its fin and scale formula shows it within the limits of variation for $C$. robustus.

\section{Family SILLAGINIDAE.}

\section{SILLAGO SIHAMA (Forskå!).}

Head, $3 \frac{1}{4}$; depth, 6 ; D. XI-I, 20; A. I, 24; scales, 65 in lateral line to caudal base and 5 more on latter; 5 scales above lateral line to spinous dorsal origin, 10 below to spinous anal origin; 25

\footnotetext{
${ }^{47}$ Proc U. S. Nat. Mus., vol. 25, 1902, p. 366, fig. 28 . Giran.

48 Idem, p. 367, fig. 29. Formosa.

49 Idem, vol. 31, 1907. p. 238.
} 
predorsal scales. Gill-rakers, $3+8$, lanceolate, one-fourth of gillfilaments, which $2 \frac{1}{3}$ in eye. Cheek scales cycloid. Scales with 7 radiating basal striae, apical denticles 44 to 47 and circuli moderately fine. Color in alcohol faded largely pale uniform brownish. Soft dorsal gray-white, with few obscure grayish spots. Spinous dorsal with dusky dots terminally. Iris slaty. Length, $125 \mathrm{~mm}$. Cebu.

SIīlAGO JAPONiCA Sch̀legel.

Head, $3 \frac{3}{5}$ to $3 \frac{2}{3}$; depth, 6 to $6 \frac{1}{8}$; D. XI, 21 or 22 ; A. I, 22 or 23 ; scales, 66 to 70 in lateral line to caudal base and 5 or 6 more on latter; 3 or 4 scales above lateral line to spinous dorsal origin, 10 below to spinous anal origin; 21 to 23 predorsal scales. Gill-rakers, $3+10$, lanceoltate, slightly less than gill-filaments, which 3 in eye. Scales with 5 or 6 basal radiating striae, apical denticles 33 to 35 , circuli moderate. Cheek scales ctenoid. Color in alcohol faded largely dull brownish, back, dorsals and caudals slightly darker. Length, 87 to $104 \mathrm{~mm}$. Ten from Takao.

Though this species appears to difier in the alleged fewer scales above the lateral line to the spinous dorsal origin and the ctenoid cheek scales, it is very close to S. sihama.

\section{Family OPHICEPHALIDAE.}

OPHICEPHALUS STRIATUS Bloch.

Head, $3 \frac{1}{8}$ to $3 \frac{1}{5}$; depth, $5 \frac{1}{2}$ to $6 \frac{2}{5}$; D. 43 ; A. 26 ; scales, 54 or 55 in lateral line to caudal base and 3 more on latter; 4 scales above lateral line to dorsal origin, 7 below from posterior division of lateral line to anal origin; 14 or 15 predorsal scales; snout, $4 \frac{1}{5}$ to $5 \frac{1}{3}$ in head from upper jaw tip; eye, $5 \frac{7}{8}$ to 6 ; maxillary, $2 \frac{1}{2}$ to $2 \frac{2}{3}$; interorbital, 4 to $4 \frac{1}{8}$. Gill-rakers, about 11 low broad tubercles; gill-filament, 2 in eye. Scales with 17 or 18 basal radiating striae, 5 to 10 pronounced apical convergent circuli and other circuli moderate. Color in alcohol with sides and above chestnut-brown, darker above. Along sides of trunk mostly two parallel rows of rather large dark blotches of darker. These blotches variable, many as oblique streaks along sides of trunk. Fins grayish-brown with darker or dusky streaks on dorsal and anal. On caudal five or six transverse dark streaks, broader and darker basally. Pectoral pale brown, with dull olive tints and obscure dusky streaks. Ventral white, like lower surface of both head and trunk. Dark brown streak from infraorbital edge back toward preopercle angle. Length, 88 to $121 \mathrm{~mm}$. Twenty-two from fresh water canal of St. Maria, Zamboanga. February 27, 1914. 


\section{Family GOBIIDAE. \\ RHINOGOBIUS GYMNAUCHEN (Bleeker).}

Head, $3 \frac{1}{4}$; depth, $4 \frac{1}{4}$; D. VI-I, 9 ; A. I, 9 ; P. 20 ; V. I, 5 ; scales, 30 in median lateral series from gill-opening above to caudal base and 2 more on latter; 11 scales traversely between soft dorsal and anal origins; head width, $1 \frac{1}{2}$ in its length; head depth at occiput about $1 \frac{1}{2}$; snout, $3 \frac{1}{6}$; eye, $3 \frac{3}{5}$; maxillary, 3 ; interorbital, $6 \frac{1}{2}$; third dorsal spine, $1 \frac{7}{8}$; third dorsal ray, $1 \frac{4}{5}$; caudal, $1 \frac{1}{4}$; third anal ray, $2 \frac{1}{3}$; pectoral, $1 \frac{1}{2}$ ventral, $1 \frac{2}{5}$; least depth of caudal peduncle, $2 \frac{1}{2}$.

Body rather robust, moderately compressed, apparently deepest about middle of spinous dorsal, edges all convex. Least depth of caudal peduncle $1 \frac{3}{4}$ its length.

Head robust, slightly wider than deep, profiles convex and cheeks with slight swollen appearance. Snout convex over surface and in profile, length two-thirds its width at front eye edges. Eye large, ellipsoid, high, superior-lateral, and hind pupil edge slightly before center in head length. Mouth large, terminal, inclined moderately. Maxillary reaches opposite front eye edge. Lips rather broadly fleshy. Band of small simple conic teeth in each jaw and an outer series in each jaw enlarged and curved. No teeth on roof of mouth or on tongue. Latter wide, depressed, free and with convex edge in front. Inner buccal folds narrow. Mandible strong, rathẹ deeply convex. Nostrils two simple pores, hind one little before last fourth in snout profile and front one nearly midway in snout profile. Interorbital narrowly convex ridge. Preorbital width slightly greater than pupil, though a little less than eye.

Gill-opening forward until about opposite last fourth in head. Gill-rakers, $1+5$, lanceolate, short, barely half of gill-filaments, which about 3 in eye. Isthmus wide, level.

Scales large, well exposed, in even longitudinal rows on trunk. Head largely naked, only few small cycloid scales on opercles, mostly above. Lower cheek with four horizontal series of close-set pores, indistinct, two short parallel horizontal series across opercle above, vertical series close behind preopercle edge and horizontal series across opercle. Scales on predorsal and occipital region sparse, small, weakly cycloid and obsolete. Except rather small scales on caudal base, all other fins naked. Scales with 20 to 24 convergent basal radiating striae, apical denticles about 50, graduated larger above and below, and circuli fine.

Spinous dorsal inserted behind pectoral base. Fin, rounded and depressed, reaches back little beyond front of soit dorsal. Latter inserted little nearer caudal base than snout tip. Anal inserted opposite soft dorsal origin. Caudal rounded, likewise pectoral, and ventral nearly long as pectoral. Vent close before anal. 
Color in alcohol pale avellaneous generally. Back and upper surface of head with many darker or brownish vermiculations, usually formed by pale apical spot on each scale. Along middle of side three obscure dusky blotches, first about middle of pectoral, second below soft dorsal, and third at caudal base. Fins all pale generally. Spinous dorsal with rather broad dusky to blackish streaks or blotches, little more inclined than spines. Soft dorsal with three to four rows of deep dusky rounded spots and fin edge dusky. Caudal similar. Anal whitish, edge dusky. Ventral pale. Eye pale brownish, pupil dusky, with metallic green luster.

Length, $91 \mathrm{~mm}$. Takao, Formosa.

We give the above account as our example differs in a number of respects from a series of Japanese examples in the Academy. Also, the species does not appear to ever have been recorded from Formosa. In profile the Formosan example has a greatly obtuse muzzle with even jaws. In the Japanese examples the lower jaw of all strongly projects. In the Formosan example the spinous dorsal has dark vertical bands, whereas in the Japanese they are black spots like those on the soft dorsal, and in some cases the apical form horizontal bands. In all other respects the color pattern is such as may evolve from that of the Japanese examples, to that of the Formosan, as a change with age. This is also true of the pores on the cheek. In none of our examples do they resemble those in the figure by Jordan and Snyder for Ctenogobius gymnauchen. ${ }^{50}$ In our Formosan example we believe much of the contrast in color pattern has faded during preservation.

RHINOGOBIUS CANDIDIUS (Regan).

Head, $2 \frac{7}{8}$ to 3 ; depth, $4 \frac{1}{2}$ to $5 \frac{3}{4} ;$ D. VI-I, 8 ; A. 9 ; scales, 32 to 34 from gill-opening above to caudal base; 10 scales transversely between soft dorsal and anal origins; snout, $2 \frac{7}{8}$ to $3 \frac{2}{3}$ in head; eye, $3 \frac{3}{4}$ to $4 \frac{1}{3}$; maxillary, $2 \frac{1}{6}$ to $2 \frac{4}{5}$; interorbital, $7 \frac{1}{2}$ to $8 \frac{1}{2}$. Tongue more or less convex in front. Gill-opening forward about opposite last fourth in head or to hind preopercle edge. Scales with 16 to 18 nearly parallel striae medio basally, apical denticles 23 to 25 in single row and circuli rather coarse. Maxillary variable, sometimes to eye front and again to its center. Color in alcohol largely dull brownish. Spinous dorsal with blackish basally, usually forward, and soft dorsal dusky medially. Often obsolete dark vertical bar at caudal base. Both soft and spinous dorsal edges pale. Length, 33 to $45 \mathrm{~mm}$. Eight from Lake Candidius, Formosa. October 10, 1907.

Our examples usually have the predorsal naked, though in some it is more or less scaly.

${ }^{\text {so }}$ Proc. U. S. Nat. Mus., vol. 24, 1902, p. 58, fig. 6. 
EXYRIAS PUNTANG (Bleeker).

Head, $3 \frac{1}{3}$; depth, $3 \frac{3}{4}$; D. VI-I, 10; A. I, 9, I; scales, 28 from gill-opening above to caudal base and 3 more on latter; 8 scales between soft dorsal and anal origins; 12 predorsal scales; snout, $3 \frac{1}{10}$ in head; eye, 4; maxillary, $2 \frac{3}{4}$, interorbital, 2 in eye. Gillrakers, $0+5$, lanceolate, $1 \frac{2}{3}$ in gill-filaments, which $1 \frac{1}{3}$ in eye. Scales with 11 to 15 basal radiating striae, apical denticles 110 to 124 and circuli very fine. Color in alcohol, dull brown generally, little paler below, each scale with obscure pale spot. Spinous dorsal with deep dusky-brown spots, paler areas streaked with brown. Soft dorsal with five or six brown spots on each ray. Caudal with about fifteen or more narrow irregular dark cross bands. Pectoral similar, only paler. Anal darker marginally, and ventral darker on innermost rays. Length, $123 \mathrm{~mm}$. Zamboanga.

OXYURICHTUS FONTANESII (Bleeker).

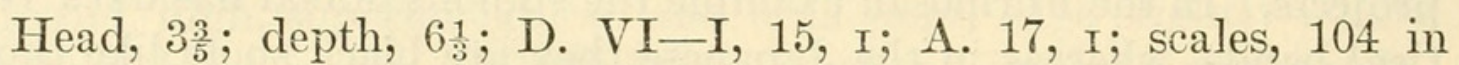
median lateral series from gill-opening above to caudal base and 10 more on latter; about 27 scales transversely at soft dorsal and anal origins; 30 predorsal scales; snout, $4 \frac{1}{3}$ in head from upper jaw tip; eye, $4 \frac{4}{5}$; maxillary, $2 \frac{2}{5}$; interorbital, $3 \frac{1}{2}$ in eye. Gill-rakers, $4+10$, lanceolate, about two-thirds of gill-filaments, which $2 \frac{4}{5}$ in eye. Scales with 10 to 12 basal radiating striae, apical denticles 12 to 28 , circuli moderate. Color in alcohol dull brownish generally. Five transverse obsolete dark cross bands or blotches, first at occiput, second at middle of spinous dorsal on which reflected, third at front of soft dorsal, fourth just before caudal peduncle and fifth at caudal base. Fins all pale brown. Lower anal edge dusky, with narrow pale or gray submarginal line. Innermost pair of ventral rays dark. Iris pale slaty. Length, $150 \mathrm{~mm}$. Cebu.

\section{Family BLENNIIDAE.}

SALARIAS FASCIATUS (Bloch).

Head, 5; depth, 4; D. XI, 19 ; A. 20 ; snout, $2 \frac{4}{5}$ in head; eye, 3 ; maxillary, $2 \frac{1}{4}$; interorbital, $2 \frac{1}{5}$ in eye. Bifid supraorbital tentacle fringed, 2 in eye. Two fringed occipital flaps, little longer than supraorbital tentacle. Nasal tentacle about half of supraorbital. No hind canines. Last dorsal ray joint caudal. Color in alcohol narly olive-brown with about eight double dark vertical cross bands, reflected on dorsal fins above and last ones at least on anal below, on trunk posteriorly. Anteriorly horizontal dark lines, parallel and above finally broken into spots. Oblique dark shades or bands across dorsals, on spinous fin finely specked or dotted with deep 
brown, simply as series of parallel dusky bars on soft fin. Caudal with few dusky spots basally and pectoral largely spotted with dusky. Ventral with three dark blotches, one of which basal. Length, $120 \mathrm{~mm}$. Cebu.

\section{Family LOPHIIDAE.}

\section{LOPHIOMUS SETIGERUS (Vahl).}

Head, measured to front edge of gill-opening, $1 \frac{7}{8}$; body depth 3 in head; D. I-I-I-I-II, 8; A. 7; snout, $2 \frac{3}{5}$ in head; maxillary, $1 \frac{4}{5}$; interorbital, $3 \frac{1}{5}$; eye, $2 \frac{2}{3}$ in interorbital. Second dorsal spine apparently high as first (tip slightly damaged). Lateral filaments moderate. Color in alcohol nearly bister above, variegated with obscure lighter spots and darker cloudings. Pectoral blackish terminally. Caudal dusky basally, outer portion pale. Tongue and surrounding branchial region inside mouth below blackish, with two rows of contrasted white spots. Under surface of body, including ventral and anal, white. Length, $67 \mathrm{~mm}$. Takao.

\section{Family ONCOCEPHALIDAE.}

halieutaea Stellata (Vahl).

Disk width, $1 \frac{1}{6}$ to $1 \frac{1}{2}$ in combined head and trunk; 4 to $4 \frac{3}{4}$; D. 5 ; A. 5 ; P. 10 ; mouth width, $2 \frac{2}{3}$ to 3 in disk width; eye little greater than interorbital, about 8 in disk width; nasal cavity threefourths to equal of eye diameter. Spinules on upper surface of disk three-rooted. Color in alcohol with lower surface nearly uniform pale olive-buff. Upper surface little darker brown, with nearly olive-brown cloudings about middle of disk. Caudal pale, with four brownish cross bars. Dorsal with dull brown shades, other fins whitish like belly. Length, 59 to $60 \mathrm{~mm}$. Takao.

Our examples agree largely with one described by Jordan and Sindo. ${ }^{51}$ Both differ, however, in the presence of more anal rays.

${ }_{51}$ Proc. U. S. Nat. Mus., vol. 24, 1902, p. 380 . Ajiro near Atami.

$60466-23$-Proc. N. M. vol. $62-13$ 


\section{$2 \mathrm{BHL}$ Biodiversity Heritage Library}

Fowler, Henry W. and Bean, Barton A. 1922. "Fishes from Formosa and the Philippine Islands." Proceedings of the United States National Museum 62(2448), 1-73. https://doi.org/10.5479/si.00963801.62-2448.1.

View This Item Online: https://www.biodiversitylibrary.org/item/54629

DOI: https://doi.org/10.5479/si.00963801.62-2448.1

Permalink: https://www.biodiversitylibrary.org/partpdf/53945

\section{Holding Institution}

Smithsonian Libraries

\section{Sponsored by}

Smithsonian

\section{Copyright \& Reuse}

Copyright Status: Public domain. The BHL considers that this work is no longer under copyright protection.

This document was created from content at the Biodiversity Heritage Library, the world's largest open access digital library for biodiversity literature and archives. Visit BHL at https://www.biodiversitylibrary.org. 